\title{
ESTUDO DO EFEITO DA REDUÇ̃̃O DA RIGIDEZ DOS PNEUMÁTICOS SOBRE A ESTABILIDADE DOS VEÍCULOS
}

Dissertação apresentada à Escola de Engenharia de São Carlos da Universidade de São Paulo como parte das exigências para a obtenção do título de Mestre em Engenharia Mecânica.

Orientador: Prof. Dr. Antonio Carlos Canale 
Às queridas Patrícia, Norma e Iracy

Que me apoiaram ao longo do período do curso, dando incentivo nos momentos de esmorecimento e,

Ao amado Rafael

Pela motivação e compreensão na privação de minha presença. 


\section{AGRADECIMENTOS}

A execução deste trabalho somente pode ser concluída graças à contribuição direta ou indireta de diversas pessoas. Manifestamos nossos agradecimentos a todas elas e particularmente:

Ao corpo docente que ao longo do curso nos transmitiu os conhecimentos para obtenção dos fundamentos necessários e, em especial, ao Prof. Dr. Antonio Carlos Canale, nosso orientador, pelos comentários e sugestões;

Aos funcionários da Escola de Engenharia de São Carlos pelo suporte operacional e, em particular, do Departamento de Pós-Graduação de Engenharia Mecânica;

Às empresas onde trabalhamos pelo suporte oferecido ao longo do período de duração deste curso;

À Pirelli Pneus pelo auxílio na realização dos testes experimentais necessários a este trabalho;

A todos os colegas que nos acompanharam ao longo do curso, pelos questionamentos que contribuíram para uma visão mais abrangente de nossos conceitos, especialmente, a Argemiro Luis de Aragão Costa e Marco Antonio Zanussi Barreto pelas enriquecedoras discussões técnicas. 
"Embora a natureza inicie em causa e termine em efeito, é necessário para nós fazermos o oposto, que é começar conhecendo o efeito e, deste ponto, seguir a investigar sua causa."

Leonardo da Vinci 


\section{SUMÁRIO}

LISTA DE FIGURAS ………………………………............................................

LISTA DE SÍMBOLOS ................................................................................................

LISTA DE TABELAS …………………………………....................................

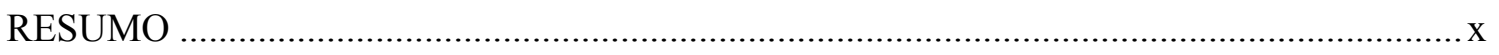

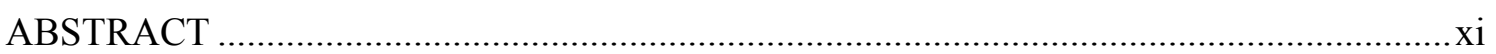

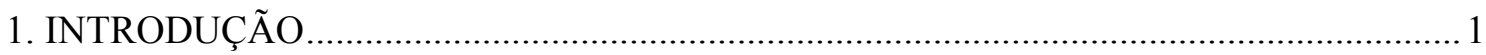

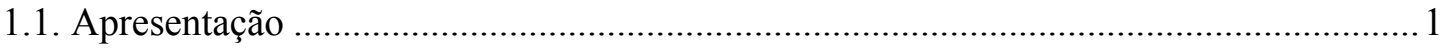

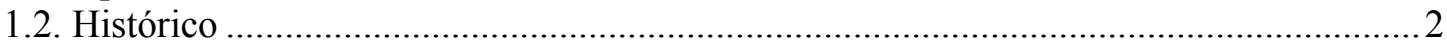

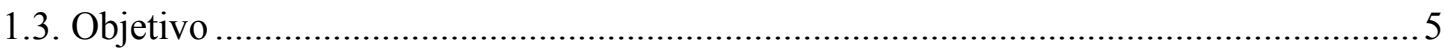

1.3. Desenvolvimento do trabalho .................................................................................

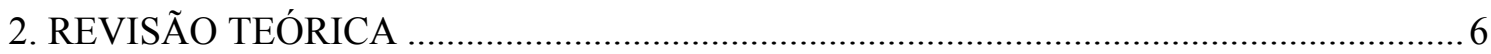

2.1. Curvas em baixa velocidade ................................................................................

2.2. Curvas em alta velocidade .................................................................................9

2.2.1. Forças laterais de esterço dos pneus ...................................................................

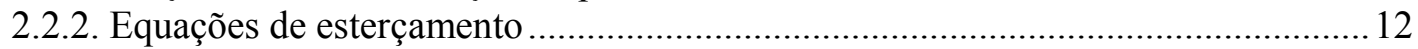

2.2.3. Gradiente de sub-esterçamento......................................................................... 15

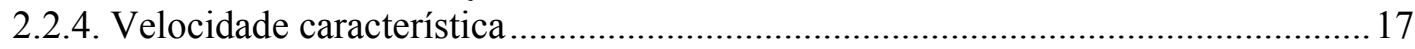

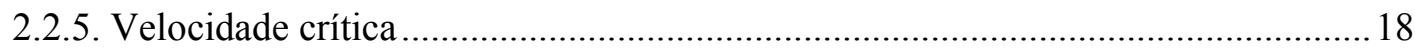

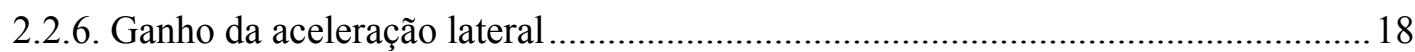

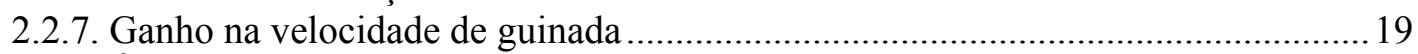

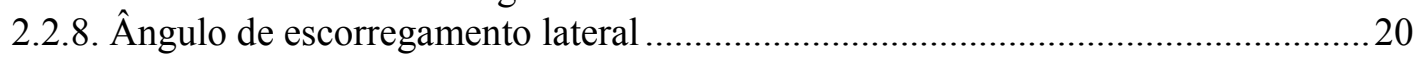

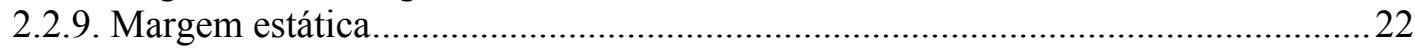

2.3. Medição experimental do gradiente de sub-esterçamento..............................................22

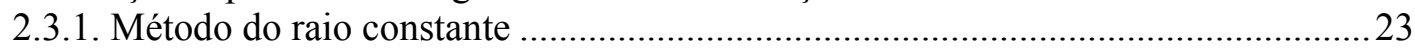

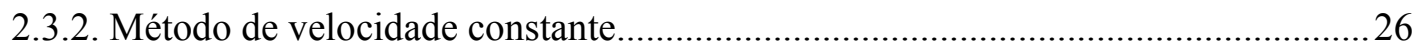

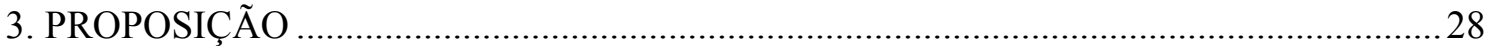

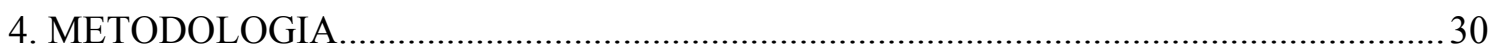

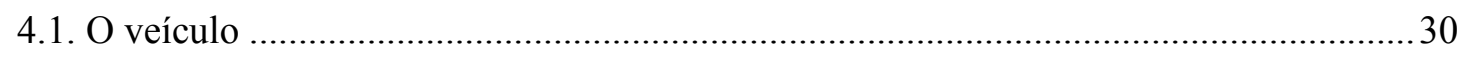

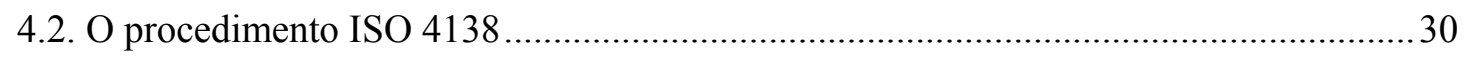

4.3. A instrumentação utilizada ....................................................................................

4.4. A pista

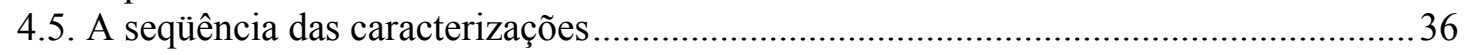

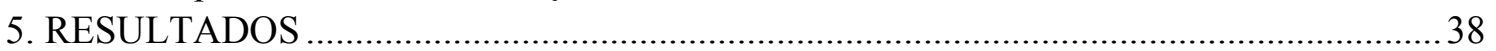

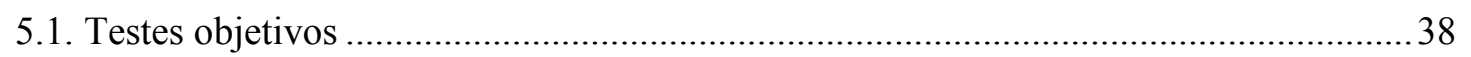

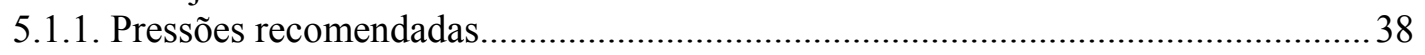

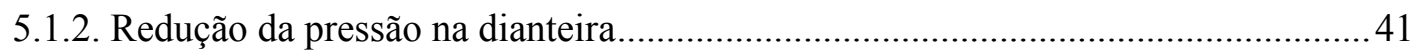

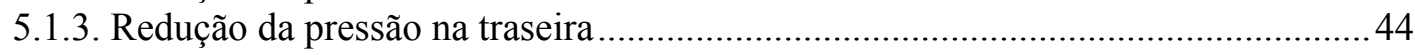

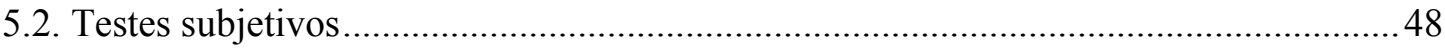

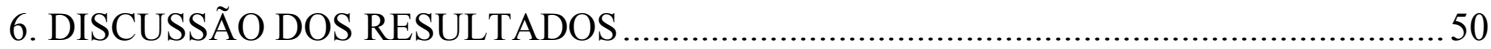

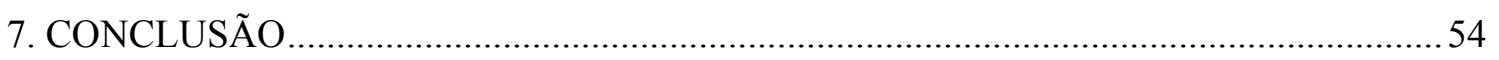

APÊNDICE A - RESULTADOS NUMÉRICOS .................................................................

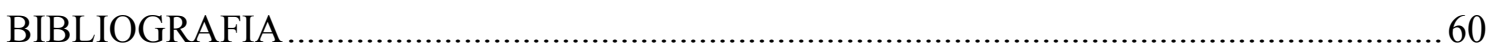




\section{LISTA DE FIGURAS}

Figura 1 - Primeiras análises de dirigibilidade feitas por Olley em 1934 ............................ 3

Figura 2 - Primeira curva real de rigidez de esterço publicada por Evans em 1935 .............. 4

Figura 3 - Geometria de um veículo em curva ................................................................ 8

Figura 4 - Propriedades das forças de esterçamento do pneu (Gillespie, 1992).................... 10

Figura 5 - Variáveis que afetam a rigidez de esterço do pneu (Gillespie, 1992)................... 11

Figura 6 - Esterçamento de um modelo bicicleta ............................................................... 13

Figura 7 - Mudança do ângulo de esterçamento com a velocidade (Gillespie, 1992).......... 17

Figura 8 - Ganho da velocidade de guinada como função da velocidade (Gillespie, 1992) 20

Figura 9 - Ângulo de escorregamento lateral em uma curva de baixa velocidade (Gillespie,

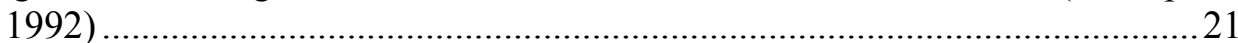

Figura 10 - Ângulo de escorregamento lateral em uma curva de alta velocidade (Gillespie,

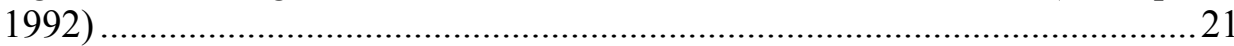

Figura 11 - Linha de esterçamento neutro em um veiculo .................................................22

Figura 12 - Exemplo de medição do gradiente de sub-esterçamento pelo método do raio constante (Gillespie, 1992) ......................................................................24

Figura 13 - Exemplo de medição do gradiente de sub-esterçamento pelo método de

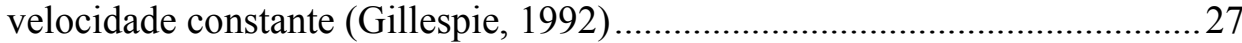

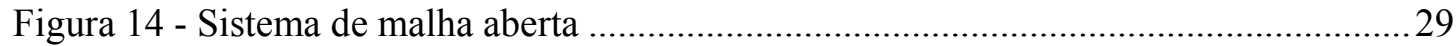

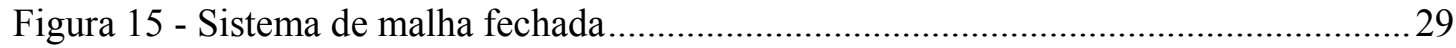

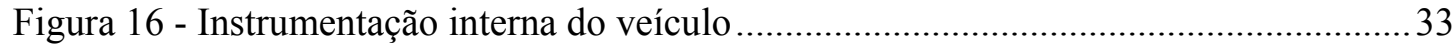

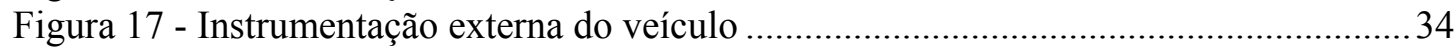

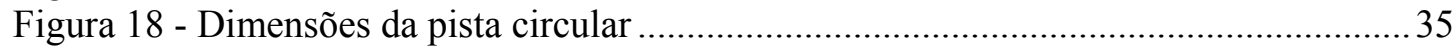

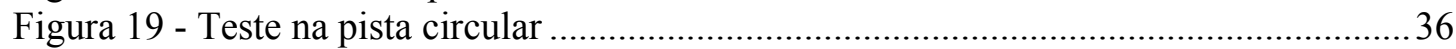

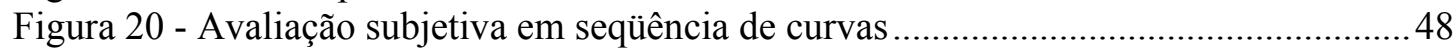

Figura 21 - Evolução do comportamento dinâmico do veículo...............................................53

Gráfico 1 - Característica do ângulo do volante com as pressões recomendadas pelo

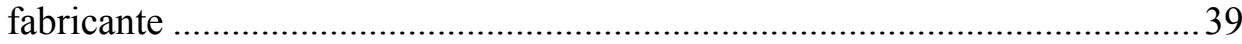

Gráfico 2 - Característica do ângulo de escorregamento lateral com as pressões

Gráfico 3 - Característica da velocidade de guinada com as pressões recomendadas pelo fabricante

Gráfico 4 - Característica do ângulo do volante com a variação das pressões na dianteira . 42

Gráfico 5 - Característica do ângulo de escorregamento lateral com a variação das pressões na dianteira.

Gráfico 6 - Característica da velocidade de guinada com a variação nas pressões da dianteira

Gráfico 7 - Característica do ângulo do volante com a variação das pressões na traseira ...45

Gráfico 8 - Característica do ângulo de escorregamento lateral com a variação das pressões na traseira

Gráfico 9 - Característica da velocidade de guinada com a variação nas pressões da traseira

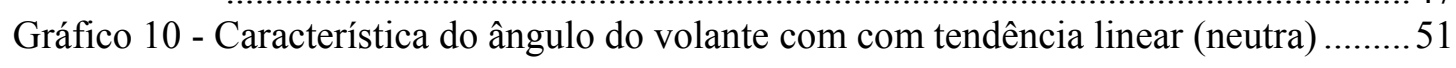




\section{LISTA DE SÍMBOLOS}

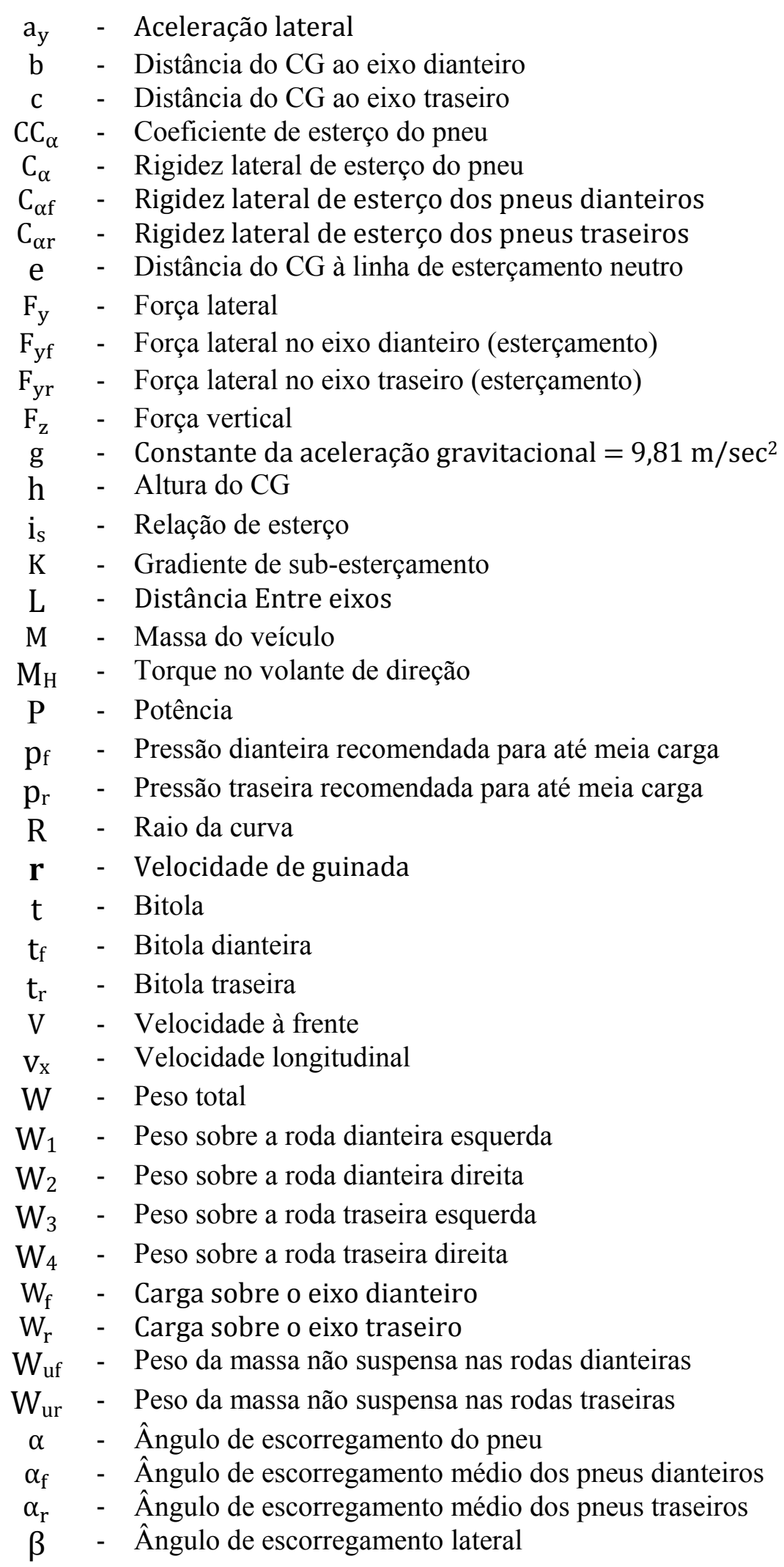


$\delta \quad$ - ângulo de esterço médio nas rodas dianteiras

$\delta_{\mathrm{H}} \quad$ - Ângulo do volante de direção

$\delta_{i} \quad$ - Ângulo de esterçamento da roda interna em uma curva

$\delta_{\mathrm{o}} \quad$ - Ângulo de esterçamento da roda externa em uma curva

$\varphi \quad$ - Ângulo de Roll do veículo

$\Psi^{*} \quad$ - Velocidade de guinada 


\section{LISTA DE TABELAS}

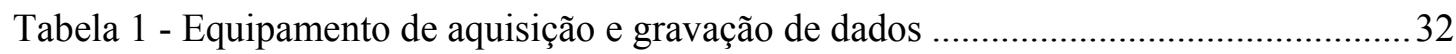

Tabela 2 - Seqüência de testes para caracterização do veículo .......................................... 37

Tabela 3 - Resultados da caracterização do veículo com as pressões recomendadas pelo

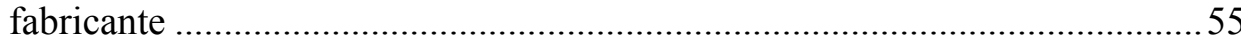

Tabela 4 - Resultados da caracterização do veículo com as pressões de 38 psi na dianteira e

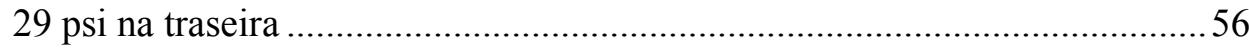

Tabela 5 - Resultados da caracterização do veículo com as pressões de 29 psi na dianteira e

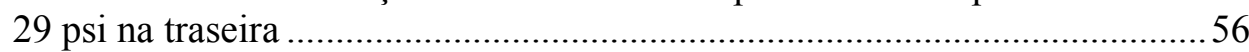

Tabela 6 - Resultados da caracterização do veículo com as pressões de 24 psi na dianteira e 29 psi na traseira ...................................................................................5 57

Tabela 7 - Resultados da caracterização do veículo com as pressões de 18 psi na dianteira e

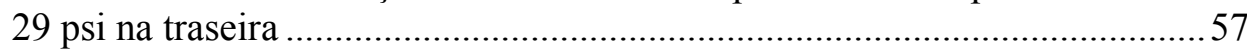

Tabela 8 - Resultados da caracterização do veículo com as pressões de 31 psi na dianteira e 38 psi na traseira .....................................................................................58

Tabela 9 - Resultados da caracterização do veículo com as pressões de 31 psi na dianteira e

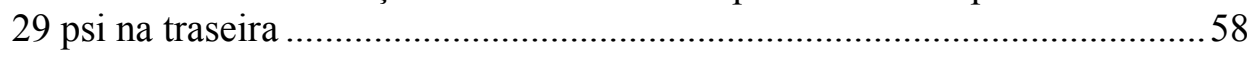

Tabela 10 - Resultados da caracterização do veículo com as pressões de 31 psi na dianteira

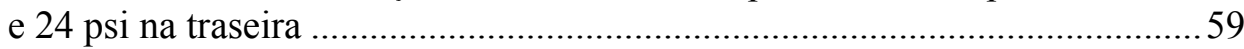

Tabela 11 - Resultados da caracterização do veículo com as pressões de 31 psi na dianteira

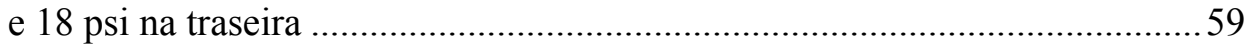


LEAL, Alexandre Tiberio Joppert de Castro. Estudo do efeito da redução da rigidez dos pneumáticos sobre a estabilidade dos veículos. São Paulo: Escola de Engenharia de São Carlos, 2008. Dissertação apresentada como parte das exigências para a obtenção do grau de Mestre em Engenharia Mecânica pela Escola de Engenharia de São Carlos da Universidade de São Paulo. Orientador: Prof. Dr. Antonio Carlos Canale.

\section{RESUMO}

Este trabalho apresenta uma metodologia para caracterizar em regime quase-estático de forças, o comportamento dinâmico de um veículo de passageiros compacto, a fim de determinar sua condição de estabilidade, inerente aos parâmetros adotados durante o desenvolvimento de seu projeto, através de uma manobra normalizada.

Apresenta e discute os dados obtidos através da medição das grandezas físicas que caracterizam este comportamento dinâmico e sua evolução, imposta pela variação de um dos parâmetros que influenciam seu equilíbrio, a rigidez lateral de um de seus pneumáticos através da variação de sua pressão, tanto no eixo dianteiro quanto ao eixo traseiro. Avalia esta evolução através da caracterização teórica de seu comportamento sub ou sobre esterçante e a compara com os resultados obtidos subjetivamente pela avaliação da sensação do condutor, realizada por profissionais especializados da indústria automobilística.

Finalmente busca uma conclusão, propondo o balanceando do comportamento dinâmico esperado para o veículo com sua resposta aos testes subjetivos, a fim de que o projeto de novos veículos possa apresentar características e condições de segurança que melhor se adéqüem a forma de dirigir do motorista comum. 
LEAL, Alexandre Tiberio Joppert de Castro. Study of the effect of a reduction in the tire rigidity over the vehicle stability condition. São Paulo: Escola de Engenharia de São Carlos, 2008. Dissertation presented as part of the requirements to obtain the Master Degree of Applied Science in Mechanical Engineering through Escola de Engenharia de São Carlos of the Universidade de São Paulo. Orientador: Prof. Dr. Antonio Carlos Canale.

\begin{abstract}
This study presents a methodology to characterize under quasi-static condition of forces, the dynamic behavior of a compact passenger vehicle to determine its condition of stability, inherent to the parameters used in the development of the project through a standardized maneuver.
\end{abstract}

It presents and discusses the data obtained through the measurement of physical quantities that characterize its dynamic behavior and the evolution of this behavior, imposed by a variation in one of the parameters that influence their balance, the lateral rigidity of one of its tires by its pressure variation, in both the front and rear axles. Assesses these evolution through the theoretical characterization of the under or oversteer behavior and compares it with the results subjectively assessed by the driver feeling, held by professional evaluators of the auto industry.

Finally search for a conclusion, offering the balance of the dynamic behavior expected for the vehicle with its response to subjective tests, aiming that the design of new vehicles may present safety and design characteristics that best suit the common driver way to drive. 


\section{INTRODUÇÃO}

\subsection{Apresentação}

Em meados do ano 2000 foram publicadas diversas notícias de acidentes ocorridos devido à perda de estabilidade em veículos originados pela má utilização ou pelo comportamento inadequado dos pneumáticos. Estes acidentes causaram várias fatalidades, gerando grande agitação nos meios de segurança automotiva, quer nos órgãos certificadores e fiscalizadores, quer junto aos fabricantes de automóveis e pneus. Esta preocupação com os pneumáticos chegou a tal ponto que, após um recall de 6,5 milhões de pneus, o governo norte americano aprovou uma lei obrigando os fabricantes de veículos a utilizarem um sistema de monitoramento de pressão dos pneumáticos.

Tendo como base estes fatos, pode-se compreender a importância de se conseguir estabelecer de forma antecipada, o comportamento esperado dos veículos. Procurando utilizar um estudo para a aplicação das diretrizes relacionadas à condição de estabilidade dos veículos e dele extrair quais informações influenciam no comportamento dos próprios veículos e de seus condutores, de forma a dar consciência dos riscos envolvidos com a perda da condição de estabilidade e reduzir os acidentes decorrentes dela, será utilizado o recurso da redução da pressão nos pneumáticos, a fim de ocasionar mudanças nas características dinâmicas destes pneumáticos e, por conseguinte, uma alteração na estabilidade dos veículos que os estão utilizando.

Enquanto estudos sobre as condições dinâmicas de veículos estão geralmente associados exclusivamente a simulações matemáticas atendidas ao se realizar os projetos de automóveis, o tema ora proposto procura levar em consideração a interação do veículo com seu condutor, avaliando a sensação de segurança ao se conduzir o veículo, buscando trazer à luz dos estudos esta ponderação entre os resultados obtidos experimentalmente, a análise decorrente do estudo teórico da dinâmica de veículos e a sensação intrínseca aos condutores.

Para tanto, foram efetuados testes objetivos e avaliações subjetivas baseados na experiência adquirida ao longo da atuação na área de desenvolvimento de veículos e embasada na aplicação dos conhecimentos teóricos adquiridos no curso em conclusão, sempre 
confrontados com livros e artigos técnicos e científicos que tratam do contexto teórico da dinâmica de veículos.

\subsection{Histórico}

O automóvel surgiu no final do século XIX como conseqüência direta da evolução dos motores. Seu projeto inicial evoluiu do conceito das carruagens puxadas por cavalos. No momento do surgimento destes primeiros automóveis, as carruagens já possuíam sistemas de suspensão devido às condições precárias das estradas daquele tempo, portanto já se podiam encontrar estudos sobre o conforto destas carruagens, entretanto muito pouco, ou virtualmente nada, havia sido estudado a respeito de sua dirigibilidade.

As primeiras carruagens dos séculos XVIII e XIX possuíam eixos rígidos e sistemas de direção onde o eixo dianteiro apresentava o pivotamento em torno de um ponto fixo central, deixando as rodas paralelas entre si e perpendiculares ao raio do arco descrito pela trajetória da curva. Este tipo de sistema trazia o inconveniente de necessitar um grande vão livre ao redor das rodas para permitir seu movimento. Em 1816 Georges Langensperger estabeleceu as condições geométricas necessárias para o esterçamento com pivotamento nas rodas. Esta disposição era muito desejada, principalmente para reduzir o atrito das rodas em manobras de baixa velocidade ou para descrever arcos com pequenos raios. Ackermann reconheceu a importância desta descoberta e através de um acordo com Langensperger patenteou-a em 1817 em Londres, tornando-a amplamente conhecida como "geometria de Ackermann". Este conceito de geometria é essencialmente cinemático, já que não considera as forças laterais ou a forma como estas forças surgem.

$\mathrm{O}$ conceito dinâmico de esterçamento somente surgiu no início do século XX e o primeiro passo significante no sentido dinâmico moderno foi o reconhecimento da necessidade das forças laterais e o surgimento do ângulo de deriva decorrente destas forças. Os créditos pelo reconhecimento do conceito de ângulo de deriva e sua significância são dados a Georges Broulhiet em seu texto de 1925.

Bradley e Allen investigaram as propriedades do atrito na superfície dos pavimentos e publicaram em 1930 o que provavelmente foi o primeiro gráfico da força lateral de um pneu 
pelo seu ângulo. De fato eles não estavam interessados no esterçamento, mas sim em frenagem e utilizaram uma roda girando com um grande ângulo de deriva como meio de investigação das propriedades do pavimento em sua máxima aderência.

Em 1931 um estudo de vibração no esterçamento realizado por Becker, Fromm e Maruhn trouxe maiores informações sobre as propriedades mecânicas dos pneus, incluindo os resultados obtidos por pneus girando em um tambor de aço. Este foi o primeiro trabalho a apresentar algumas das características da rigidez de esterço dos pneus. Olley em seu trabalho de 1934 demonstrou o entendimento dos princípios da relação entre os ângulos de deriva dianteiros e traseiros e incluiu um diagrama (Figura 1) com análises preliminares de dirigibilidade.

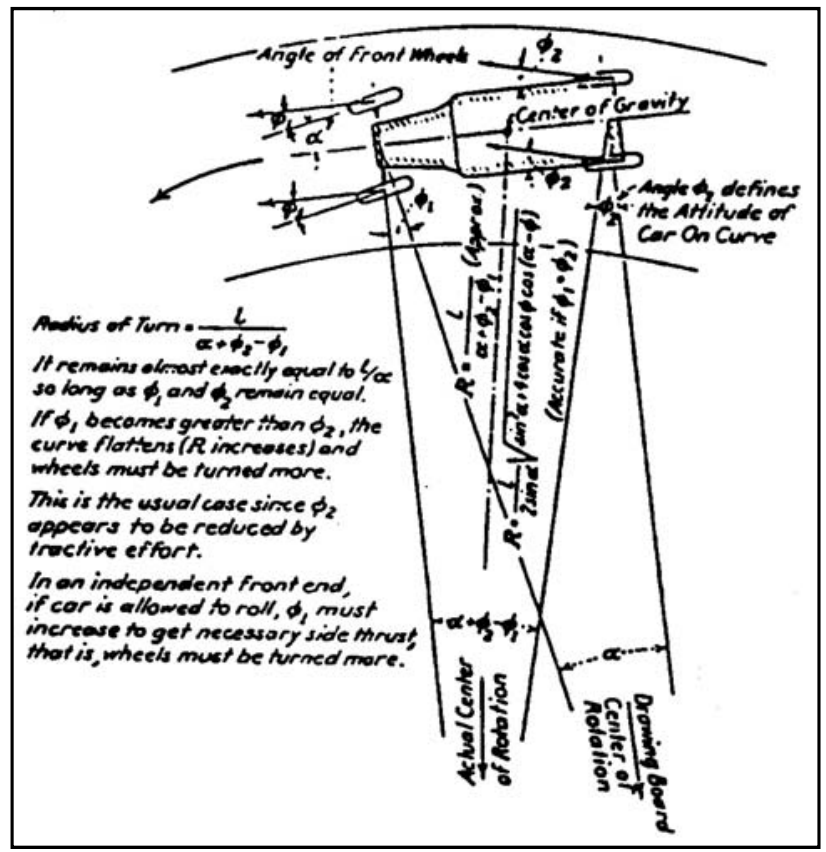

Figura 1 - Primeiras análises de dirigibilidade feitas por Olley em 1934

Em seus trabalhos posteriores, Olley indicava que o esterçamento devido à rolagem do veículo e as pressões dos pneus eram sabidamente muito importantes na estabilidade e controle destes veículos, e apesar de seu trabalho de 1934 apresentar as relações básicas que governam as forças dos pneus e os ângulos de deriva, foi somente em 1935 que Evans da Goodyear publicou seus resultados com a primeira curva real da força de esterço do pneu (Figura 2). É também dado a Olley o crédito pelo conceito e interpretação do subesterçamento e sobre-esterçamento lineares. 


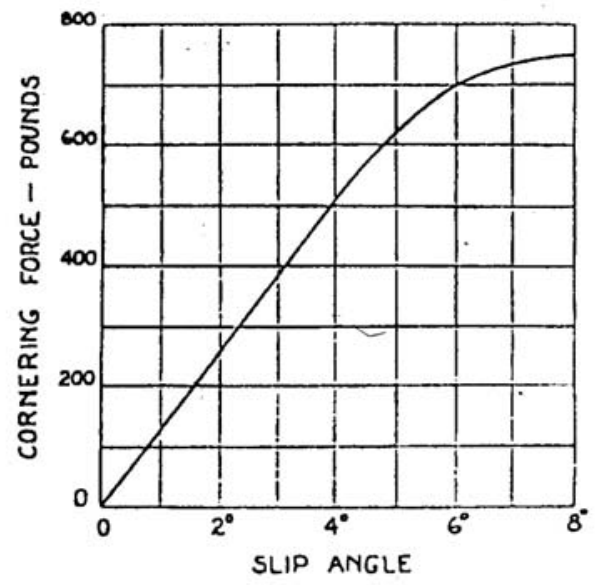

Figura 2 - Primeira curva real de rigidez de esterço publicada por Evans em 1935

Desta forma, ao final dos anos 30 os ingredientes importantes da teoria de dirigibilidade estavam disponíveis e um número razoável de modelos matemáticos teóricos já estava em utilização e mesmo hoje em uma de suas obras mais conceituadas no estudo da dinâmica de veículos, Gillespie ainda expressa a importância dos modelos matemáticos e físicos para o entendimento do comportamento dinâmico dos veículos

“[...] O entendimento da dinâmica dos veículos pode ser realizado em dois níveis, o empírico e o analítico. $O$ entendimento empírico provém da tentativa e erro pelo qual se aprende quais fatores influenciam o desempenho do veículo, em que sentido e sob quais condições. [...] O método analítico procura descrever a mecânica em questão, utilizando as leis conhecidas da física, de forma que um modelo analítico possa ser estabelecido. Nos casos mais simples estes modelos podem ser representados por equações algébricas ou diferenciais que relacionam forças ou movimentos de interesse às entradas de controle e às propriedades do veículo ou dos pneus. Estas equações permitem então que se possa avaliar o papel de cada propriedade do veículo no fenômeno de interesse. A existência do modelo fornece um meio de identificar os fatores importantes, o modo que eles operam e sob quais condições. $O$ modelo fornece também uma capacidade de predição, de 
forma que as mudanças necessárias para se atingir uma determinada meta de desempenho possa ser identificada. [...]”

\subsection{Objetivo}

O objetivo deste trabalho é apresentar e discutir uma das metodologias utilizada para a caracterização de uma condição de estabilidade do veículo e através de seu resultado, realizar a análise do comportamento dinâmico deste veículo e da variação deste comportamento com a alteração da pressão em apenas um de seus pneumáticos.

Além disto, este trabalho tem ainda o objetivo de dar base e motivação a novos estudos que possam considerar outros fatores responsáveis pela perda da condição de estabilidade dos veículos e a mitigação destes fatores.

\subsection{Desenvolvimento do trabalho}

Durante o desenvolvimento do trabalho, são tratados, além das características do próprio veículo, apresentados no item 4.1, o procedimento normatizado da caracterização no item 4.2 e a instrumentação utilizada no 4.3. A sequência adotada para a execução destas caracterizações, apresentada no item 4.5, mostra a abrangência dos experimentos realizados e, apesar de a norma permitir alguma variação em suas dimensões, algumas características específicas da pista utilizada são apresentadas no item 4.4, totalizando o capítulo 4 sobre a metodologia utilizada.

Os testes objetivos realizados na pista circular de raio constante quantificam o ângulo do volante de direção, a aceleração lateral do veículo, o ângulo de escorregamento lateral do pneu, a velocidade de guinada, a velocidade longitudinal do veículo, o torque no volante de direção e o ângulo de rolagem do veículo conforme descrito na norma ISO4138 e apresentado no item 5.1. A apresentação dos resultados dos testes subjetivos realizados em outra pista, desta vez um trecho retilíneo demarcado com cones para a realização de uma manobra de

dupla mudança de faixa de rolagem, com o objetivo de fechar a malha do sistema dinâmico, 
logo após a cada medição objetiva, nas mesmas condições de cargas e pressões, é feita no capítulo 5.2, do capítulo 5 .

A característica do ângulo do volante, também conhecida como gradiente de subesterçamento, é calculada e graficamente apresentada para toda a sequência de condições de pressão. A avaliação do gradiente e suas implicações na estabilidade do veículo em regime permanente, ou quase-estático e a qualificação e quantificação dos testes subjetivos realizada pelo piloto de testes, sustentam então a discussão dos resultados realizada no capítulo 6 .

Finalmente, após a discussão dos resultados, o capítulo 7 apresenta a conclusão resultante destes testes e análises.

\section{REVISÃO TEÓRICA}

O comportamento em curva de um veículo automotor é um importante fator de desempenho comumente referido como dirigibilidade. "Dirigibilidade" é um termo utilizado para designar a capacidade de resposta que um veículo possui a entrada imposta pelo seu condutor, ou facilidade de controle. Como tal, a dirigibilidade é uma medida da combinação veículo-piloto. O piloto e o veículo é um sistema de malha fechada significando que o piloto observa a direção e posição do veículo e corrige sua entrada para alcançar a trajetória desejada. A fim de caracterizar o comportamento apenas do veículo utiliza-se um sistema de malha aberta. Malha aberta refere-se à resposta dos veículos a entradas específicas de esterçamento, e é mais precisamente definido como comportamento da resposta direcional [Good, 1977].

A grandeza mais utilizada para medição da resposta direcional é o gradiente de subesterçamento [SAE J670. 2008]. Gradiente de sub-esterçamento é uma medida de desempenho em condição de regime permanente, embora possa ser utilizada para determinar propriedades de desempenho sob condições não totalmente em regime permanente (condições de regime quase permanente).

Curva em condição de malha aberta, ou comportamento da resposta direcional serão examinados mais adiante nesta seção. A abordagem é de primeiramente analisar o 
comportamento em curvas a baixas velocidades, e a seguir considerar as diferenças que surgem para as condições de alta velocidade. A importância das propriedades dos pneus surgirá nos casos de curvas em mais altas velocidades e fornecerá um ponto singular para o estudo sistemático das propriedades da suspensão que influenciam o comportamento em curva.

\subsection{Curvas em baixa velocidade}

O primeiro passo para a realização do estudo dinâmico do veículo automotor em curva é analisar o comportamento deste veículo executando curvas em baixa velocidade. A baixa velocidade (manobras de estacionamento) os pneus não necessitam desenvolver forças laterais. Assim, eles rolam sem ângulo de escorregamento, e o veículo deve "negociar" a curva conforme ilustrado na Figura 3 . Se as rodas traseiras não têm ângulo de escorregamento, o centro da curva deve recair na projeção do eixo traseiro. Da mesma forma, a perpendicular a cada uma das rodas dianteiras deve passar pelo mesmo ponto (o centro da curva). Se eles não passarem pelo mesmo ponto, os pneus dianteiros irão "brigar" entre si durante a curva, cada um escorregando lateralmente. Os ângulos de esterçamento ideais para as rodas dianteiras são estabelecidos pela geometria apresentada na figura 3 e definem os ângulos de esterçamento para a curva.

Para uma geometria propícia na curva (assumindo pequenos ângulos), os ângulos de esterçamento são fornecidos por:

$$
\begin{aligned}
& \delta_{\mathrm{o}} \cong \frac{\mathrm{L}}{\mathrm{R}+\mathrm{t} / 2} \\
& \delta_{\mathrm{i}} \cong \frac{\mathrm{L}}{\mathrm{R}-\mathrm{t} / 2}
\end{aligned}
$$

O ângulo médio das rodas dianteiras (novamente assumindo pequenos ângulos) é definido [SAE J670] como ângulo de Ackerman: 
Os termos "Esterçamento de Ackerman" ou "Geometria de Ackerman" são comumente utilizados para designar a geometria exata das rodas dianteiras como mostrado na Figura 3. Os ângulos corretos dependem da distância entre-eixos do veículo e do ângulo da curva [Durstine, 1973]. Erros, ou desvios, da geometria de Ackerman nos ângulos de esterçamento à direita ou esquerda podem ter uma influência significativa no desgaste dos pneus dianteiros. Erros não têm uma influência significativa na resposta direcional [Lugner, Sringer, 1974]; entretanto, afetam os torques autoalinhantes do sistema de direção [Pitts, Wildig, 1978]. Com a correta geometria de Ackerman, os torques de resistência ao esterçamento tendem a aumentar consistentemente com o ângulo de esterçamento, proporcionando ao condutor uma sensação natural de retorno pelo volante de direção. No outro extremo com o esterçamento paralelo, os torques de esterçamento inicialmente crescem com o ângulo, mas podem diminuir a partir de um certo ponto, e até mesmo tornar-se negativos (tendência a aumentar o esterçamento durante a curva). Este tipo de comportamento do sistema de direção é indesejável.

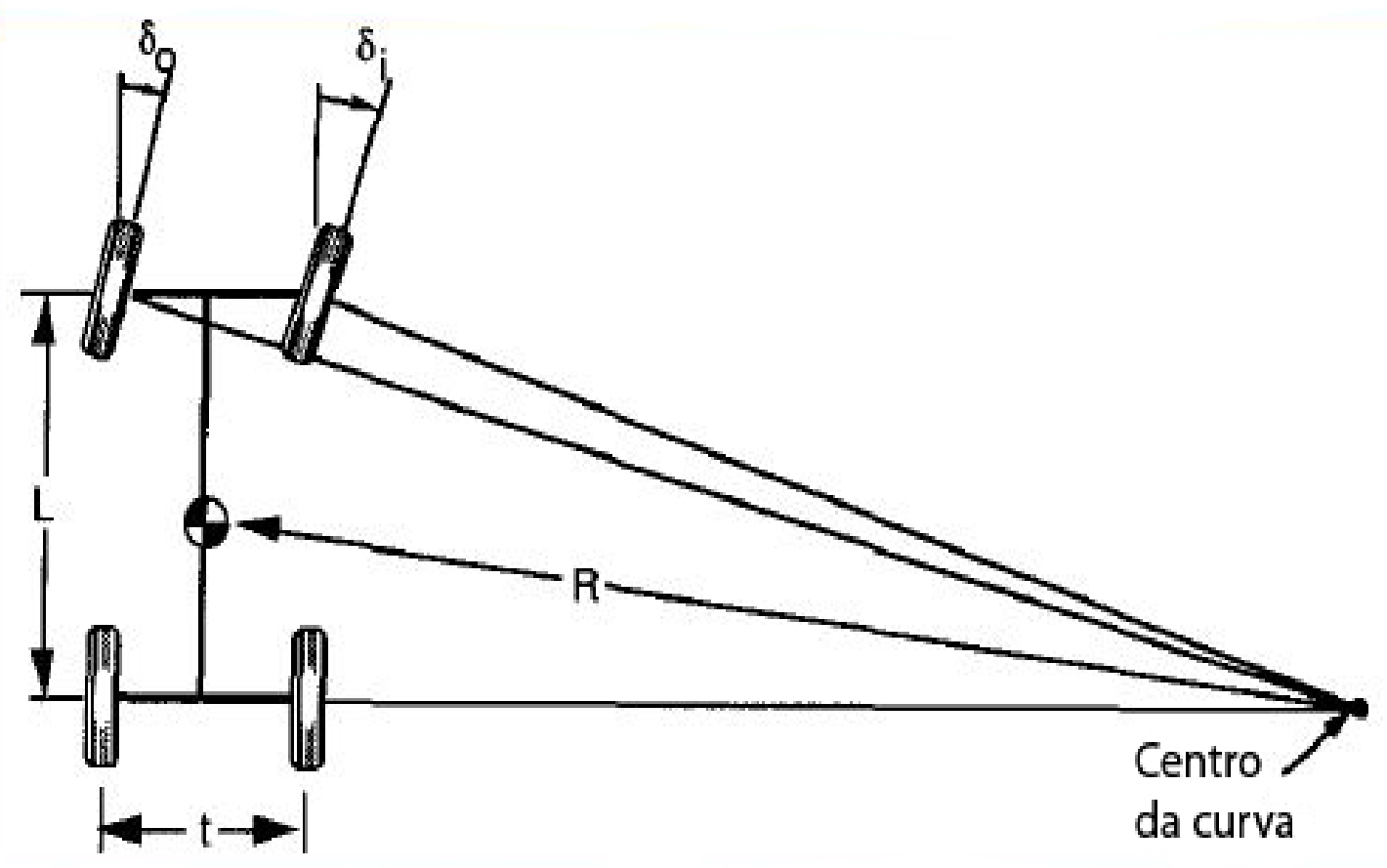

Figura 3 - Geometria de um veículo em curva 
O outro aspecto significativo do estudo do comportamento do veículo em curva de baixa velocidade é o deslocamento de trajetória que ocorre nas rodas traseiras. A distância do deslocamento de trajetória, $\Delta$, pode ser calculada por simples relações geométricas como:

$\Delta=\mathrm{R}[1-\cos (\mathrm{L} / \mathrm{R})]$

Utilizando a expressão para uma expansão em série de cossenos, a saber:

$\cos \mathrm{z}=1-\frac{\mathrm{z}^{2}}{2 !}+\frac{\mathrm{z}^{4}}{4 !}-\frac{\mathrm{z}^{6}}{6 !} \cdots$

Então

$\Delta \cong \frac{\mathrm{L}^{2}}{2 \mathrm{R}}$

Por razões óbvias, o deslocamento da trajetória é primariamente uma preocupação para veículos de entre eixos longo tais como caminhões ou ônibus. Para caminhões articulados, as equações geométricas se tornam mais complicadas e são conhecidas como equações "tractrix".

\subsection{Curvas em alta velocidade}

Em altas velocidades, as equações diferem, pois estará presente a aceleração lateral. Para contrapor a aceleração lateral os pneus deverão desenvolver forças laterais, e ângulos de escorregamento estarão presentes em cada roda.

\subsubsection{Forças laterais de esterço dos pneus}

Sob condições de curva, nas quais o pneu deverá desenvolver força lateral, o pneu irá experimentar um escorregamento lateral enquanto rola. $\mathrm{O}$ ângulo entre a direção para a qual 
ele aponta e a de sua trajetória é conhecido como ângulo de escorregamento, $\alpha$ [SAE J670]. Eles são ilustrados na Figura 4.

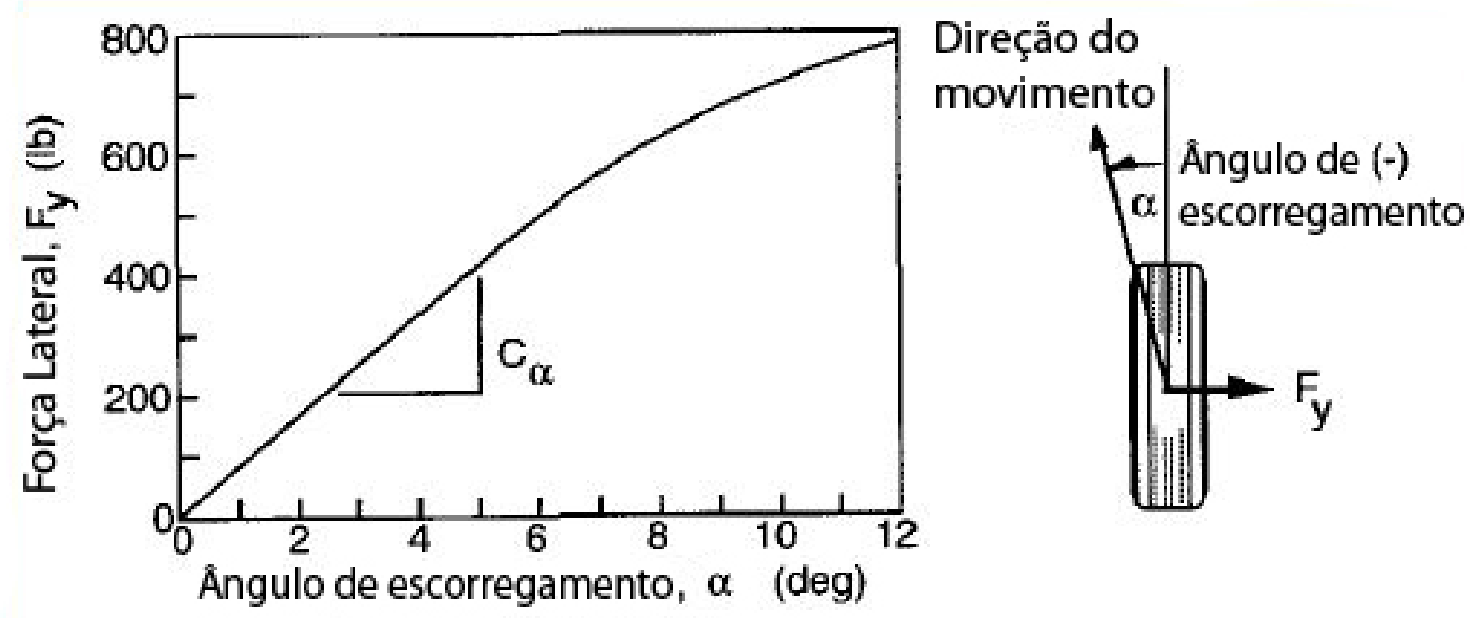

Figura 4 - Propriedades das forças de esterçamento do pneu (Gillespie, 1992)

A força lateral, representada por $\mathrm{F}_{\mathrm{y}}$, é chamada de "força de esterçamento" quando o ângulo de cambagem é zero. A um determinado carregamento sobre o pneu, a força de esterço aumenta com o ângulo de escorregamento. Em pequenos ângulos de escorregamento (5 graus ou menos) esta relação é linear, por conseguinte, a força de esterçamento é descrita por:

$\mathrm{F}_{\mathrm{y}}=\mathrm{C}_{\alpha} \cdot \alpha$

A constante de proporcionalidade $\mathrm{C}_{\alpha}$ é conhecida como "rigidez de esterço", e é definida como a inclinação da curva de $\mathrm{F}_{\mathrm{y}}$ versus $\alpha$ em $\alpha=0$. Um ângulo de escorregamento positivo produz uma força negativa no pneu (à esquerda), implicando que $\mathrm{C}_{\alpha}$ seja negativa, entretanto, a Sociedade de Engenharia Automotiva (SAE) define a rigidez de esterço como negativa, de forma que $\mathrm{C}_{\alpha}$ assume um valor positivo [SAE J670].

A rigidez de esterço é dependente de muitas variáveis [Nordeen, Cortese, 1963]. Tamanho e tipo de pneu (construção com lonas radiais ou diagonais), número de lonas, ângulos do tecido, largura das rodas e banda de rodagem são variáveis significativas. Para um determinado pneu, a carga sobre ele e a sua pressão de inflação são as principais variáveis. A velocidade não influencia de forma significativa as forças de esterçamento produzidas pelo pneu. Os gráficos na Figura 5 ilustram a influência de muitas destas variáveis. 

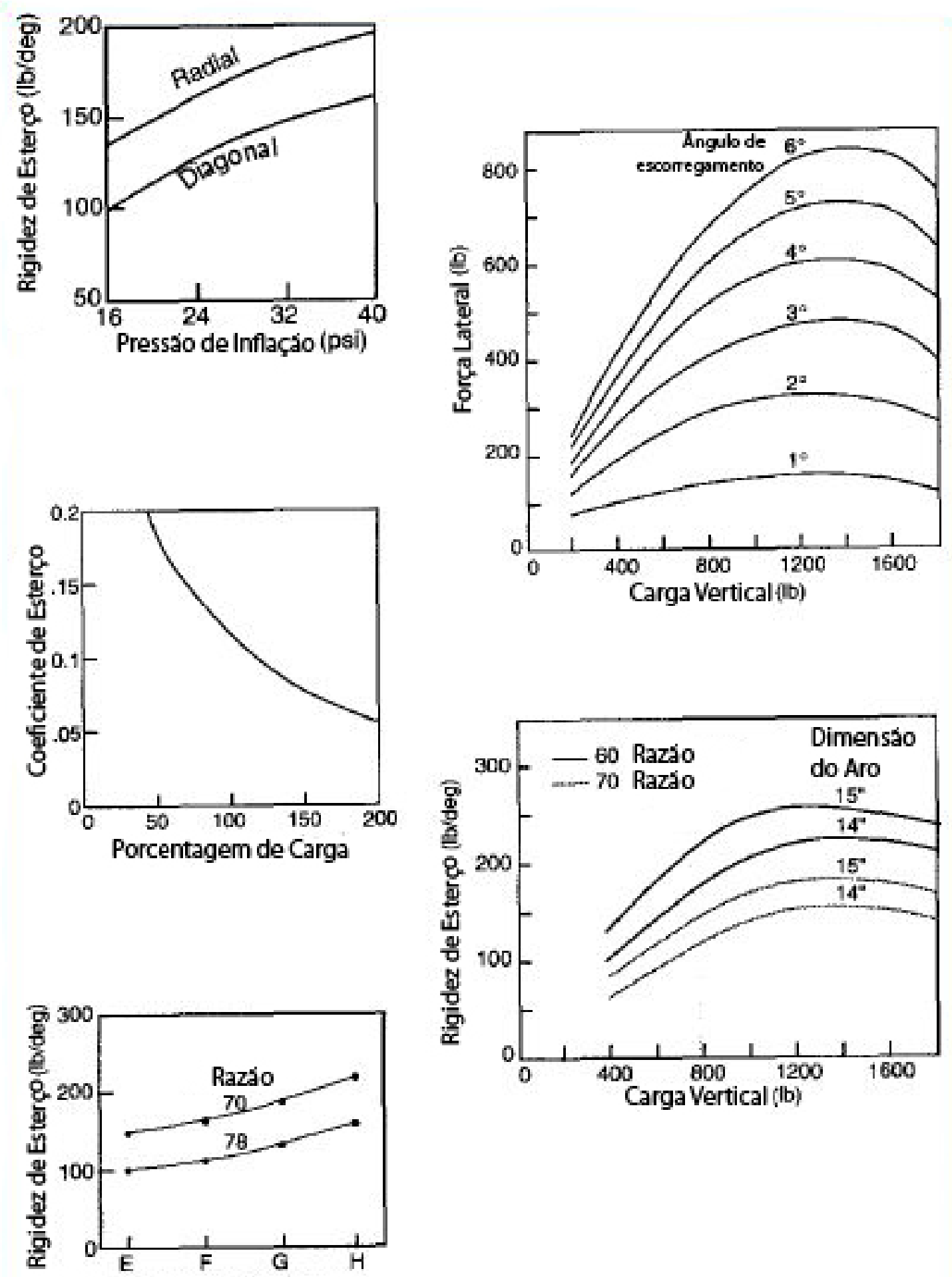

Designaçáo da Dimensáo do Pneu

Figura 5 - Variáveis que afetam a rigidez de esterço do pneu (Gillespie, 1992) 
Devido à forte dependência da força de esterço à carga sobre o pneu, as propriedades de esterço podem também ser descritas como "coeficiente de esterço" que é a rigidez de esterço dividida pela carga. Assim, o coeficiente de esterço, $\mathrm{CC}_{\alpha}$ é dado por:

$\mathrm{CC}_{\alpha}=\mathrm{C}_{\alpha} / \mathrm{F}_{\mathrm{z}} \quad\left(\mathrm{kg}_{\mathrm{y}} / \mathrm{kg}_{\mathrm{z}} / \mathrm{deg}\right)$

Coeficiente de esterço é geralmente maior em cargas leves, diminuindo continuamente conforme a carga se aproxima de seu valor nominal (carga nominal da Tire \& Rim Association). A 100\% de carga, o coeficiente de esterço tipicamente encontra-se na faixa de $0.89 \mathrm{~N}$ de força de esterço por grau de ângulo de escorregamento.

\subsubsection{Equações de esterçamento}

As equações de esterçamento em regime permanente são derivadas da aplicação da segunda lei de Newton, juntamente com a equação descrevendo a geometria da curva (modificada pelas condições do ângulo de escorregamento necessárias nos pneus). Para fins de análises, é conveniente representar o veículo pelo modelo bicicleta apresentado na Figura 6. As altas velocidades o raio da curva é muito maior que o entre eixos do veículo. Então podem ser assumidos pequenos ângulos, e a diferença entre os ângulos de esterçamento das rodas dianteiras externa e interna podem ser representadas por uma roda, a um ângulo de esterçamento, $\delta$, com uma força de esterçamento equivalente à de ambas as rodas. $\mathrm{O}$ mesmo pressuposto é feito para as rodas traseiras.

Aplicando-se a segunda lei de Newton para um veículo se deslocando para frente com uma velocidade V, a soma das forças laterais dos pneus deve igualar a massa multiplicada pela aceleração centrípeta.

$\Sigma \mathrm{F}_{\gamma}=\mathrm{F}_{\mathrm{yf}}+\mathrm{F}_{\mathrm{yr}}=\mathrm{M} \cdot \mathrm{V}^{2} / \mathrm{R}$

onde:

$\mathrm{F}_{\mathrm{yf}} \quad=$ Força lateral no eixo dianteiro (esterçamento)

$\mathrm{F}_{\mathrm{yr}} \quad$ = Força lateral no eixo traseiro (esterçamento)

$\mathrm{M} \quad=$ Massa do veículo 


$$
\begin{array}{ll}
\mathrm{V} & =\text { Velocidade à frente } \\
\mathrm{R} & =\text { Raio da curva }
\end{array}
$$

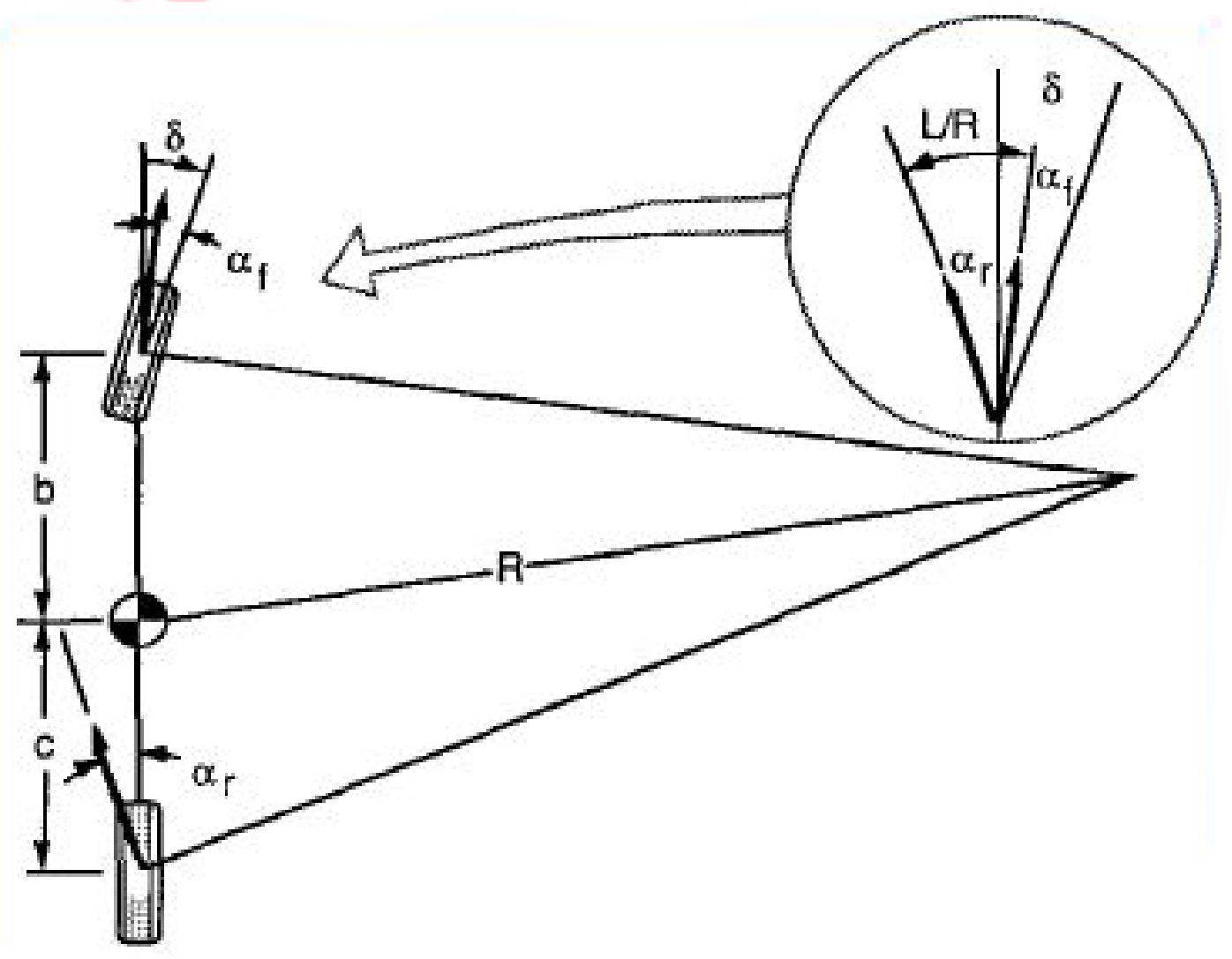

Figura 6 - Esterçamento de um modelo bicicleta

Também, para o veículo estar em equilíbrio em torno do centro de gravidade, a resultante dos momentos das forças laterais dianteira e traseira deve ser zero.

$\mathrm{F}_{\mathrm{yf}} \cdot \mathrm{b}-\mathrm{F}_{\mathrm{yr}} \cdot \mathrm{c}=0$

Deste modo

$\mathrm{F}_{\mathrm{yf}}=\mathrm{F}_{\mathrm{yr}} \cdot \mathrm{c} / \mathrm{b}$

Substituindo de volta na Eq. (7) teremos:

$\mathrm{M} \cdot \mathrm{V}^{2} / \mathrm{R}=\mathrm{F}_{\mathrm{yr}}(\mathrm{c} / \mathrm{b}+1)=\mathrm{F}_{\mathrm{yr}}(\mathrm{c} / \mathrm{b}+1)=\mathrm{F}_{\mathrm{yr}}(\mathrm{b}+\mathrm{c}) / \mathrm{b}=\mathrm{F}_{\mathrm{yr}} \cdot \mathrm{L} / \mathrm{b}$ 
$\mathrm{F}_{\mathrm{yr}}=\mathrm{M} \cdot \mathrm{b} / \mathrm{L}\left(\mathrm{V}^{2} / \mathrm{R}\right)$

Mas (M b/L) é simplesmente a parte da massa do veículo transportado sobre o eixo traseiro (i.e., $\mathrm{W}_{\mathrm{r}} / \mathrm{g}$ ); assim a Eq. (11) simplesmente nos diz que a força lateral desenvolvida no eixo traseiro deve ser $\mathrm{W}_{\mathrm{r}} / \mathrm{g}$ multiplicada pela aceleração lateral naquele ponto. Resolvendo para $\mathrm{F}_{\mathrm{yf}}$ da mesma maneira indicará que a força lateral no eixo dianteiro deve ser $\mathrm{W}_{\mathrm{f}} / \mathrm{g}$ multiplicado pela aceleração lateral.

Com as forças laterais requeridas conhecidas, os ângulos de escorregamento das rodas dianteira e traseira também são determinados a partir da Eq. (5). Sejam eles:

$\alpha_{\mathrm{f}=} \mathrm{W}_{\mathrm{f}} \cdot \mathrm{V}^{2} /\left(\mathrm{C}_{\alpha \mathrm{f}} \cdot \mathrm{g} \cdot \mathrm{R}\right)$

$\mathrm{e}$

$\alpha_{\mathrm{r}}=\mathrm{W}_{\mathrm{r}} \cdot \mathrm{V}^{2} /\left(\mathrm{C}_{\alpha \mathrm{r}} \cdot \mathrm{g} \cdot \mathrm{R}\right)$

Temos de olhar agora para a geometria do veículo na curva para concluir a análise. Com um pouco de estudo da Figura 6, é possível constatar que:

$\delta=57,3 \mathrm{~L} / \mathrm{R}+\alpha_{\mathrm{f}}-\alpha_{\mathrm{r}}$

Agora substituindo por $\alpha_{\mathrm{f}}$ e $\alpha_{\mathrm{r}}$ das Eqs. (12) e (13) nos dá:

$$
\begin{aligned}
& \delta=57,3 \frac{\mathrm{L}}{\mathrm{R}}+\frac{\mathrm{W}_{\mathrm{f}} \cdot \mathrm{V}^{2}}{\mathrm{C}_{\alpha \mathrm{f}} \cdot \mathrm{g} \cdot \mathrm{R}}-\frac{\mathrm{W}_{\mathrm{r}} \cdot \mathrm{V}^{2}}{\mathrm{C}_{\alpha \mathrm{r}} \cdot \mathrm{g} \cdot \mathrm{R}} \\
& \delta=57,3 \frac{\mathrm{L}}{\mathrm{R}}+\left(\frac{\mathrm{W}_{\mathrm{f}}}{\mathrm{C}_{\alpha \mathrm{f}}}-\frac{\mathrm{W}_{\mathrm{r}}}{\mathrm{C}_{\alpha \mathrm{r}}}\right) \frac{\mathrm{V}^{2}}{\mathrm{~g} \cdot \mathrm{R}}
\end{aligned}
$$

onde:

$\delta=$ ângulo de esterço nas rodas dianteiras (deg)

$\mathrm{L} \quad=$ Entre eixos (m)

$\mathrm{R} \quad=$ Raio da curva (m)

$\mathrm{V} \quad=$ Velocidade à frente $(\mathrm{m} / \mathrm{sec})$ 


$$
\begin{array}{ll}
\mathrm{g} & =\text { Aceleração gravitacional }=9,81 \mathrm{~m} / \mathrm{s}^{2} \\
\mathrm{~W}_{\mathrm{f}} & =\text { Carga sobre o eixo dianteiro }(\mathrm{kg}) \\
\mathrm{W}_{\mathrm{r}} & =\text { Carga sobre o eixo traseiro }(\mathrm{kg}) \\
\mathrm{C}_{\alpha \mathrm{f}} & =\text { Rigidez de esterço dos pneus dianteiros }\left(\mathrm{kg}_{\mathrm{y}} / \mathrm{deg}\right) \\
\mathrm{C}_{\alpha \mathrm{r}} & =\text { Rigidez de esterço dos pneus traseiros }\left(\mathrm{kg}_{\mathrm{y}} / \mathrm{deg}\right)
\end{array}
$$

\subsubsection{Gradiente de sub-esterçamento}

A equação é comumente escrita na forma reduzida como se segue:

$\delta=57,3 \mathrm{~L} / \mathrm{R}+\mathrm{Ka}_{\mathrm{y}}$

onde:

$\mathrm{K} \quad$ = Gradiente de sub-esterçamento $(\mathrm{deg} / \mathrm{g})$

$\mathrm{a}_{\mathrm{y}} \quad=$ Aceleração lateral (g)

A equação (15) é muito importante para as propriedades da resposta em curva de um veículo automotor, ela descreve como o ângulo de esterçamento do veículo deve ser modifícado com

o raio da curva, $\mathbf{R}$, aceleração lateral $\mathrm{V}^{2} /(\mathrm{g} \mathbf{R})$. A expressão $\left[\mathrm{W}_{\mathrm{f}} / \mathrm{C}_{\alpha \mathrm{f}}-\mathrm{W}_{\mathrm{r}} / \mathrm{C}_{\alpha \mathrm{r}}\right]$ determina a magnitude e a direção das entradas de direção requeridas. Ela consiste em dois termos, cada um deles é razão da carga sobre o eixo (dianteiro ou traseiro) à rigidez de esterço dos pneus no eixo, ela é chamada "gradiente de sub-esterçamento", e será indicado pelo símbolo, K, que possui as unidades de grau/g. Existem três possibilidades:

\section{1) Esterçamento Neutro: $\quad \mathrm{W}_{\mathrm{f}} / \mathrm{C}_{\alpha \mathrm{f}}=\mathrm{W}_{\mathrm{r}} / \mathrm{C}_{\alpha \mathrm{r}} \rightarrow \mathrm{K}=0 \rightarrow \alpha_{\mathrm{f}}=\alpha_{\mathrm{r}}$}

Em uma curva de raio constante nenhuma alteração no ângulo de esterçamento será requerido com a variação da velocidade. Especificamente, o ângulo de esterçamento requerido para realizar a curva será equivalente ao ângulo de Ackerman, 57,3 L/R. Fisicamente, o caso de esterçamento neutro corresponde a um equilíbrio no veículo de modo que a "força" da aceleração lateral no CG causa um aumento idêntico no ângulo de escorregamento em ambas as rodas dianteira e traseira. 


\section{2) Sub-esterçamento}

$$
\mathrm{W}_{\mathrm{f}} / \mathrm{C}_{\alpha \mathrm{f}}>\mathrm{W}_{\mathrm{r}} / \mathrm{C}_{\alpha \mathrm{r}} \rightarrow \mathrm{K}>0 \rightarrow \alpha_{\mathrm{f}}>\alpha_{\mathrm{r}}
$$

Em uma curva de raio constante o ângulo de esterçamento deve aumentar com a velocidade proporcionalmente a K (graus/g) vezes a aceleração lateral em g’s. Assim o ângulo aumenta linearmente com a aceleração lateral e com o quadrado da velocidade. No caso sub-esterçante a aceleração lateral do CG causa nas rodas dianteiras um escorregamento lateral em uma quantidade maior do que nas rodas traseiras. Então, para desenvolver a força lateral nas rodas dianteiras necessária para manter o raio da curva constante, estas rodas devem ser esterçadas de um ângulo maior.

\section{3) Sobre-esterçamento}

$$
\mathrm{W}_{\mathrm{f}} / \mathrm{C}_{\alpha \mathrm{f}}<\mathrm{W}_{\mathrm{r}} / \mathrm{C}_{\alpha \mathrm{r}} \rightarrow \mathrm{K}<0 \rightarrow \alpha_{\mathrm{f}}<\alpha_{\mathrm{r}}
$$

Em uma curva de raio constante o ângulo de esterçamento deverá diminuir conforme a velocidade (e aceleração lateral) é aumentada. Neste caso, a aceleração lateral no CG causa um aumento do ângulo de escorregamento das rodas traseiras maior do que as rodas dianteiras. A deriva para o lado externo da traseira do veículo vira as rodas dianteiras para dentro, diminuindo então o raio da curva. O aumento na aceleração lateral que se segue causa na traseira que esta derive ainda mais e o processo continua a menos que o ângulo de esterçamento seja reduzido para manter o raio da curva.

A forma como ângulo de esterçamento muda com a velocidade numa curva de raio constante para cada um desses casos é ilustrado na Figura 7. Com o veículo de esterçamento neutro, o ângulo de esterçamento para manter a curva a qualquer velocidade é simplesmente o ângulo de Ackerman. Com o sub-esterçamento o ângulo aumenta com o quadrado da velocidade alcançando o dobro do ângulo inicial na velocidade característica. No caso sobre-esterçante o ângulo de esterçamento diminui com o quadrado da velocidade e chega a zero no valor da velocidade crítica. 


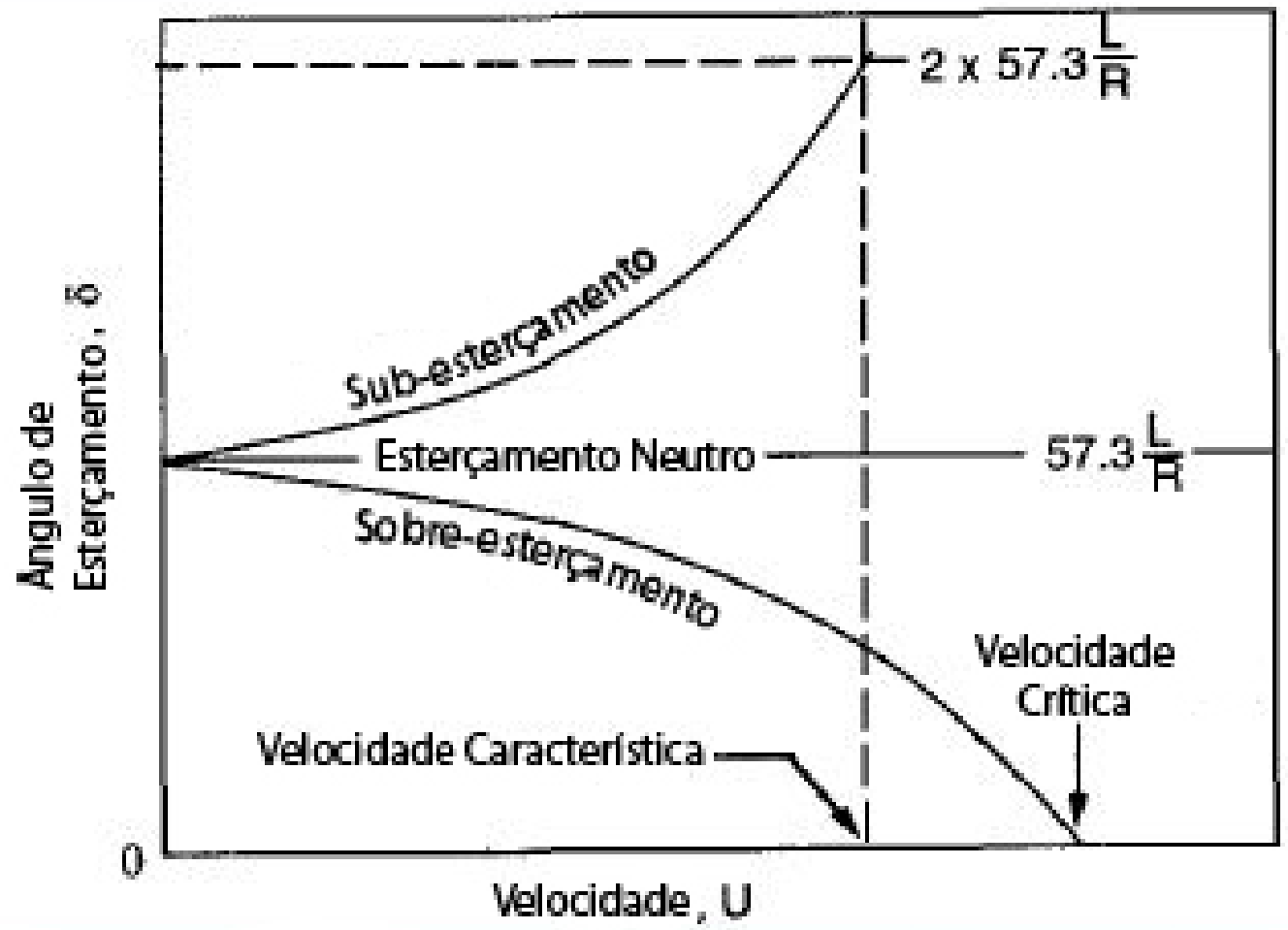

Figura 7 - Mudança do ângulo de esterçamento com a velocidade (Gillespie, 1992)

\subsubsection{Velocidade característica}

Para um veículo sub-esterçante o nível de sub-esterçamento pode ser quantificado por um parâmetro conhecido como velocidade característica [Bundorf, 1967]. Velocidade característica é simplesmente aquela velocidade na qual o ângulo requerido para percorrer qualquer curva é o dobro do ângulo de Ackerman. Isso pode ser visto da Eq. (16) quando:

$\mathrm{Ka}_{\mathrm{y}}=57,3 \mathrm{~L} / \mathrm{R}$

Uma vez que $a_{y}$ é uma função do quadrado da velocidade, a velocidade característica é:

$\mathrm{V}_{\mathrm{char}}=\sqrt{57,3 \mathrm{~L} \cdot \mathrm{g} / \mathrm{K}}$ 


\subsubsection{Velocidade crítica}

No caso do sobre-esterçamento, uma velocidade crítica irá existir acima da qual o veículo será instável. A velocidade crítica é dada pela expressão:

$\mathrm{V}_{\text {crit }}=\sqrt{-57,3 \mathrm{~L} \cdot \mathrm{g} / \mathrm{K}}$

Onde deve ser lembrado que o valor de $\mathbf{K}$ é negativo, de tal forma que a expressão sob o radical seja positiva e possua um valor real. Note-se que a velocidade crítica é dependente da distância entre eixos do veículo; para um determinado nível de sobre-esterçamento, veículos com entre eixos mais longo possuem uma velocidade critica mais alta do que veículos com entre eixos curto. Um veículo sobre-esterçante pode ser dirigido a velocidades inferiores a crítica mas ele se torna direcionalmente instável quando atinge ou ultrapassa velocidade crítica. A significância da velocidade crítica se torna mais aparente através de sua influência no ganho da aceleração lateral e no ganho da velocidade de guinada conforme será discutido mais a frente.

\subsubsection{Ganho da aceleração lateral}

Na medida em que um dos propósitos para esterçar um veículo é produzir aceleração lateral, a equação de esterçamento pode ser utilizada para examinar o desempenho a partir desta perspectiva. A eq. (16) pode ser resolvida para a razão de aceleração lateral $a_{y}$, ao ângulo de esterçamento, $\delta$. A razão é o ganho da aceleração lateral, e é dada por:

$$
\frac{\mathrm{a}_{\mathrm{y}}}{\delta}=\frac{\frac{\mathrm{V}^{2}}{57,3 \mathrm{~L} \cdot \mathrm{g}}}{1+\frac{\mathrm{K} \cdot \mathrm{V}^{2}}{57,3 \mathrm{~L} \cdot \mathrm{g}}} \quad(\mathrm{deg} / \mathrm{sec})
$$

Note que quando o valor de $\mathbf{K}$ é zero (esterçamento neutro), o ganho da aceleração lateral é determinado apenas pelo numerador e é diretamente proporcional ao quadrado da velocidade. Quando o valor de K é positivo (sub-esterçante), o ganho é diminuído pelo segundo termo do denominador e é sempre menor que aquele de um veículo de esterçamento neutro. 
Finalmente, quando o valor de $\mathrm{K}$ é negativo (sobre-esterçante), o segundo termo no denominador subtrai de 1, aumentando o ganho da aceleração lateral. A magnitude do termo depende do quadrado da velocidade e segue em direção ao valor 1 quando a velocidade se aproxima da velocidade crítica, assim a velocidade crítica da Eq. (19) corresponde ao denominador atingindo zero (ganho infinito) na Eq. (20).

\subsubsection{Ganho na velocidade de guinada}

A segunda razão para esterçar o veículo é mudar o ângulo de direção pelo desenvolvimento de uma velocidade de guinada (algumas vezes chamada "razão de guinada"). A velocidade de guinada, r, é a taxa de rotação do ângulo de direção e é dada por:

$\mathbf{r}=57,3 \mathrm{~V} / \mathrm{R} \quad(\mathrm{deg} / \mathrm{sec})$

Substituindo esta expressão na Eq. (16) e resolvendo para a razão da velocidade de guinada pelo ângulo de esterçamento resulta:

$\frac{\mathbf{r}}{\delta}=\frac{\mathrm{V} / \mathrm{L}}{1+\frac{\mathrm{K} \cdot \mathrm{V}^{2}}{57,3 \mathrm{~L} \cdot \mathrm{g}}}$

A razão representa um “ganho”, o qual é proporcional á velocidade no caso de um veículo de esterçamento neutro, isso é ilustrado na Figura 8. É facilmente comprovado que no caso sobre-esterçante o ganho da velocidade de guinada se torna infinito quando a velocidade atinge a velocidade crítica de acordo com a Eq. (19). No caso do veículo sub-esterçante a velocidade de guinada aumenta com a velocidade até a velocidade característica e em seguida começa a diminuir. Assim a velocidade característica tem a significância daquela em que o veículo apresenta maior resposta em guinada. 


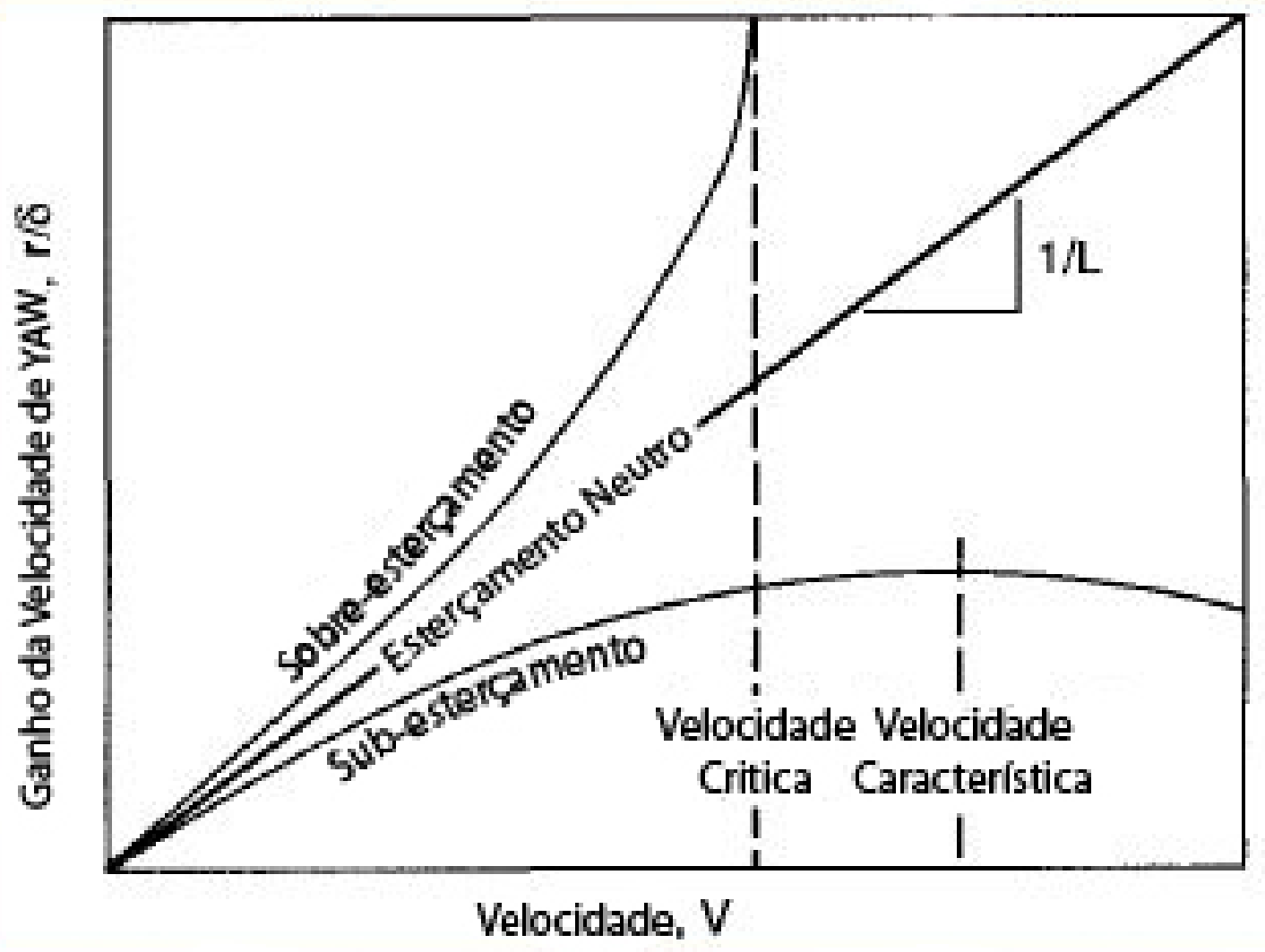

Figura 8 - Ganho da velocidade de guinada como função da velocidade (Gillespie, 1992)

\subsection{8. Ângulo de escorregamento lateral}

A partir da discussão do comportamento em curva fica evidente que quando a aceleração lateral é desprezível, o traçado da roda traseira segue internamente ao da roda dianteira. Mas, conforme a aceleração lateral aumenta a traseira do veículo deve derivar para fora no sentido de desenvolver os ângulos de escorregamento necessários nos pneus traseiros. A qualquer ponto no veículo um ângulo de escorregamento pode ser definido como sendo o ângulo entre o eixo longitudinal e a direção do movimento local. Em geral, o ângulo de escorregamento lateral será diferente a cada ponto para um veículo durante a execução da curva.

Tomando o centro de gravidade como o ponto em questão, o ângulo de escorregamento lateral é definido conforme mostrado na figura 9. O ângulo de escorregamento lateral é definido como positivo neste caso porque a direção do movimento (o vetor da velocidade local) é orientado no sentido horário a partir do eixo longitudinal (ângulos horários observados por 
cima são considerados positivos na convenção SAE). Em alta velocidade o ângulo de escorregamento das rodas traseiras impõe que ângulo de escorregamento lateral no CG se torne negativo, como apresentado na Figura 10.

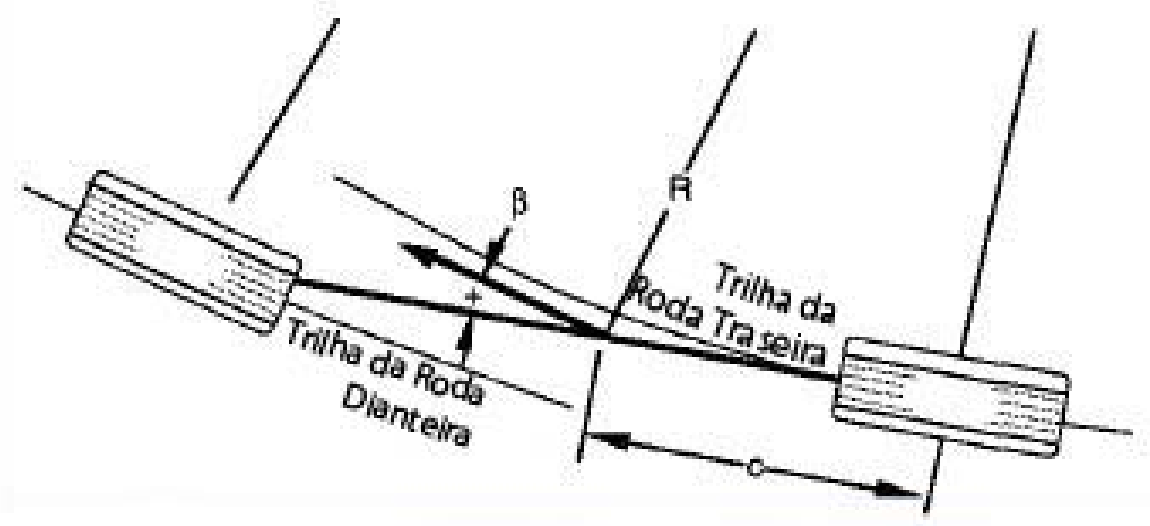

Figura 9 - Ângulo de escorregamento lateral em uma curva de baixa velocidade (Gillespie, 1992)

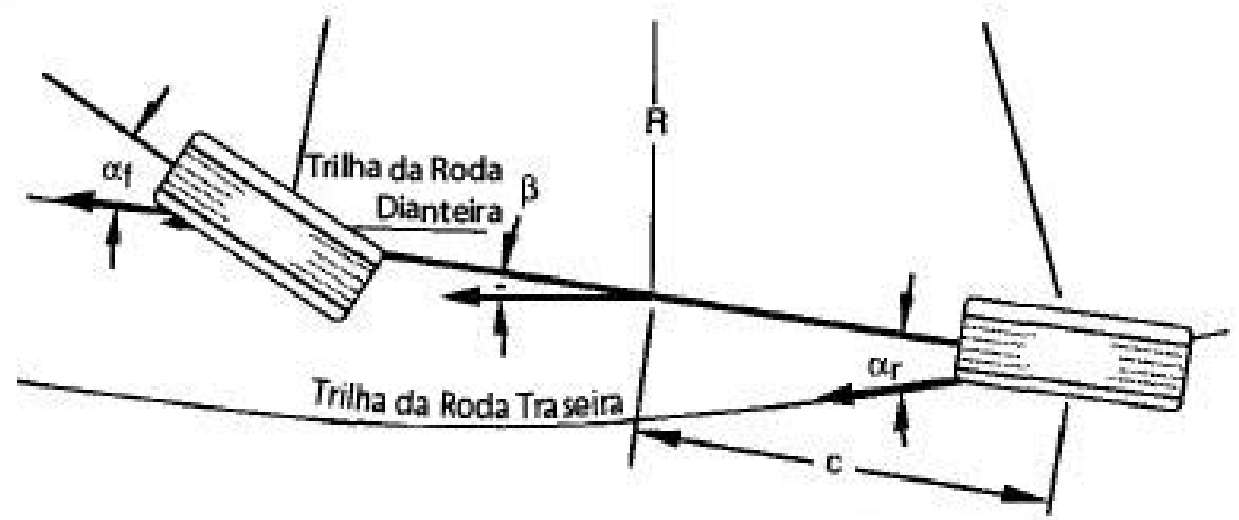

Figura 10 - Ângulo de escorregamento lateral em uma curva de alta velocidade (Gillespie, 1992)

Para qualquer velocidade o ângulo de escorregamento lateral, $\beta$, no CG será:

$\beta=57,3 \mathrm{c} / \mathrm{R}-\alpha_{\mathrm{r}}=57,3 \mathrm{c} / \mathrm{R}-\mathrm{W}_{\mathrm{r}} \cdot \mathrm{V}^{2} /\left(\mathrm{C}_{\alpha \mathrm{r}} \cdot \mathrm{g} \cdot \mathrm{R}\right)$

Note-se que a velocidade na qual o ângulo de escorregamento lateral se torna zero é:

$\beta=0 \therefore \mathrm{V}_{\beta}=\sqrt{57,3 \cdot \mathrm{g} \cdot \mathrm{c} \cdot \mathrm{C}_{\alpha \mathrm{r}} / \mathrm{W}_{\mathrm{r}}}$ 
e é independente do raio da curva.

\subsubsection{Margem estática}

Um termo comumente utilizado nas discussões sobre dirigibilidade é a margem estática e, assim como, o coeficiente de sub-esterçamento ou a velocidade característica fornece uma medida do comportamento da dirigibilidade em regime permanente.

A margem estática é determinada pelo ponto no veículo onde uma força lateral não produzirá velocidade de guinada em regime permanente (ou seja, o ponto de esterçamento neutro). Nós podemos ir um passo além e definir uma linha de esterçamento neutro conforme mostrado na Figura 11. A linha de esterçamento neutro é o lócus dos pontos no plano x-z, ao longo do qual forças laterais externas não produzem velocidade de guinada em regime permanente.

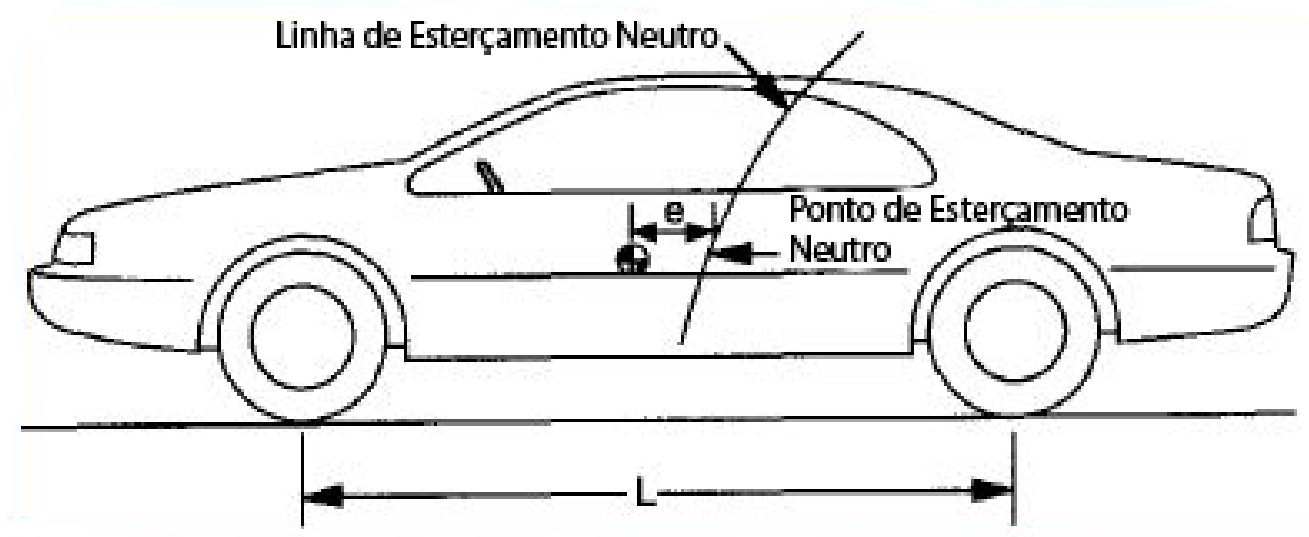

Figura 11 - Linha de esterçamento neutro em um veiculo

A margem estática é definida como a distância do ponto de esterçamento neutro até o CG, normalizada pelo entre eixos. Isto é:

Margem Estática $=\mathrm{e} / \mathrm{L}$

Quando o ponto está atrás do CG a margem estática é positiva e o veículo é sub-esterçante. No CG a margem é zero e o veículo tem esterçamento neutro. Quando a frente do CG, o 
veículo é sobre-esterçante. Em veículos típicos a margem fica na faixa de 0,05 para 0,07 atrás do CG.

\subsection{Medição experimental do gradiente de sub-esterçamento}

Gradiente de sub-esterçamento é definido pela SAE [SAE J670] como "A quantidade obtida pela subtração do gradiente do ângulo de esterço de Ackerman do valor do gradiente do ângulo de esterço de referência em uma pista plana e para uma determinada condição estática". Métodos para medição experimental do gradiente de sub-esterçamento [SAE J266, SAE J2181, ISO 4138] são todos baseados na definição do gradiente representada pela Eq. (16). Ou seja,

$\delta=57,3 \mathrm{~L} / \mathrm{R}+\mathrm{K} \cdot \mathrm{a}_{\mathrm{y}}$

A dedução desta equação assume que o veículo esteja em condição de operação em regime permanente; portanto, gradiente de sub-esterçamento é definido como a propriedade do regime permanente. Para medição experimental o veículo deve ser conduzido em uma curva em regime quase estático com a medição apropriada dos valores na equação acima de forma que o valor de $\mathrm{K}$ possa ser determinado. Quatro métodos de teste têm sido sugeridos como meio de medir esta propriedade: raio constante, velocidade constante, ângulo de esterçamento constante e aceleração constante. Apenas os dois primeiros refletem razoavelmente circunstâncias de condução normal, portanto, a discussão será limitada a estes dois.

\subsubsection{Método do raio constante}

Sub-esterçamento pode ser medido conduzindo-se o veículo em uma curva de raio constante e observando o ângulo de esterçamento versos a aceleração lateral. O método se aproxima da operação de um veículo em muitas situações de rodovia, tais como, raios constantes em decessos de rodovias. Como mínimo, a instrumentação deve estar disponível para medir o ângulo do volante de direção e a aceleração lateral. Dado um raio de curva e a algum tipo de medição da velocidade do veículo (do velocímetro, quinta roda ou tempo de volta), aceleração lateral pode ser computada usando a relação: 
$\mathrm{a}_{\mathrm{y}}=\mathrm{V}^{2} /(\mathrm{R} \cdot \mathrm{g})$

O procedimento recomendado é o de dirigir o veículo em um circulo a uma velocidade muito baixa, a qual a aceleração lateral é desprezível, e gravar o ângulo de esterçamento (ângulo de esterçamento de Ackerman) requerido para manter a curva. (O engenheiro de teste é desafiado a desenvolver uma boa técnica para este processo, pois inclinações na superfície de teste, irregularidades, etc., causaram ao veículo uma derivação para dentro ou para fora conforme ele prossegue, complicando a determinação do ângulo de esterço médio). A velocidade do veículo é então aumentada em estágios que irão produzir uma aceleração lateral de incrementos razoáveis (tipicamente $0,1 \mathrm{~g}$ ), registrando o ângulo de esterçamento a cada velocidade. O ângulo de esterçamento (dividido pela razão de esterço a fím de se obter o ângulo de esterçamento na roda) é, então, plotado como uma função da aceleração lateral, conforme mostrado na Figura 12.

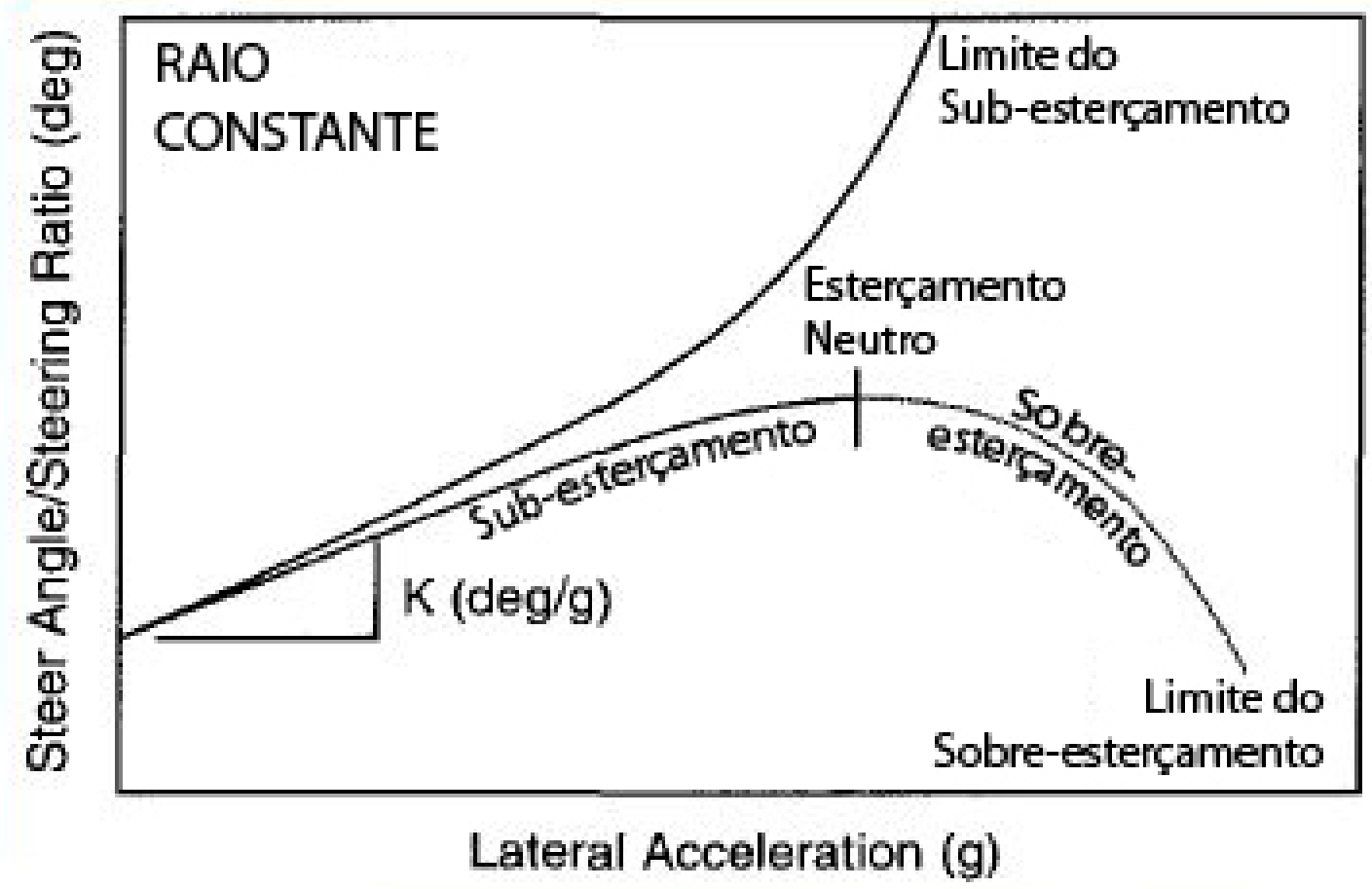

Figura 12 - Exemplo de medição do gradiente de sub-esterçamento pelo método do raio constante (Gillespie, 1992)

O significado deste registro pode ser visto tomando-se a derivada da Eq. (16): 


$$
\frac{\partial \delta}{\partial \mathrm{a}_{\mathrm{y}}}=\frac{\partial}{\partial \mathrm{a}_{\mathrm{y}}}\left(57,3 \frac{\mathrm{L}}{\mathrm{R}}\right)+\mathrm{K} \frac{\partial \mathrm{a}_{\mathrm{y}}}{\partial \mathrm{a}_{\mathrm{y}}}
$$

Uma vez que o raio da curva é constante o ângulo de esterçamento do Ackerman também é constante e sua derivada é zero. Assim:

$$
\mathrm{K}=\frac{\partial \delta}{\partial \mathrm{a}_{\mathrm{y}}}
$$

A inclinação da curva do ângulo de esterçamento é o gradiente de sub-esterçamento. Uma inclinação positiva indica sub-esterçamento, inclinação zero é o esterçamento neutro e uma inclinação negativa é sobre-esterçamento. Medições típicas terão uma das formas apresentadas na Figura 12. Alguns veículos serão sub-esterçantes em toda sua faixa de operação permanecendo assim até o limite. Outros podem ser sub-esterçantes a níveis de baixa aceleração lateral, mas mudar para sobre-esterçantes em altos níveis de aceleração lateral e apresentar um limite sobre-esterçante.

Note que o ângulo de esterçamento das rodas (obtido dividindo-se o ângulo de esterçamento do volante de direção pela relação de esterço) é usado para caracterização do gradiente de sub-esterçamento. Enquanto o sub-esterçamento é medido no volante de direção, o gradiente é definido pelos graus por $\mathrm{g}$ de esterçamento requerido na roda, como se sabe, a relação de esterço não é uma constante devido à histerese do sistema. Isso não invalida o método de medição, mas ao contrario, reconhece que estas propriedades no sistema de direção são uma fonte legítima de sub-esterçamento no veículo, no caso em que o ângulo de esterçamento das rodas é medido diretamente, um gradiente de sub-esterçamento diferente será obtido, pois, os efeitos no sistema de direção não serão incluídos. Embora este método não seja incorreto, ele falha em caracterizar totalmente as propriedades de sub-esterçamento do veículo pela exclusão da contribuição do sistema de direção. Reconhecendo que o motorista deve controlar o veículo a partir do volante de direção, os efeitos do sistema de direção devem ser incluídos numa caracterização completa do sub-esterçamento.

O método do raio constante tem a vantagem de que um mínimo de instrumentação é necessário, mas tem a desvantagem de que é difícil de executar de forma objetiva. A determinação de um ângulo de esterçamento de volante preciso é difícil devido aos desvios 
necessários para manter o veículo no raio da curva selecionado. Este aspecto da técnica de teste não é facilmente controlado.

O raio mínimo de curva para este procedimento de teste é de normalmente $30 \mathrm{~m}$ (aproximadamente 100 pés). Para veículos de dois eixos o gradiente de sub-esterçamento não é afetado pelo raio do círculo. O gradiente para caminhões multi-eixos (três eixos ou mais), entretanto, é sensível ao raio da curva neste intervalo.

\subsubsection{Método de velocidade constante}

Sub-esterçamento pode ser medido a uma velocidade constante pela variação do ângulo de esterçamento. Medições por este método referem muitas situações reais de condução uma vez que os veículos são normalmente dirigidos próximos a uma velocidade constante. Com este método o raio da curva irá variar continuamente requerendo uma coleta de dados mais extensa para determinar o gradiente. Adicionalmente á medição da velocidade e do ângulo de esterçamento, o raio da curva também precisa ser determinado para cada condição. O meio mais prático de medir o raio da curva é pela medição da aceleração lateral ou pela velocidade de guinada. O raio da curva é derivado das medições usando a forma apropriada das relações abaixo:

$\mathrm{R}=\mathrm{V}^{2} / \mathrm{a}_{\mathrm{y}}=\mathrm{V} / \mathbf{r}$

onde:

$$
\begin{array}{ll}
\mathrm{V} & =\text { Velocidade à frente }(\mathrm{m} / \mathrm{sec}) \\
\mathrm{a}_{\mathrm{y}} & =\text { Aceleração lateral }\left(\mathrm{m} / \mathrm{sec}^{2}\right) \\
\mathrm{r} & =\text { Velocidade angular de guinada (radians } / \mathrm{sec})
\end{array}
$$

O gradiente do ângulo de esterçamento de Ackerman para este procedimento de teste é obtido pela substituição da Eq. (26) na Eq. (16), eliminando o raio. Isso produz a forma:

$\delta=57,3 \mathrm{~L} / \mathrm{R}+\mathrm{K} \cdot \mathrm{a}_{\mathrm{y}}=57,3 \mathrm{~L} \cdot \mathrm{a}_{\mathrm{y}} / \mathrm{V}^{2}+\mathrm{K} \cdot \mathrm{a}_{\mathrm{y}}$ 
Novamente tomando as derivadas com respeito à aceleração lateral obtemos a expressão para o gradiente de sub-esterçamento:

$\mathrm{K}=\frac{\partial \delta}{\partial \mathrm{a}_{\mathrm{y}}}-\frac{\partial}{\partial \mathrm{a}_{\mathrm{y}}}\left(57,3 \frac{\mathrm{L}}{\mathrm{V}^{2}}\right)$

Uma vez que a velocidade e o entre eixos do veículo são constantes, o gradiente do ângulo de esterçamento de Ackerman (segundo termo do lado direito da equação) é uma linha reta de inclinação constante e aparece no registro dos dados conforme apresentado na Figura 13. O gradiente do ângulo de esterçamento de Ackerman é o esterçamento neutro. Nas regiões onde o gradiente do ângulo de esterçamento é maior do que o do Ackerman o veículo é subesterçante. Um ponto onde os dois tenham a mesma inclinação tem esterçamento neutro e onde o gradiente do ângulo de esterçamento é menor que o Ackerman, o veículo é sobreesterçante. Para o veículo sobre-esterçante o ponto onde a inclinação da curva do ângulo de esterçamento é zero é a fronteira da estabilidade correspondendo à velocidade crítica.

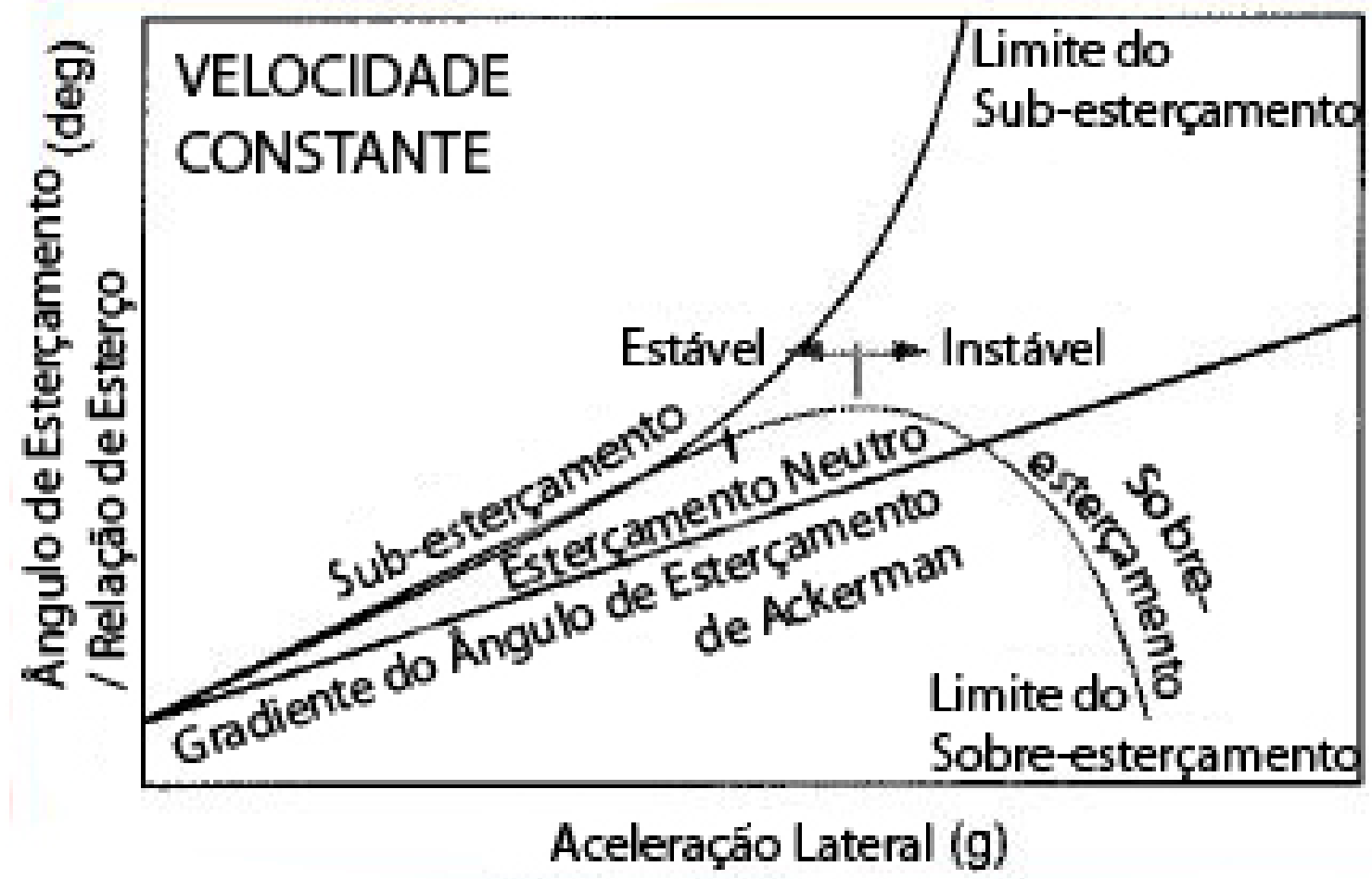

Figura 13 - Exemplo de medição do gradiente de sub-esterçamento pelo método de velocidade constante (Gillespie, 1992) 


\section{PROPOSIÇÃO}

O trabalho consiste na utilização de um veículo compacto e, através da sua caracterização em regime quase-estático de forças, determinar uma condição inicial de estabilidade. Posteriormente, variar uma das características de projeto que influenciem em sua estabilidade, a rigidez lateral dos pneumáticos ou cornering stiffness e a seguir, verificar a variação desta condição de estabilidade teórica e praticamente, tanto objetiva quanto subjetivamente.

Para viabilizar o trabalho sem grande impacto no prazo e na complexidade para obtenção dos componentes com variações em suas características, o caminho encontrado foi o da variação da pressão dos pneumáticos para desta forma poder, imediatamente, alterar as suas rigidezes.

Mais que imediata, esta opção se apresentou muito econômica, pois, além de evitar a construção de peças protótipos de alto custo e complexidade, também evitou a necessidade da verificação da efetividade das alterações impostas a estes protótipos, garantindo que todas as demais características tais como atrito, uniformidade dos materiais e processos produtivos, montagem dos pneumáticos nas rodas, etc. permanecessem totalmente inalteradas.

Devido ao caráter comparativo do trabalho, uma manobra para caracterização do veículo que sofra grande influência do parâmetro variado deveria favorecer a interpretação dos resultados obtidos, razão pela qual foi escolhida a manobra de condução em pista circular de raio constante e aceleração lateral crescente em regime de malha aberta, normalizada através da ISO 4138:1996(E) (Steady-state circular driving behaviour - open-loop test procedure). A realização desta manobra na condição do veículo com as pressões dos pneumáticos recomendada pelo fabricante para até meia carga, resulta na condição inicial de estabilidade procurada (comportamento sub ou sobre-esterçante) e a variação das pressões dos pneumáticos para cima e para baixo impõe a variação de sua rigidez nos mesmos sentidos. A realização de novas caracterizações do veículo nestas novas condições determina uma tendência de comportamento do veículo (sub ou sobre-esterçante) com o incremento ou decremento desta rigidez. Estas variações, impostas ora ao eixo dianteiro ora ao eixo traseiro do veículo, aumentam a abrangência do estudo. A manobra realizada em regime de malha aberta, conforme sintetizado pela Figura 14, assegura a isenção necessária para executar a comparação dos resultados numéricos obtidos. 


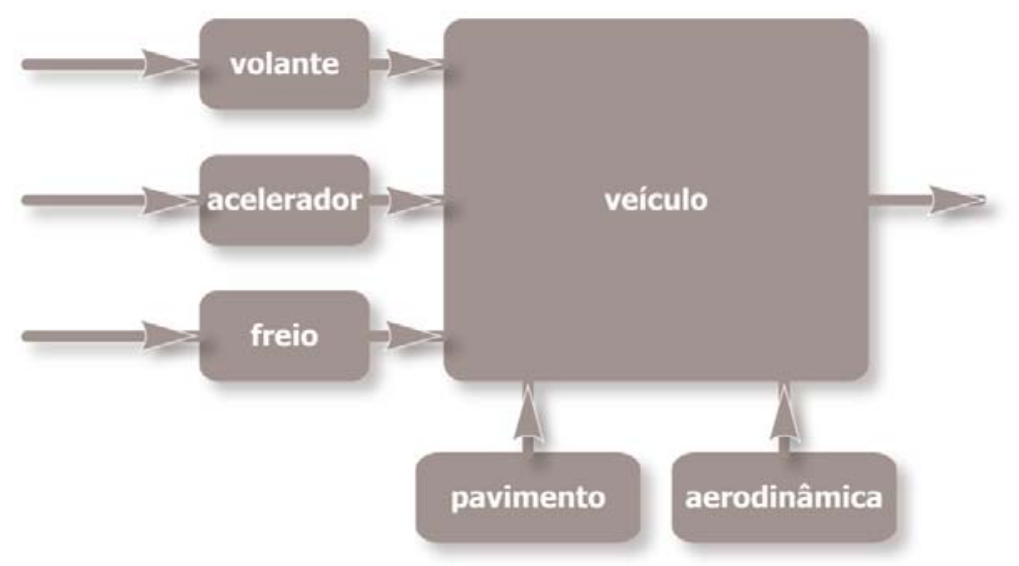

Figura 14 - Sistema de malha aberta

Em paralelo à caracterização objetiva através das medições, também serão realizadas avaliações subjetivas do comportamento do veículo para que uma comparação entre o resultado físico-matemático e a sensação de segurança percebida pelo condutor possa ser traçada e discutida.

A prática da avaliação subjetiva é largamente utilizada nos desenvolvimentos realizados pela indústria automobilística, buscando equilibrar os resultados cada vez mais precisos conseguidos com a evolução computacional dos simuladores e processadores, com a análise e consideração dos fenômenos biológicos e psicológicos que traduzem a sensação de dirigibilidade, sendo este o elemento de retro-alimentação do sistema que fechará a malha do sistema "veículo", conforme representado na Figura 15.

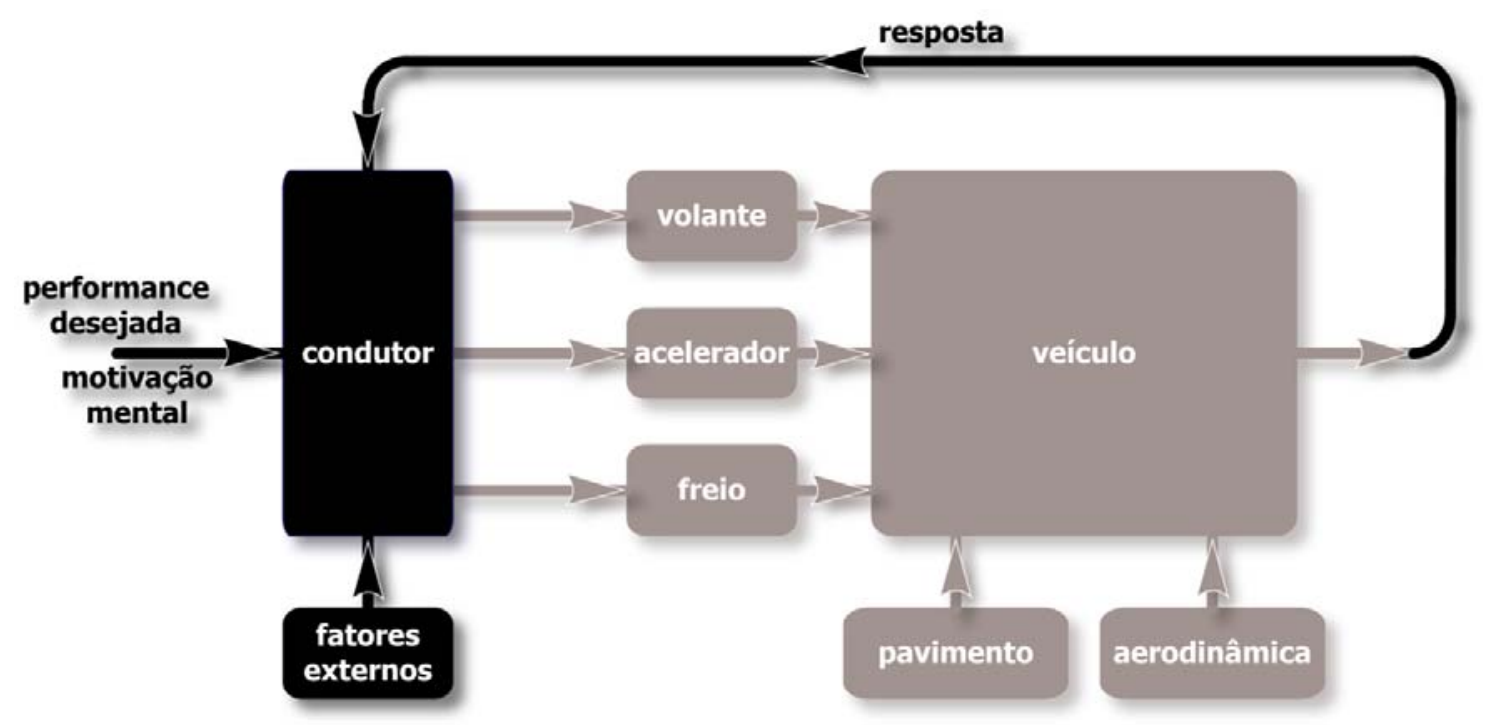

Figura 15 - Sistema de malha fechada 


\section{METODOLOGIA}

\subsection{O veículo}

Este trabalho utiliza um veículo compacto (plataforma tamanho A0) por se tratar do tamanho mais comum no país, com o veículo na condição de pressões dos pneumáticos recomendada pelo fabricante para até meia carga, carregado com dois passageiros mais o equipamento de medição e, através da sua caracterização em regime quase-estático de forças, determinar uma condição inicial de estabilidade.

Características do veículo utilizado:

Potência ( P ): $74 \mathrm{kw}$

Entre eixos ( L ): 2647mm;

Bitola dianteira $\left(t_{\mathrm{f}}\right): 1428 \mathrm{~mm}$;

Bitola traseira $\left(t_{\mathrm{r}}\right): 1424 \mathrm{~mm}$;

Distância do CG ao eixo dianteiro ( b ): $935 \mathrm{~mm}$;

Distância do CG ao eixo traseiro ( c ): $1712 \mathrm{~mm}$;

Altura do CG ( h ): 586mm;

Peso total operacional ( W ): $1254 \mathrm{~kg}$, distribuído da seguinte forma:

Peso sobre a roda dianteira esquerda $\left(\mathrm{W}_{1}\right): 404 \mathrm{~kg}$;

Peso sobre a roda dianteira direita $\left(\mathrm{W}_{2}\right): 357,5 \mathrm{~kg}$;

Peso sobre a roda traseira esquerda $\left(\mathrm{W}_{3}\right): 247 \mathrm{~kg}$;

Peso sobre a roda traseira direita $\left(\mathrm{W}_{4}\right): 245,5 \mathrm{~kg}$;

Peso da massa não suspensa nas rodas dianteiras $\left(\mathrm{W}_{\mathrm{uf}}\right): 78 \mathrm{~kg}$;

Peso da massa não suspensa nas rodas traseiras $\left(\mathrm{W}_{\mathrm{ur}}\right): 60 \mathrm{~kg}$;

Dimensão dos pneumáticos: 175/65R14 82T;

Pressão dianteira recomendada para até meia carga $\left(\mathrm{p}_{\mathrm{f}}\right)$ : 2,1374 bar (31 psi);

Pressão traseira recomendada para até meia carga $\left(\mathrm{p}_{\mathrm{r}}\right)$ : 1,9995 bar (29 psi);

Relação de esterço ( $\left.i_{s}\right): 16,27: 1$

\subsection{O procedimento ISO 4138}

Conforme explanado na própria introdução da norma:

“O comportamento dinâmico de um veículo terrestre é a parte mais importante da segurança ativa do veículo. Qualquer veículo, juntamente com seu condutor e o meio ambiente que o 
envolve, constituem um sistema de malha fechada que é único.

A tarefa de avaliar o comportamento dinâmico é portanto muito difícil já que a expressiva interação dos elementos condutor-veículo-pavimento já é complexo cada um por si só”.

A intenção deste procedimento de teste é medir o ângulo do volante de direção do veículo como função da aceleração lateral e descrever o seu comportamento sub ou sobre-esterçante. As características da resposta do controle direcional do veículo são determinadas pelos dados obtidos conduzindo-o a velocidades cada vez mais altas por uma trajetória de raio constante conhecido.

Para esta caracterização, foram medidos e gravados os valores das seguintes variáveis:

Ângulo do volante de direção $\left(\delta_{\mathrm{H}}\right)$;

Aceleração lateral $\left(\mathrm{a}_{\mathrm{y}}\right)$;

Opcionalmente foram também medidos e gravados os valores das seguintes variáveis:

Ângulo de escorregamento lateral ( $\beta$ );

Velocidade de guinada $(\Psi \cdot)$;

Velocidade longitudinal $\left(\mathrm{v}_{\mathrm{x}}\right)$;

Torque no volante de direção $\left(\mathrm{M}_{\mathrm{H}}\right)$;

Ângulo de rolagem do veículo $(\varphi)$

\subsection{A instrumentação utilizada}

A instrumentação foi realizada de forma a cobrir todos os requisitos do procedimento, tanto das variáveis necessárias, quanto das variáveis opcionais listadas no mesmo. A tabela 1 apresenta cada uma destas variáveis e os transdutores utilizados para aquisição e gravação de seus valores ao longo da execução do procedimento de teste. As Figuras 16 e 17 mostram a sua instalação interna e externa no veículo.

\begin{tabular}{|l|c|c|}
\hline \multicolumn{3}{|c|}{ Equipamento de aquisição e gravação de dados } \\
\hline \multicolumn{1}{|c|}{ Variável } & Transdutor & Número de série \\
\cline { 1 - 1 } Ângulo do volante de direção $\left(\delta_{\mathrm{H}}\right)$ & Volante TB1 & 9A300.9930-01 \\
\cline { 1 - 1 } Torque no volante de direção $\left(\mathrm{M}_{\mathrm{H}}\right)$ & & \\
\hline
\end{tabular}




\begin{tabular}{|l|c|r|}
\hline Velocidade de guinada $\left(\Psi^{*}\right)$ & Crossbow VG600AA-202 & 104268 \\
\cline { 1 - 1 } Ângulo de Rolagem do veículo $(\varphi)$ & Correvit S-400 & 41217 \\
\cline { 1 - 1 } Velocidade longitudinal $\left(\mathrm{v}_{\mathrm{x}}\right)$ & Acelerômetro Endevco 7290A & 19545 \\
\cline { 1 - 2 } Ângulo de escorregamento lateral $(\beta)$ & MGC Plus - R\&H Test system & 3317 \\
\cline { 1 - 2 } Aceleração lateral $\left(\mathrm{a}_{\mathrm{y}}\right)$ & Aquisição e gravação de dados & \\
\cline { 1 - 2 }
\end{tabular}

Tabela 1 - Equipamento de aquisição e gravação de dados

O sistema de aquisição e gravação de dados utilizado foi o MGC Plus HBM, com precisão de classe 0,03 e capacidade de aquisição digital de 19200 valores por segundo por canal. Sua arquitetura modular utiliza placas multicanal para o condicionamento de sinais similares, sendo assim, foram utilizadas para esta aplicação, placas para o condicionamento de sinais de tensão e de pulsos.

O Volante TB01 apresenta duas saídas de sinal, uma em pulso, com indicação do sentido de giro e precisão de 360 pulsos por volta para a medição do ângulo de esterço do volante de direção $\left(\delta_{\mathrm{H}}\right)$ e outra em tensão, com precisão de classe 0,05 para a medição do torque na faixa de $\pm 100 \mathrm{Nm}$, aplicado ao volante de direção $\left(\mathrm{M}_{\mathrm{H}}\right)$ durante a realização das manobras.

O acelerômetro 7290A utilizado para esta medição possui um fundo de escala de $2 \mathrm{~g}$ e é montado em um dispositivo tri-ortogonal (em conjunto a dois outros acelerômetros de forma a se obter um conjunto tri-axial de acelerômetros). Para a medição prevista no procedimento, somente a aceleração lateral $\left(\mathrm{a}_{\mathrm{y}}\right)$ foi considereda.

O canhão de luz S-400, largamente utilizado em medições automotivas, possui saída em tensão e permite a configuração para medição de duas grandezas simultâneas. Neste caso, foi utilizado para a medição da velocidade longitudinal $\left(\mathrm{v}_{\mathrm{x}}\right)$ com campo de utilização de 0,5 a 250 $\mathrm{km} / \mathrm{h}$ e precisão maior que $\pm 0,1 \%$ e do ângulo de escorregamento lateral $(\beta)$ com campo de utilização de $\pm 40^{\circ}$ e precisão de maior que $\pm 0,1^{\circ}$.

A plataforma inercial de estado sólido VG600AA-202 realiza a medição dos movimentos angulares do veículo conforme definição dos eixos estabelecida pela SAE e nesta aplicação é responsável pela aquisição dos ângulos de rolagem (roll) e arfagem (pitch) dentro do campo 
de $\pm 90^{\circ}$ e pelas velocidades angulares de rolagem, arfagem e guinada (roll rate, pitch rate e yaw rate) com $\pm 200^{\circ} / \mathrm{s}$

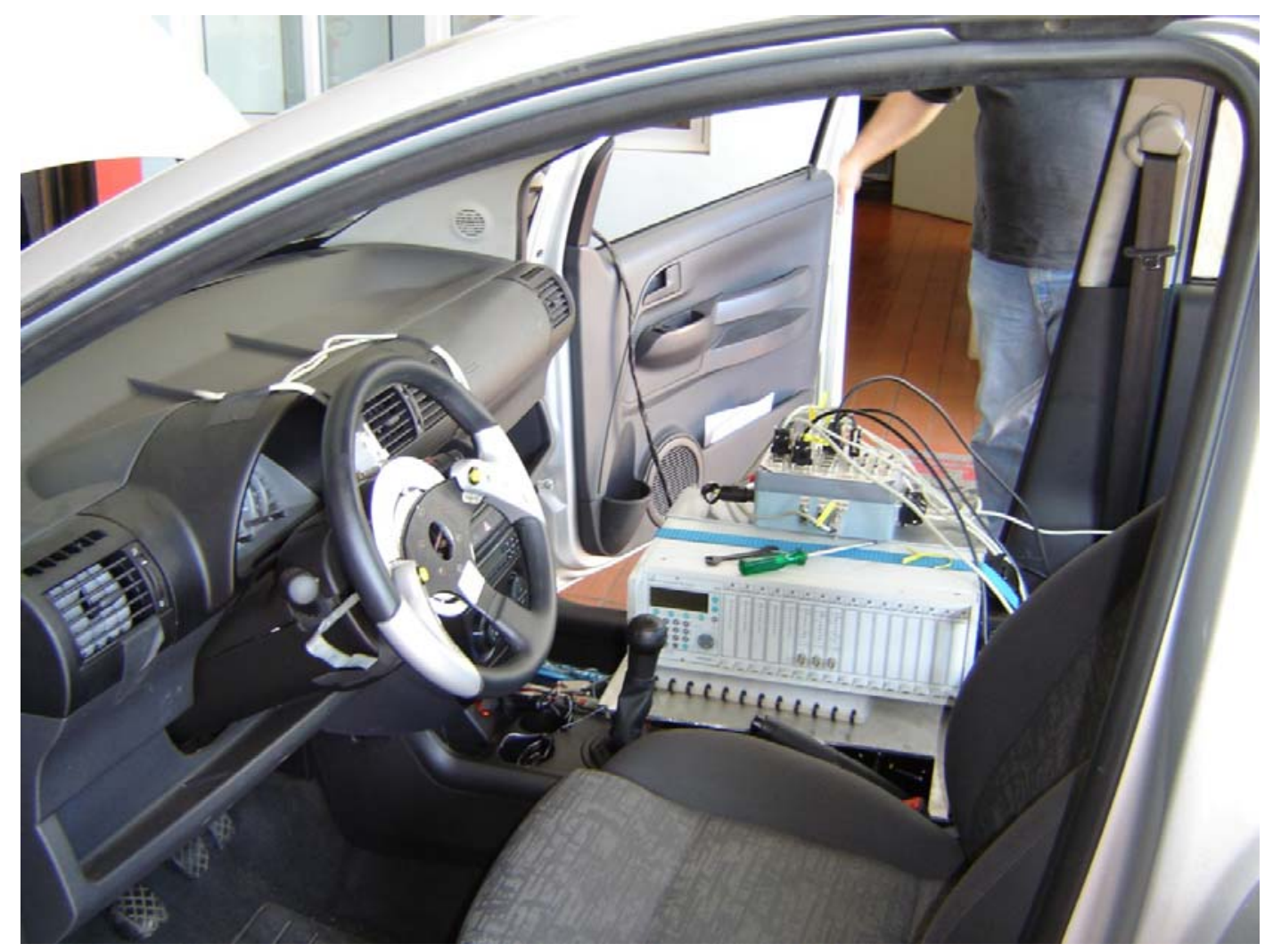

Figura 16 - Instrumentação interna do veículo 


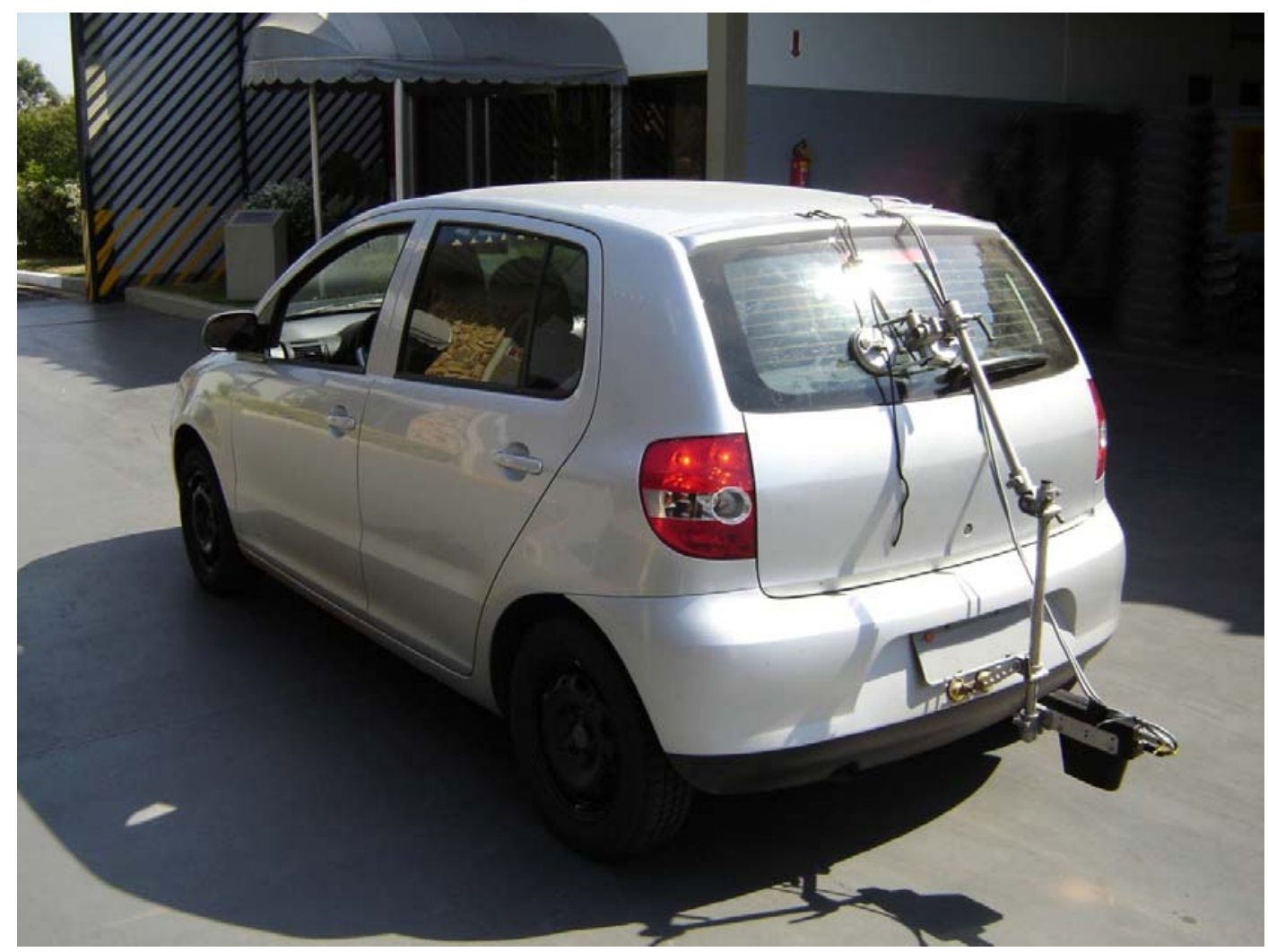

Figura 17 - Instrumentação externa do veículo

\subsection{A pista}

Conforme especificado no procedimento, deve-se utilizar uma pista de $100 \mathrm{~m}$ de raio, podendo ser utilizada uma pista com raio menor, porém com um mínimo de $30 \mathrm{~m}$. Assim a pista utilizada é uma pista circular constituída por duas faixas de rolagem, com raio interno de $40 \mathrm{~m}$ e raio externo de $50 \mathrm{~m}$. Para realização do teste foi utilizada a linha de separação das duas faixas como referência de posicionamento do veículo, tendo assim o teste, um raio efetivo de 45m, conforme apresentado nas Figuras 18 e 19. 


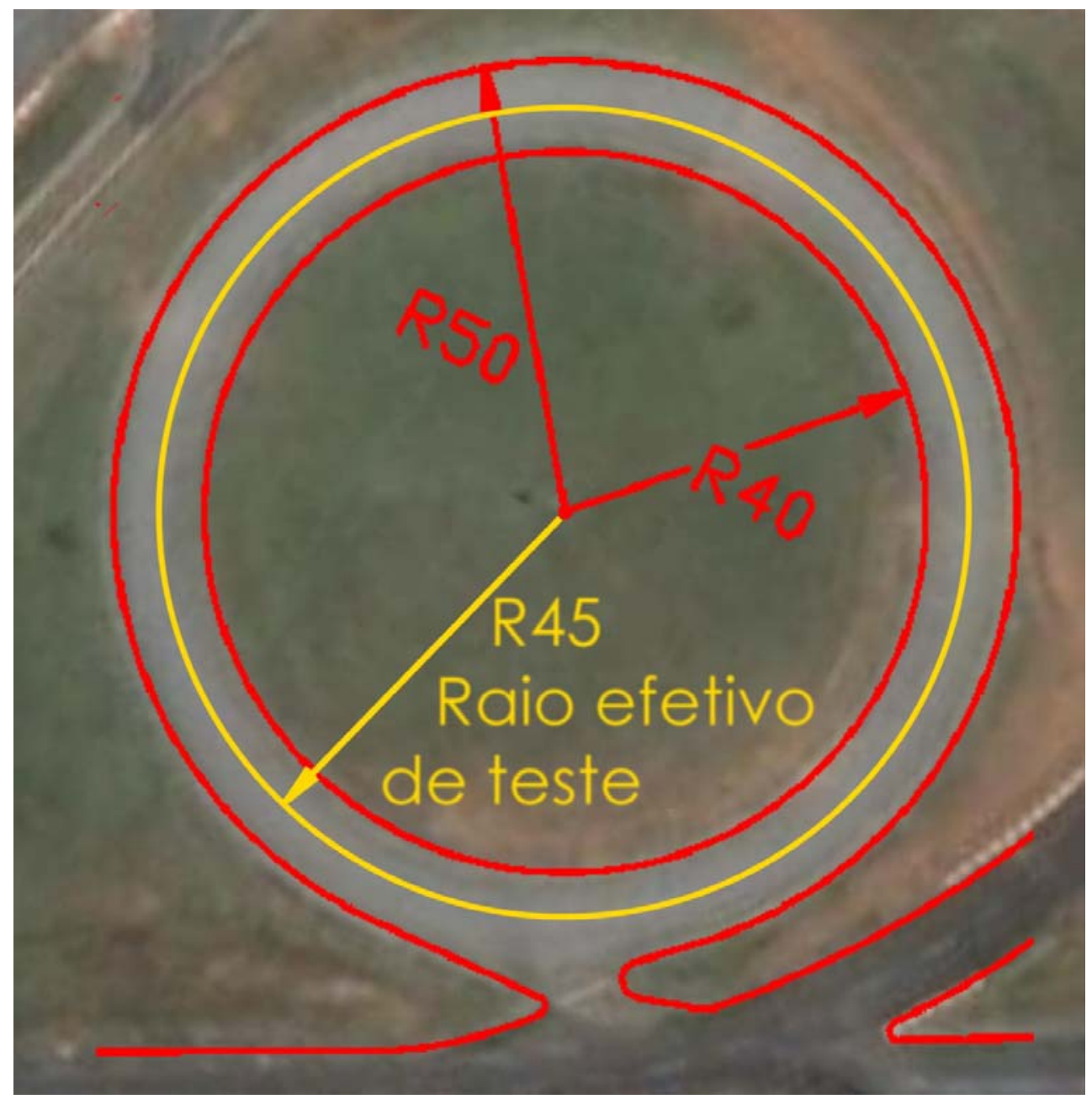

Figura 18 - Dimensões da pista circular 


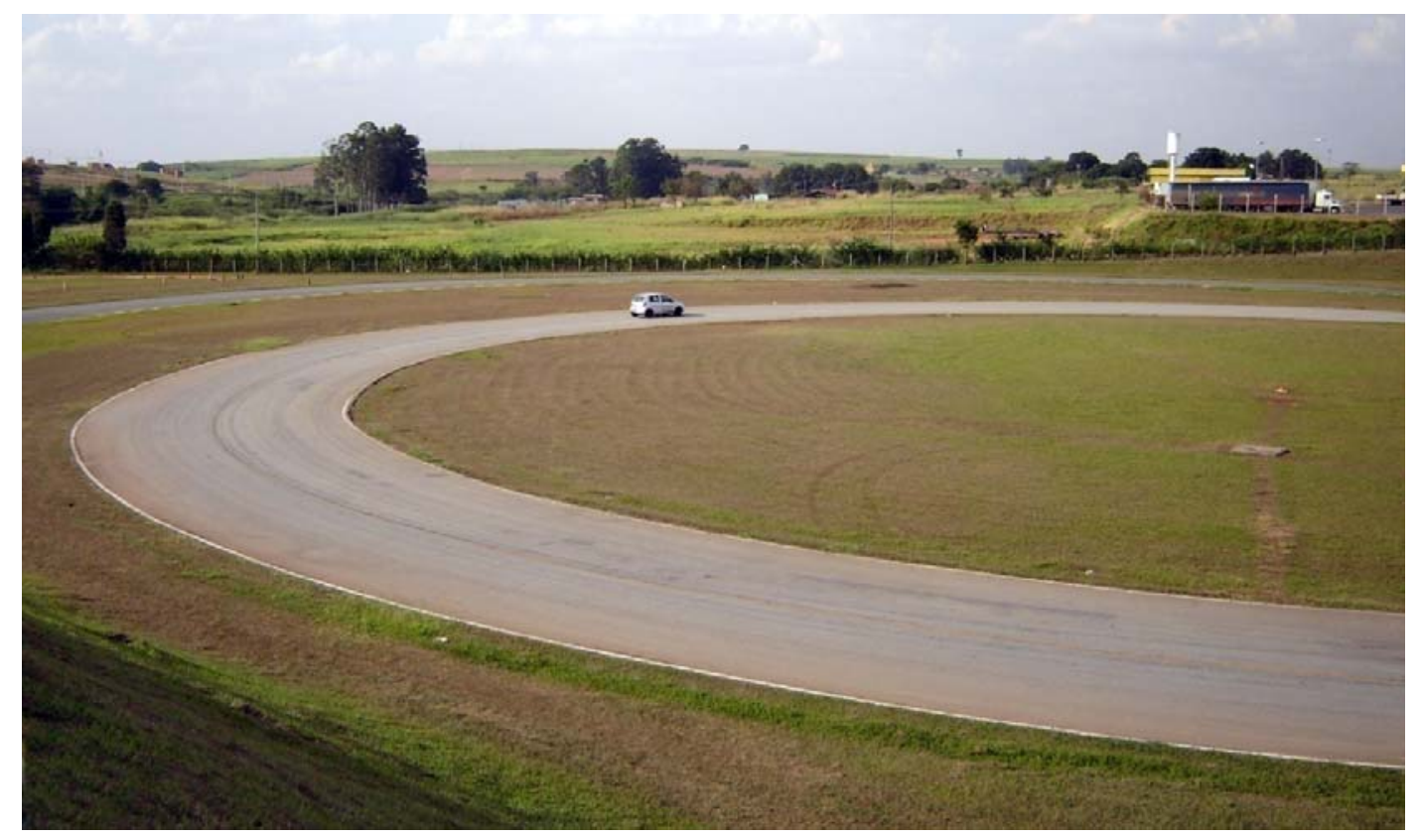

Figura 19 - Teste na pista circular

\subsection{A seqüência das caracterizações}

A caracterização do veículo quanto ao seu gradiente de sub-esterçamento é inicialmente realizada com as pressões de inflação especificadas para o veículo na condição de até meia carga, ou seja, carga equivalente a três passageiros de $68 \mathrm{~kg}$ mais sua bagagem padrão de 7 kg. As pressões de inflação recomendadas para o veículo nesta condição são de 31 psi para as rodas dianteiras $\left(\mathrm{p}_{\mathrm{f}}\right)$ e 29 psi para as rodas traseiras $\left(\mathrm{p}_{\mathrm{t}}\right)$.

Com o veículo nestas condições inicia-se o procedimento, percorrendo a pista descrita anteriormente, e gradativamente eleva-se a velocidade longitudinal $\left(\mathrm{v}_{\mathrm{x}}\right)$ de forma a obter-se um incremento da aceleração lateral $\left(\mathrm{a}_{\mathrm{y}}\right)$ imposta ao veículo, em intervalos constantes e até uma condição máxima ligeiramente acima da especificada no procedimento, de forma a garantir a faixa de aceleração em sua totalidade.

A seguir iniciam-se as variações na pressão da roda dianteira, sempre no lado externo ao circuito percorrido, pois é aquela que recebe incremento de carga e, portanto sofre maior influência na característica cuja variação se quer verificar. 
A pressão de inflação do pneumático dianteiro externo é aumentada a 38 psi e o procedimento refeito. Este ponto de caracterização com pressão acima do especificado, dá um controle da dispersão dos resultados na extrapolação dos dados coletados. A fim de minimizar a influência que as condições climáticas poderiam trazer ao se aguardar todo o resfriamento e re-estabelecimento da pressão inicial, as pressões são reduzidas por diferença, às pressões equivalentes de 29 psi, 24 psi e 18 psi e imediatamente refeito o procedimento a cada redução de pressão.

O próximo passo é o das variações na pressão da roda traseira, novamente no lado externo ao circuito percorrido. Agora é a pressão de inflação do pneumático traseiro externo que é aumentada a 38 psi e o procedimento refeito. Novamente por diferença, pressões são reduzidas às equivalentes de 29 psi, 24 psi e 18 psi e imediatamente refeito o procedimento a cada redução de pressão.

A tabela a seguir apresenta a seqüência de caracterização estipulada para o teste:

\begin{tabular}{|c|c|c|c|}
\hline \multicolumn{4}{|c|}{ Seqüência de testes para caracterização do veículo } \\
\hline \multicolumn{4}{|c|}{$\begin{array}{l}\text { Caracterização do veículo com pressão dos pneumáticos conforme especificado pelo } \\
\text { fabricante (pressões em psi no formato Dianteiros x Traseiros) }\end{array}$} \\
\hline & $31 \times 29$ & & \\
\hline \multicolumn{4}{|c|}{$\begin{array}{l}\text { Caracterização do veículo com variação da pressão dos pneumáticos dianteiros (pressões em } \\
\text { psi no formato Dianteiro externo x Traseiros) }\end{array}$} \\
\hline $38 \times 29$ & $29 \times 29$ & $24 \times 29$ & $18 \times 29$ \\
\hline \multicolumn{4}{|c|}{$\begin{array}{l}\text { Caracterização do veículo com variação da pressão dos pneumáticos traseiros (pressões em } \\
\text { psi no formato Dianteiros x Traseiro externo) }\end{array}$} \\
\hline $31 \times 38$ & $\begin{array}{c}31 \text { x } 29 \\
\text { (verificação) }\end{array}$ & $31 \times 24$ & $31 \times 18$ \\
\hline
\end{tabular}

Tabela 2 - Seqüência de testes para caracterização do veículo

Em seguida, uma avaliação subjetiva das características de tendência direcional, equilíbrio entre eixos e rigidez lateral é realizada pelo circuito, com a mesma condição de carga e pressões, para comparação da condição do veículo. 


\section{RESULTADOS}

A seguir são apresentados os resultados numéricos dos testes realizados:

\subsection{Testes objetivos}

Os resultados dos testes objetivos são apresentados na forma como foram utilizados após a gravação e tratamento do sinal, tabelados a cada patamar de aceleração lateral obtida.

\subsubsection{Pressões recomendadas}

Conforme já mencionado, esta medição será a base de caracterização do veículo e, baseado nestes resultados poderá ser avaliada a evolução do comportamento do veículo.

As pressões recomendadas pelo fabricante para a condição de teste são de 31 psi para as rodas do eixo dianteiro e de 29 psi para as rodas do eixo traseiro. Os resultados obtidos são apresentados numericamente pela tabela 3 no Anexo A e plotados abaixo nos Gráficos 1, 2 e 3. 


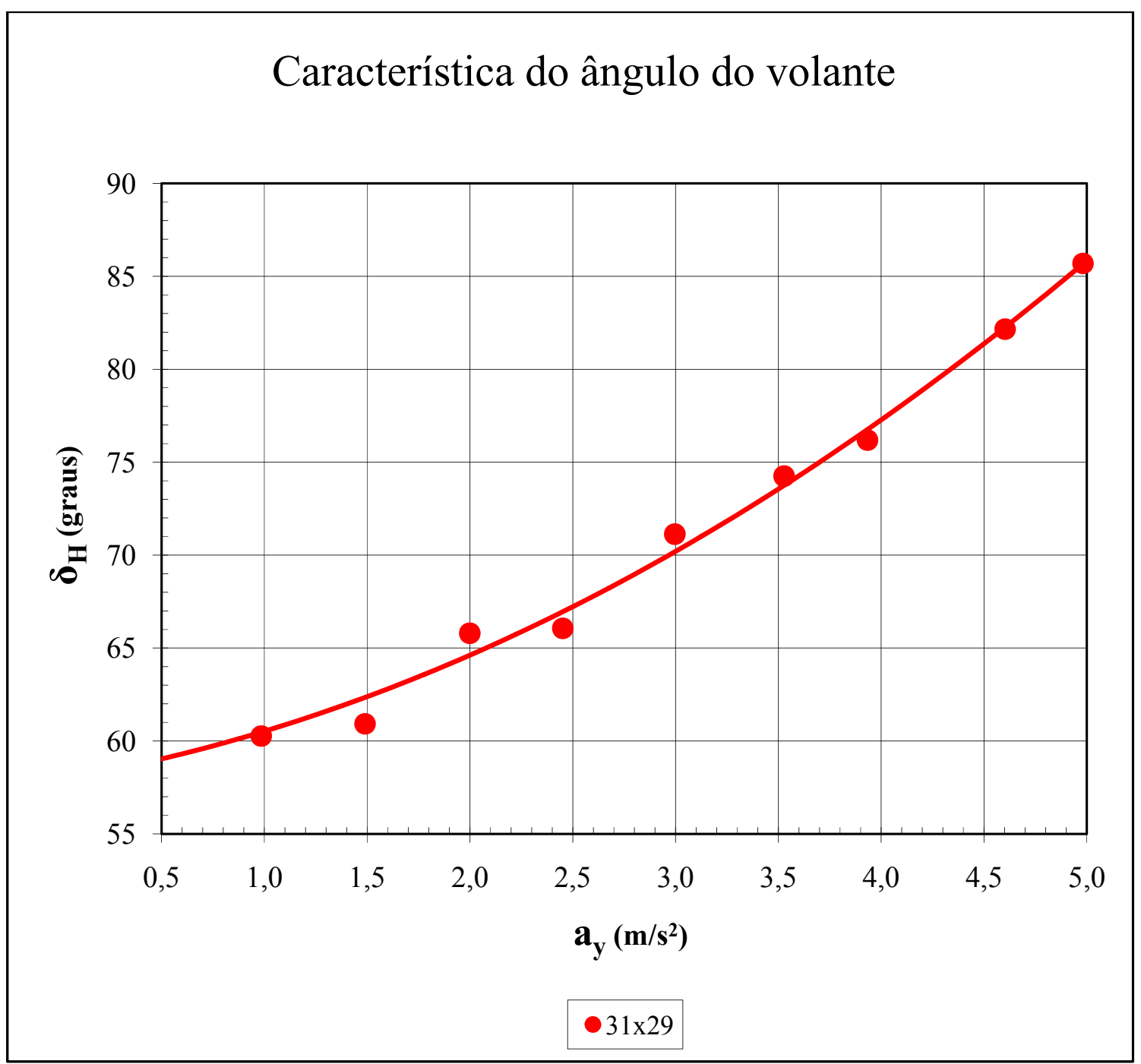

Gráfico 1 - Característica do ângulo do volante com as pressões recomendadas pelo fabricante 


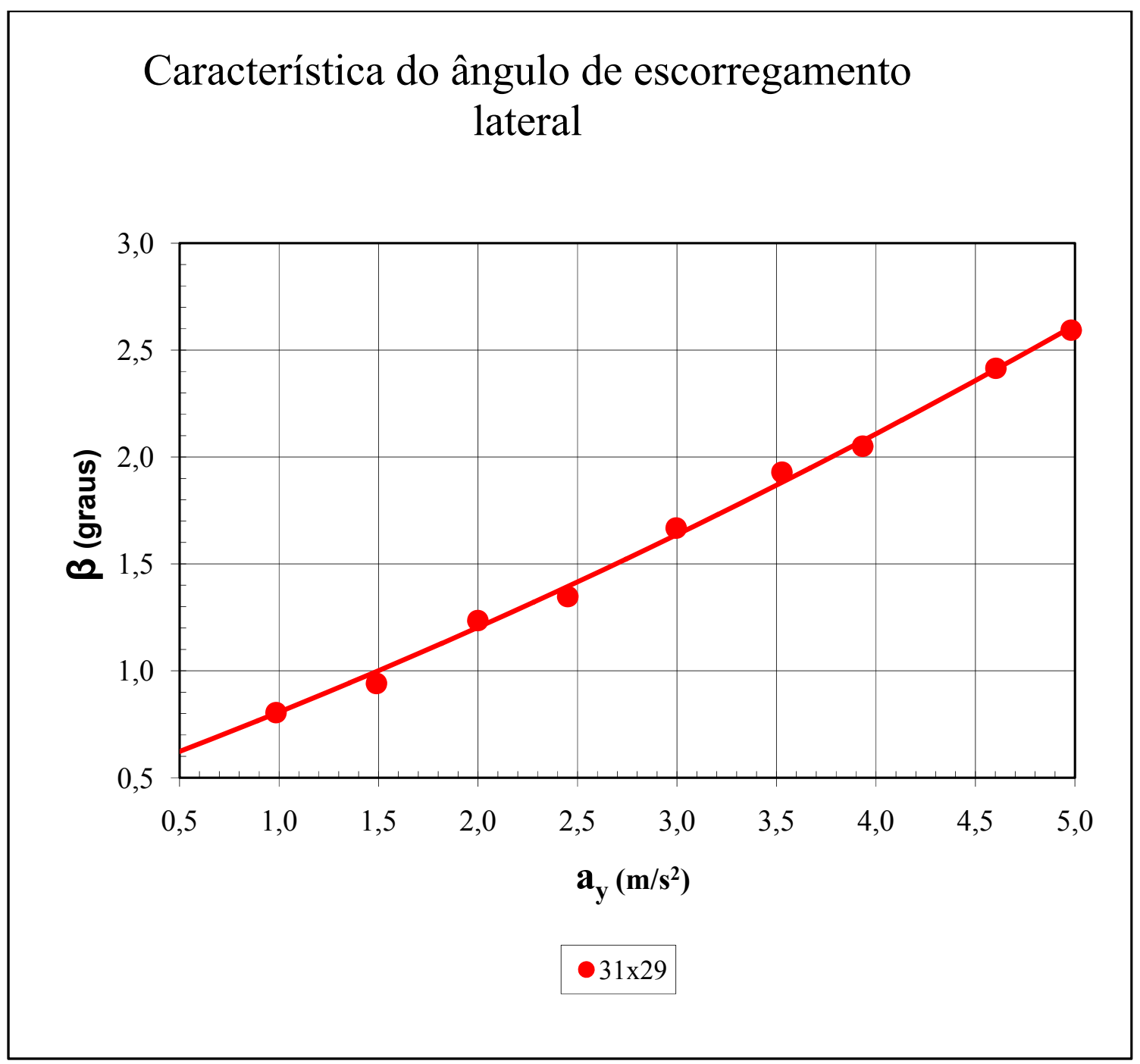

Gráfico 2 - Característica do ângulo de escorregamento lateral com as pressões recomendadas pelo fabricante 


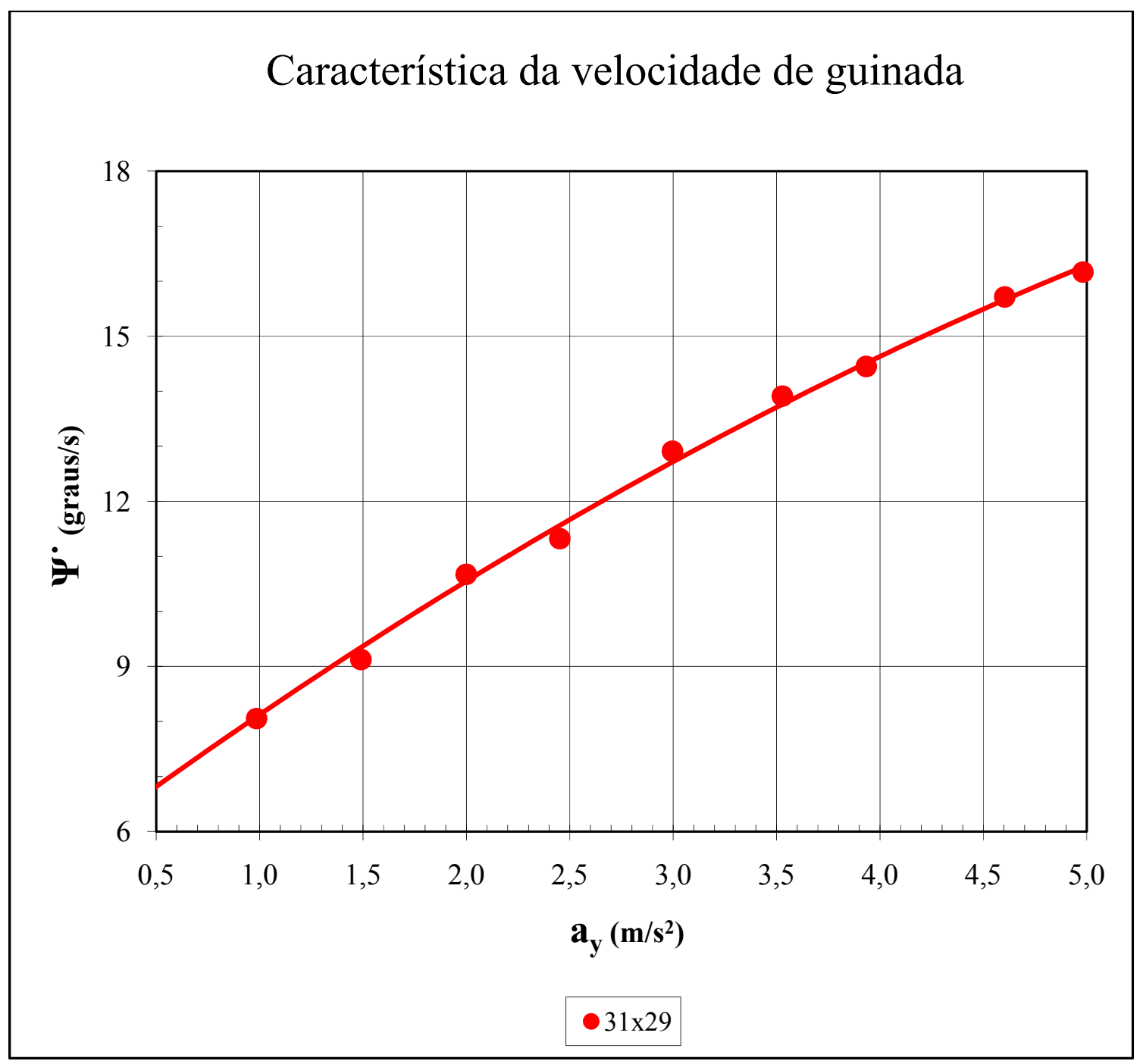

Gráfico 3 - Característica da velocidade de guinada com as pressões recomendadas pelo fabricante

\subsubsection{Redução da pressão na dianteira}

A seguir foi iniciado o procedimento de variação das pressões na dianteira. Para tal, a pressão do pneu dianteiro esquerdo foi inicialmente elevada a 38 psi, para, a seguir iniciar o processo de redução da pressão.

Durante a execução do procedimento, haverá uma natural elevação da temperatura dos pneumáticos. Sendo o sistema evidentemente estanque, o processo de redução da pressão será então realizado através da subtração de pressão em relação ao ponto inicial da medição. Esta sistemática, comumente utilizada durante avaliações subjetivas e determinação das pressões 
de equilíbrio, demonstra ser bastante repetitiva e suficientemente precisa para ser utilizada durante o procedimento de redução de pressão.

Os resultados numéricos obtidos são apresentados nas Tabelas 4, 5, 6 e 7 do Anexo A e, também plotados nos Gráficos 4, 5 e 6 .

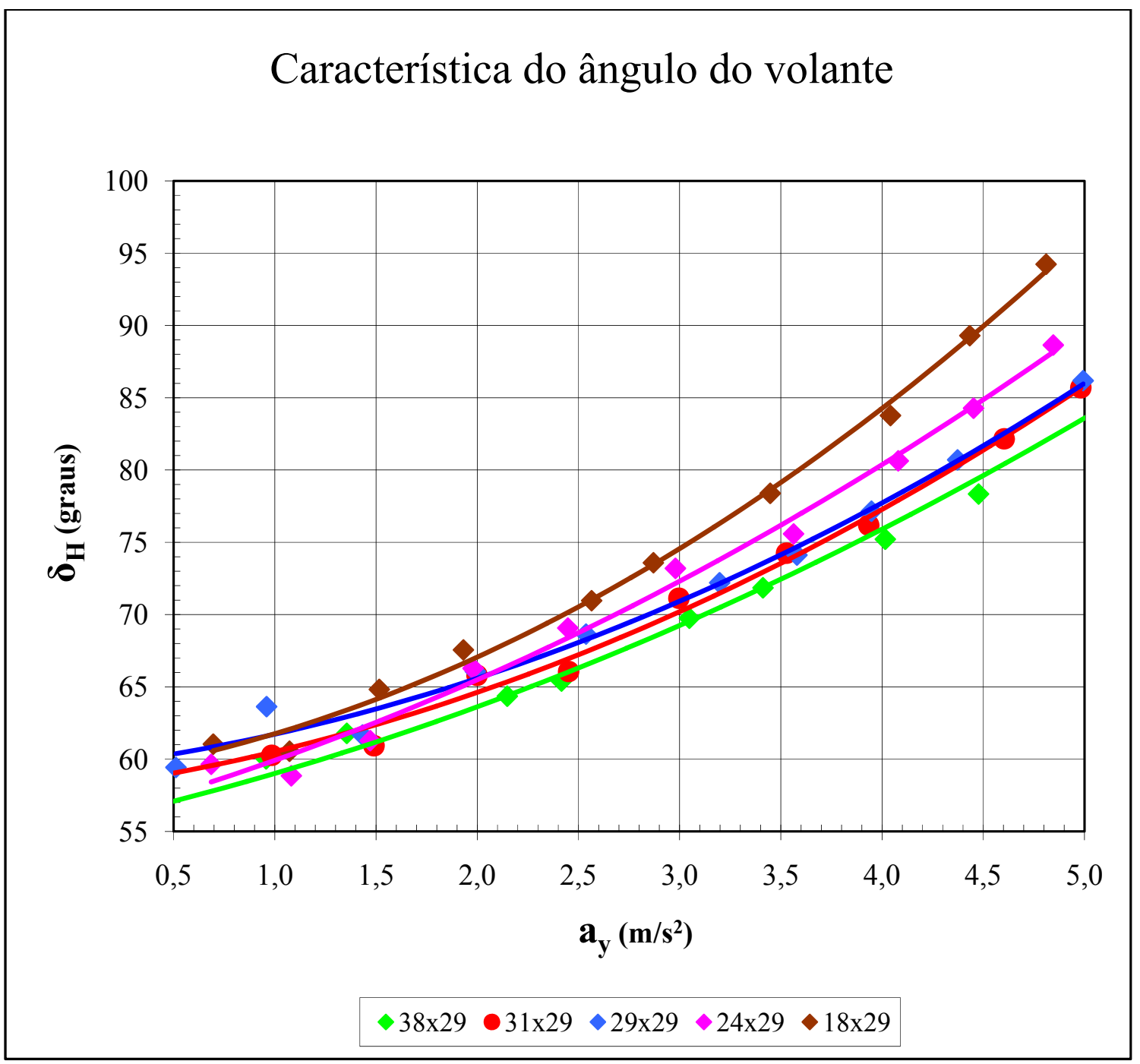

Gráfico 4 - Característica do ângulo do volante com a variação das pressões na dianteira 


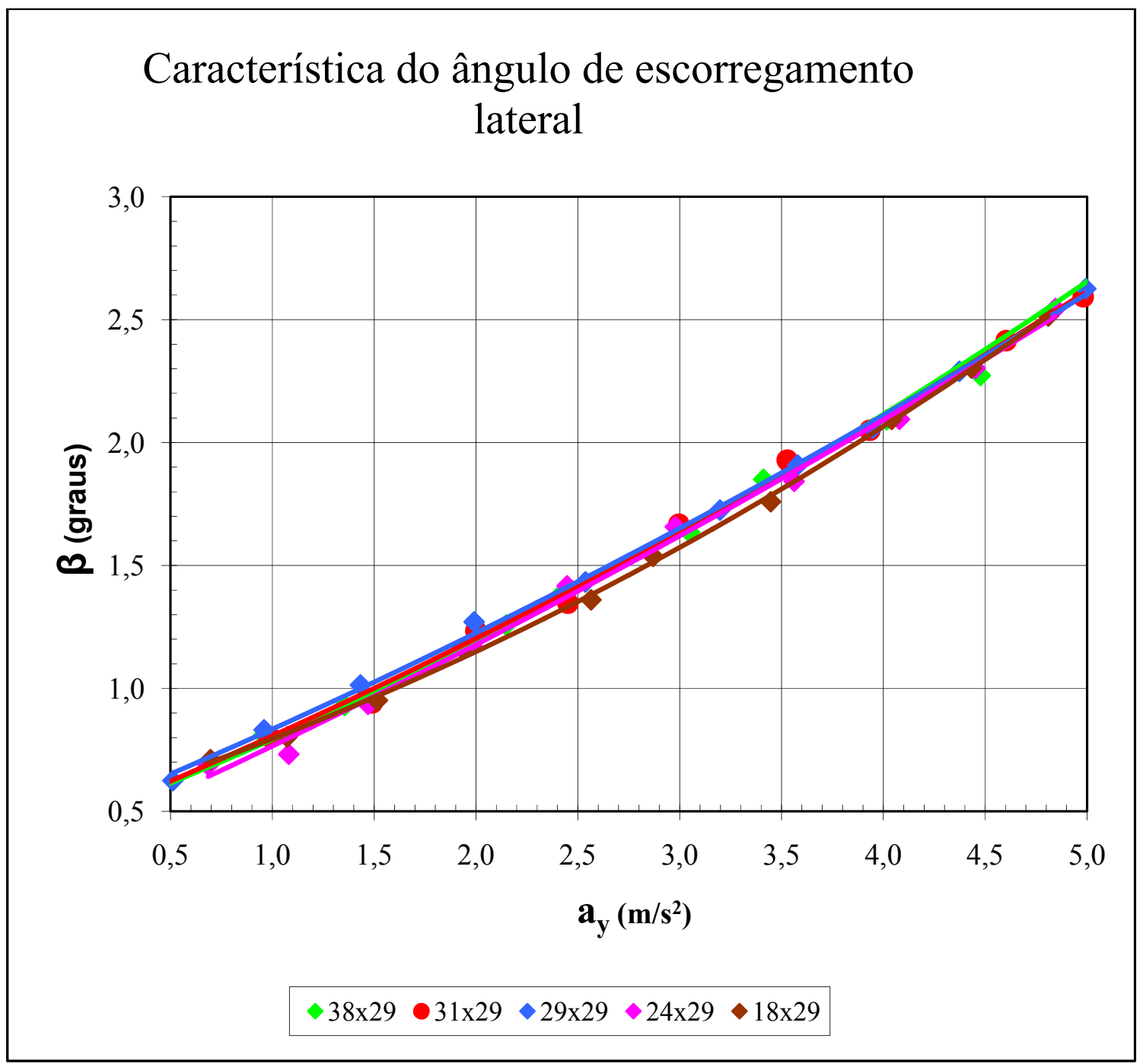

Gráfico 5 - Característica do ângulo de escorregamento lateral com a variação das pressões na dianteira 


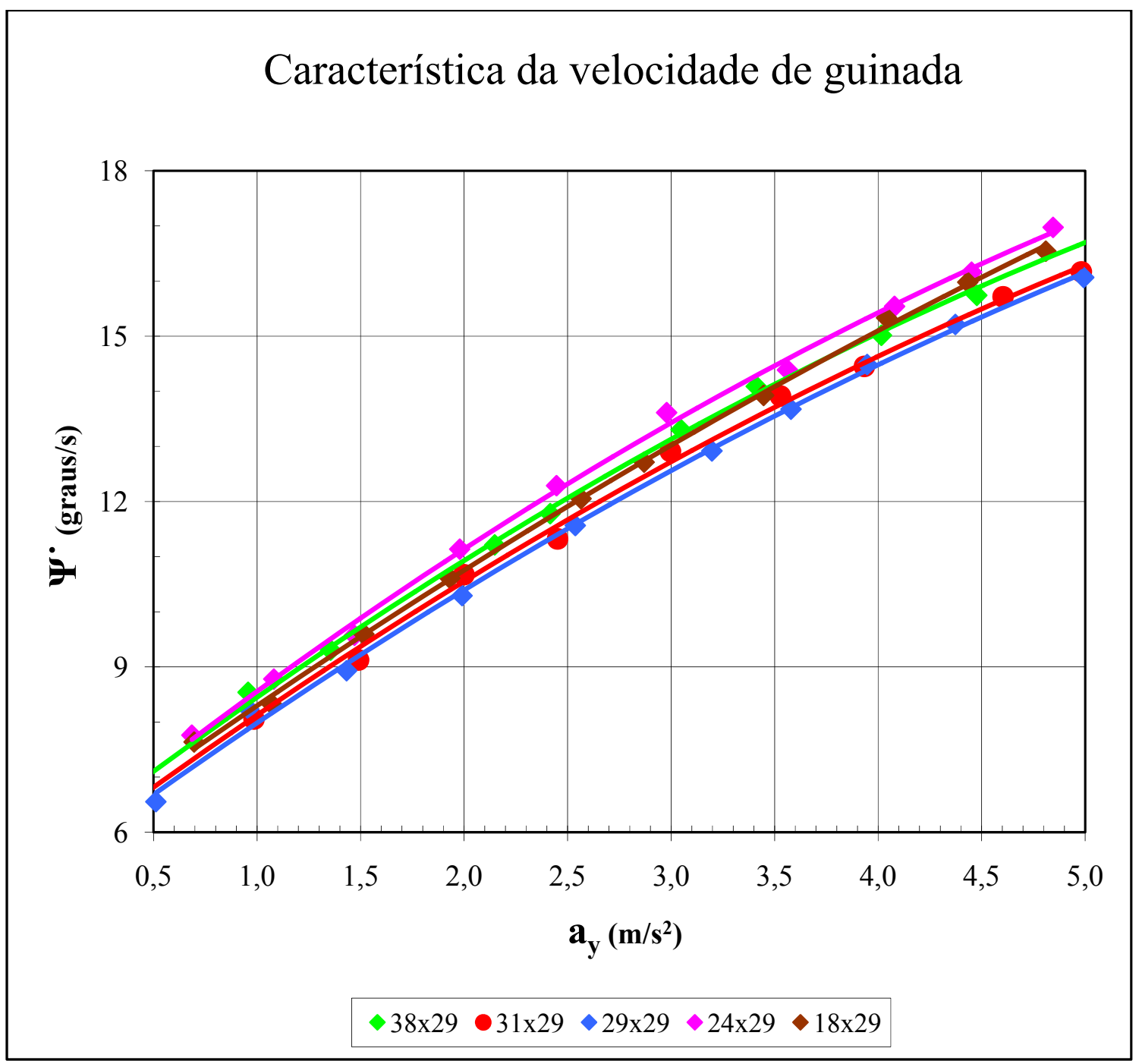

Gráfico 6 - Característica da velocidade de guinada com a variação nas pressões da dianteira

Nota-se no gráfico 4 que a tendência do gradiente de sub-esterçamento é bastante acentuada em direção ao ponto do limite de sub-esterçamento com o decaimento da pressão, ou seja, com o decaimento de sua rigidez de esterço.

\subsubsection{Redução da pressão na traseira}

O passo seguinte, o procedimento na traseira, também foi iniciado com a elevação da pressão do pneu, desta vez traseiro esquerdo a 38 psi, para, a seguir, iniciar o processo de redução da pressão. 
Mais uma vez haverá a elevação da temperatura dos pneumáticos, portanto será utilizado o mesmo processo de redução da pressão através da subtração de pressão em relação ao ponto inicial da medição.

Os resultados numéricos obtidos são apresentados nas Tabelas 8, 9, 10 e 11 do Anexo A e plotados nos Graficos 7, 8 e 9.

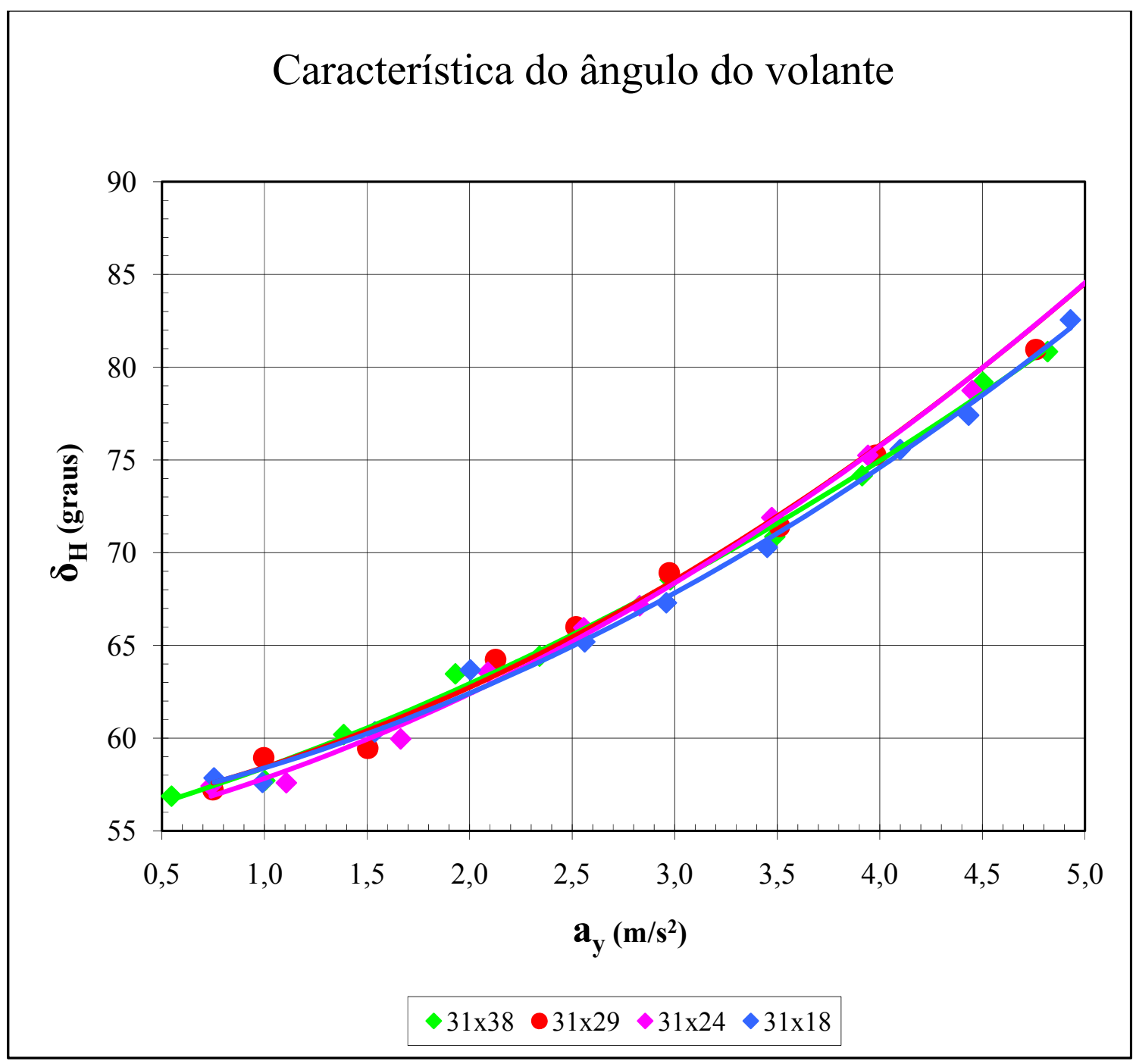

Gráfico 7 - Característica do ângulo do volante com a variação das pressões na traseira 


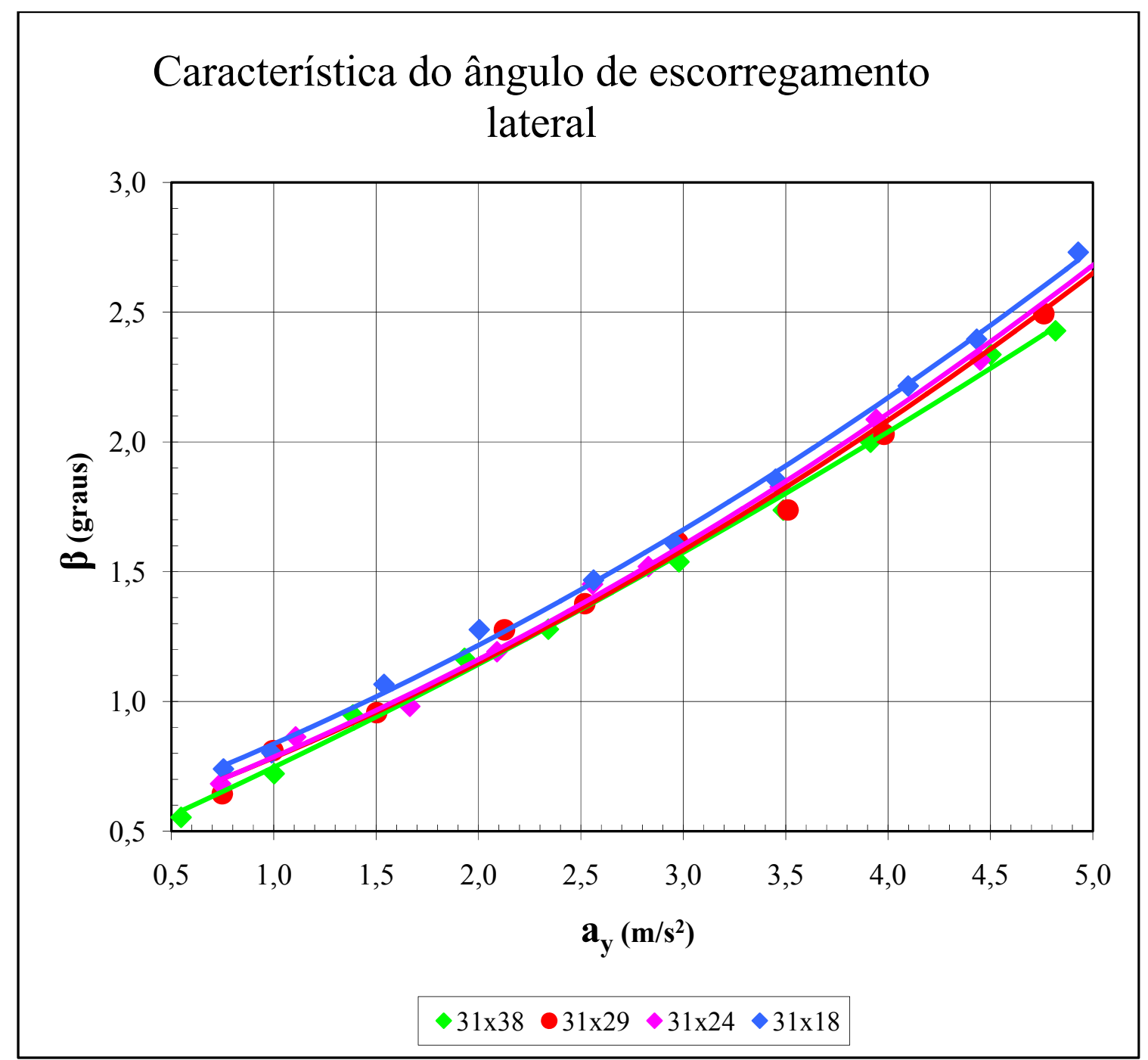

Gráfico 8 - Característica do ângulo de escorregamento lateral com a variação das pressões na traseira 


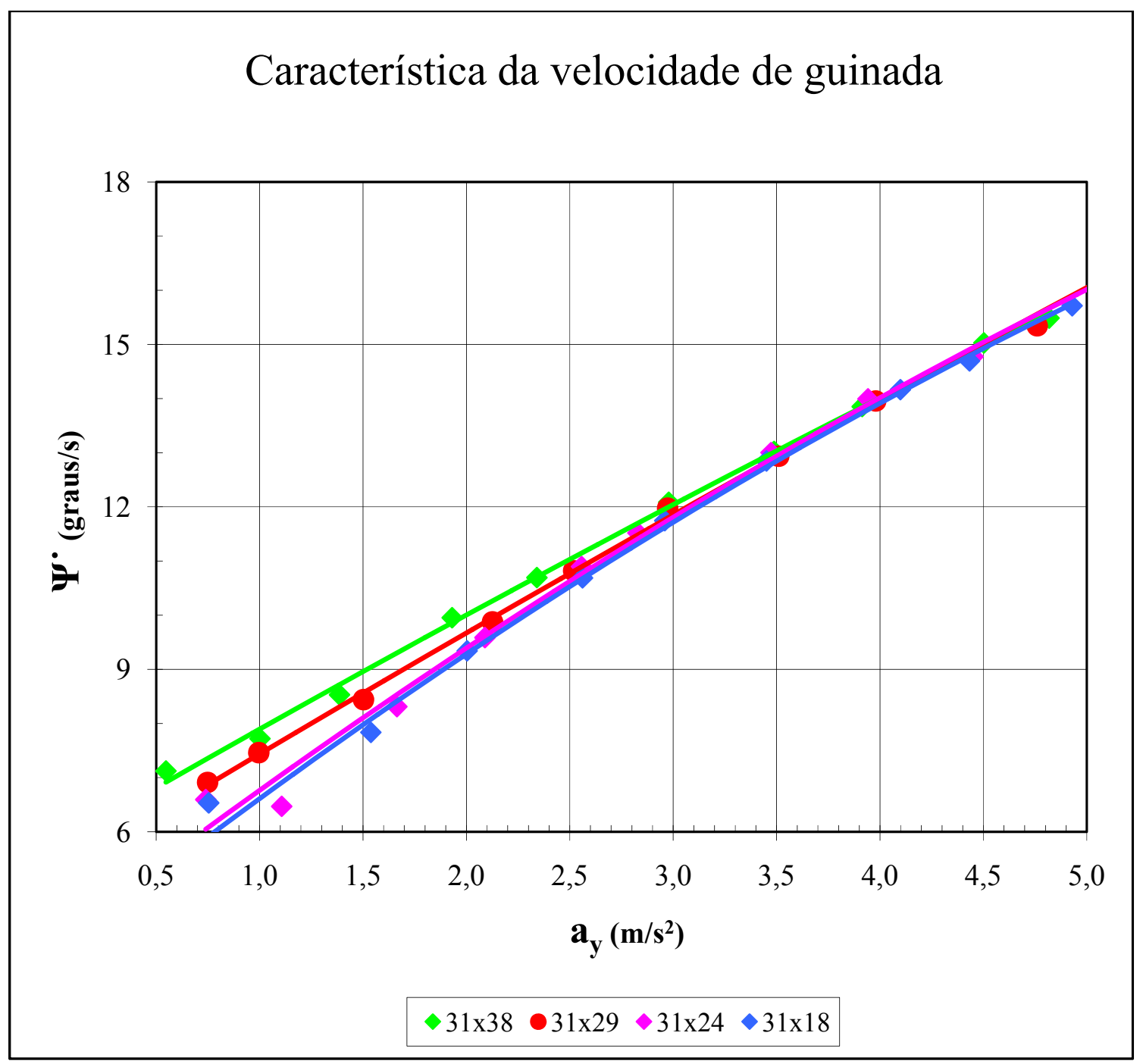

Gráfico 9 - Característica da velocidade de guinada com a variação nas pressões da traseira

Diferentemente do que ocorreu anteriormente, o gráfico do coeficiente de sub-esterçamento não apresenta uma tendência tão clara para o decaimento da pressão na traseira nesta faixa de acelerações, dificultando a análise puramente objetiva. Concluídos os resultados objetivos obtidos com a instrumentação e a medição realizadas durante o procedimento, para aprofundar a análise destes resultados e a extrair deles maiores informações, lança-se mão das avaliações subjetivas, da mesma forma em que são utilizadas pela indústria automobilística no seu processo de desenvolvimento. 


\subsection{Testes subjetivos}

Imediatamente após cada procedimento realizado na pista circular, uma passagem por outra pista, em um trecho retilíneo demarcado por cones de sinalização para a realização de seqüência de curvas alternadas e de dupla mudança de faixa de rolagem, foi realizada para que a caracterização subjetiva pudesse ser feita. O processo de avaliação subjetiva de pneus é realizado por profissionais treinados, capacitados e com larga experiência prática nesta área, realizando esta avaliação na maioria das vezes de forma comparativa a uma referência. Atribui-se notas absolutas a um pneu de referência e subsequentemente quantifica-se os outros pneus, ou construções, nas diversas características de conforto, acústico e mecânico, precisão direcional e dirigibilidade em pavimento seco e molhado.

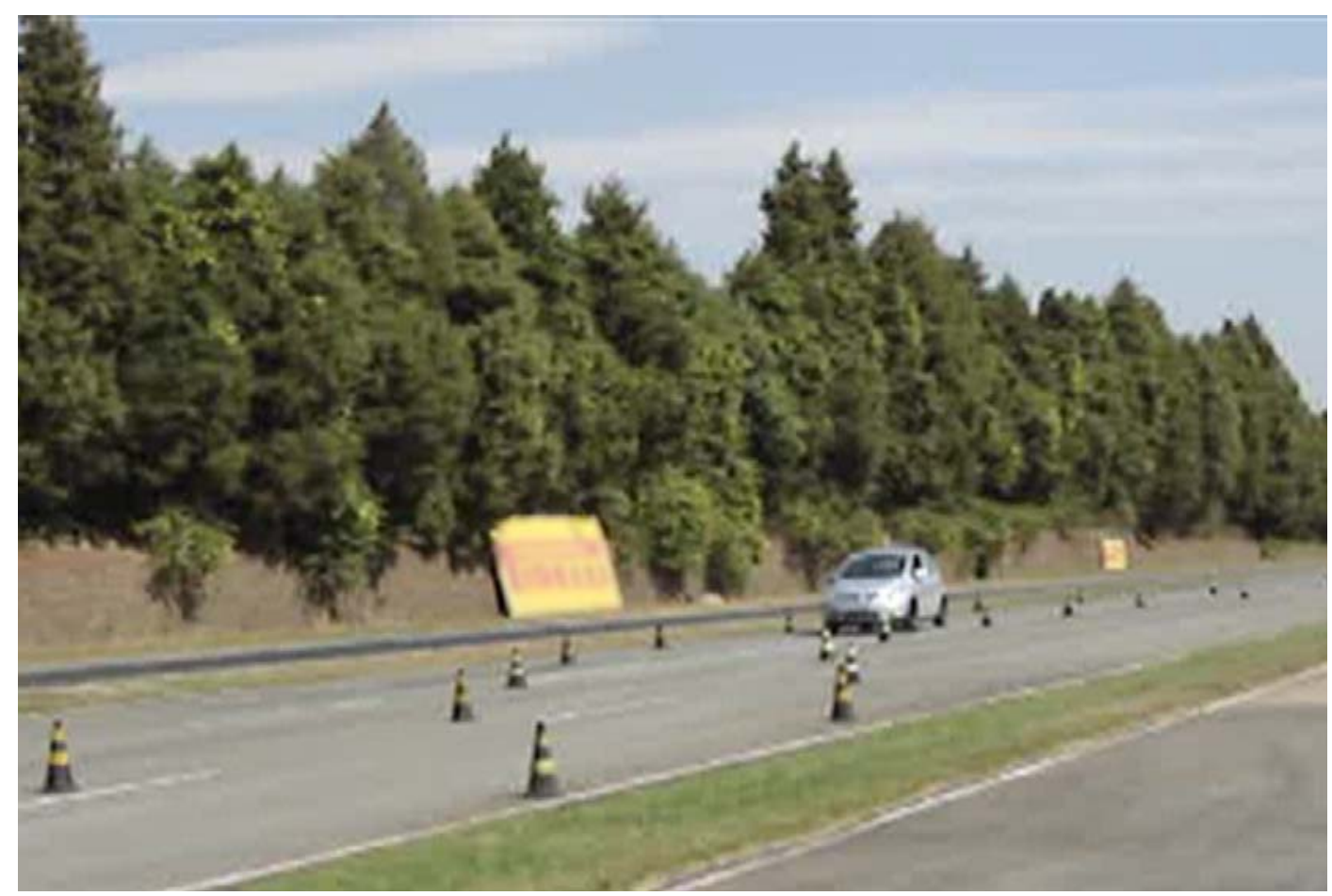

Figura 20 - Avaliação subjetiva em seqüência de curvas

Com o objetivo de evitar alterações significativas nas características do pneumático entre as medições objetivas, neste caso, a avaliação subjetiva foi realizada de forma reduzida, essencialmente para verificar alguns dos atributos relativos à resposta frente ao incremento da carga lateral. A referência utilizada aqui foi o pneu na condição de pressão inicial ao teste, (pressão recomendada pelo fabricante) e as variações a serem comparativamente avaliadas 
foram as sucessivas condições de redução das pressões. Porém, somente algumas das características de dirigibilidade em piso seco foram avaliadas: a rigidez lateral, o equilíbrio entre eixos e a tendência direcional por serem mais significativos às características que se buscava avaliar. Os resultados percebidos são apresentados a seguir:

Durante a avaliação com redução na pressão do pneumático dianteiro, pode-se perceber um pequeno aumento no escorregamento dos pneus do eixo dianteiro do veículo, deixando-o com característica ligeiramente mais sub-esterçante e um significativo incremento no ângulo do volante de direção, de forma a conseguir realizar as manobras. Além disto, o veículo passou a apresentar uma tendência direcional na direção do pneu com redução da pressão, que deu ao condutor uma clara indicação da condição de alteração da pressão. Por outro lado, com a redução da pressão do pneumático traseiro, percebe-se uma maior flexão no flanco do pneumático, empurrando, de forma oposta, a frente do veículo em direção ao centro da curva, ou seja, induzindo ao veículo um comportamento sobre-esterçante. O que se destaca nesta condição é que a percepção de diferenciação de comportamento fica tênue em uma faixa de baixa aceleração lateral e se acentua bruscamente com o aumento da mesma. Além disso, a diferenciação em manobras realizadas para um lado ou para o outro é também bastante acentuada nesta condição de aceleração lateral mais acentuada, já que, quando a transferência de carga ocorre para o lado oposto àquele em que se reduziu a pressão, muito pouco do efeito se faz sentir. 


\section{DISCUSSÃO DOS RESULTADOS}

Os resultados obtidos permitem alguma discussão, principalmente no que tange a segurança do condutor, visto que nem todas as deduções são as mais obvias.

Pôde ser verificado que o comportamento sub-esterçante do veículo com a redução da pressão na dianteira vai se acentuando gradativamente com a queda da pressão ou com o aumento da aceleração lateral dentro da faixa de comportamento linear do veículo, isto pode ser evidenciado, principalmente verificando-se os gráficos da característica do ângulo do volante (gradiente de sub-esterçamento), em que os resultados chegam a variar 12\% entre as medições de maior e menor pressão ou $10 \%$ se considerada a condição de pressão recomendada pelo fabricante comparada com a condição de menor pressão, diferença esta levantada na condição de aceleração lateral de $4.5 \mathrm{~m} / \mathrm{s}^{2}(0,46 \mathrm{~g})$.

Já na redução da pressão traseira, o comportamento na mesma condição de aceleração lateral, permanece aparentemente quase inalterado, com uma redução de apenas $2 \%$ entre as condições de maior e menor pressão para a variação no pneumático do eixo traseiro, ou seja, inserido dentro da faixa linear de comportamento do veículo, conforme apresentado no Gráfico 10. 


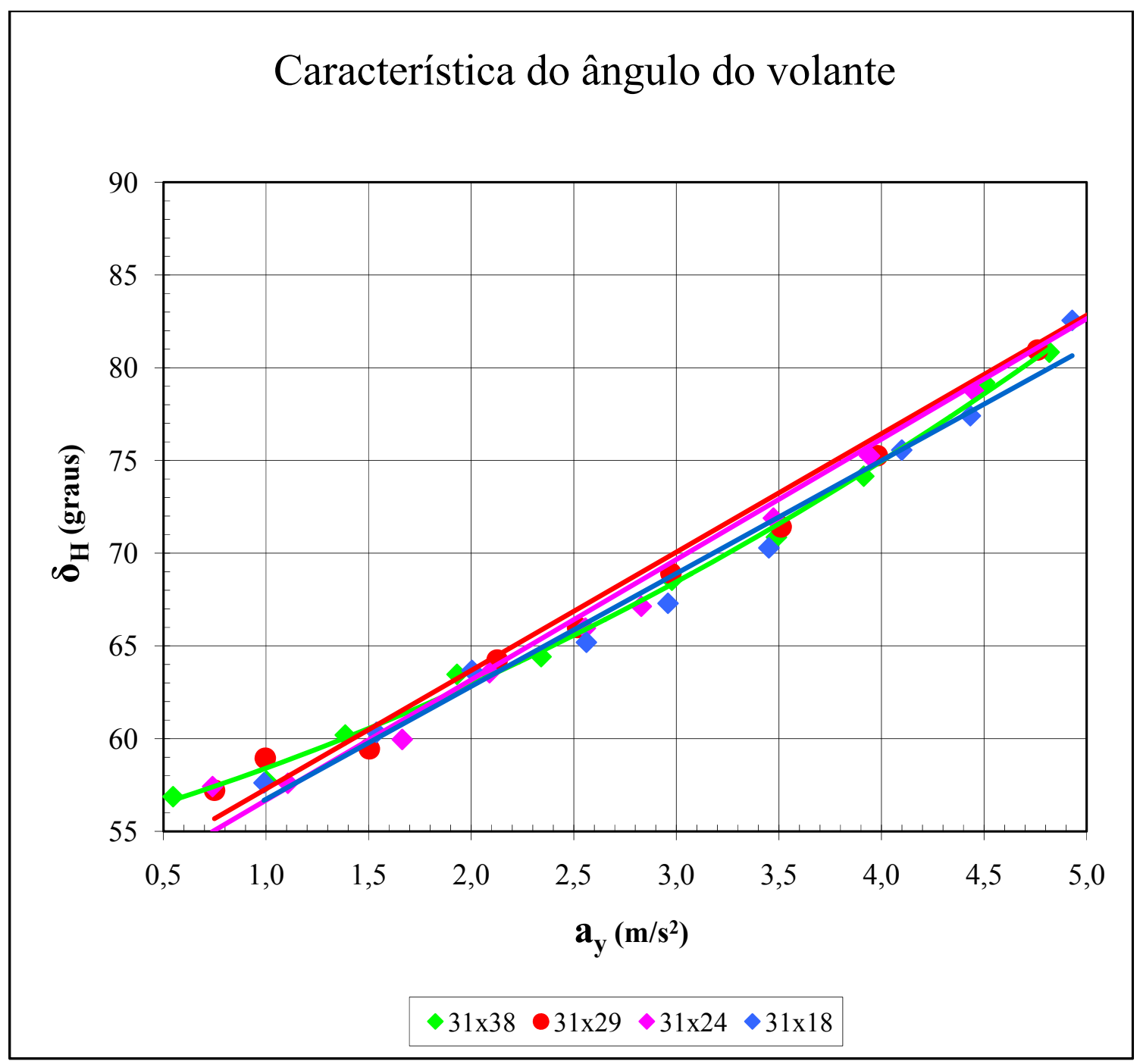

Gráfico 10 - Característica do ângulo do volante com tendência linear (neutra)

Esta característica, que poderia evidenciar um melhor comportamento do sistema pode levar a uma conclusão errada, pois acaba, em alguns casos, sendo contraposta quando a malha do sistema se fecha, ou seja, quando considerada a retro alimentação de informações e sensações percebidas pelo condutor, seus sentidos, condição física e de motivação mental e as reações naturais decorrentes delas, filtradas ou amplificadas pela surpresa, pela sua atenção, destreza, experiência e sensibilidade. Na realidade esta aparente constância encobre uma mudança de comportamento do veículo, detectada pela avaliação subjetiva, pode-se começar a visualizar os resultados desta característica já como neutra ou levemente sobre-esterçante. 
Assim, numa condição menos perceptível ao condutor, este tende a ultrapassar a faixa de aceleração lateral dentro da região de comportamento linear, região esta que já apresenta uma variação significativa de comportamento conforme já mencionado, executando manobras onde o veículo poderá responder com um comportamento sobre-esterçante de forma muito mais brusca e incontrolável. Este se torna justamente o ponto de dedução inusual do sistema de malha fechada. A falta de informação quanto à deterioração no comportamento do veículo e mais ainda a aparente constância das informações devido à diferença de resposta em manobras para um ou outro lado, leva o condutor não a reduzir, mas a manter, ou eventualmente a aumentar, o ímpeto na realização de manobras mais bruscas, levando-o a incorrer na perda de controle do veículo. Desta forma, o que inicialmente poderia evidenciar um comportamento do veículo enquanto sistema dinâmico de malha aberta e em baixas acelerações laterais, passa a apresentar um outro comportamento de maior risco quando a malha é fechada e em uma faixa de aceleração lateral ligeiramente superior, não somente pela condição de estabilidade do sistema, mas pela qualidade da informação retro alimentada ao condutor ou sua capacidade de recepção desta informação. A Figura 21 demonstra como a proximidade de comportamento apresentado para a faixa de baixas acelerações laterais pode evoluir para comportamentos opostos sob a ação de maiores acelerações laterais quando a redução de pressão ocorre no pneu dianteiro ou no traseiro.

A criticidade se acentua ainda mais quando a perda de pressão ocorre nas rodas do eixo traseiro ou ainda quando a carga vertical sobre estas rodas é aumentada, por exemplo, com o carregamento do veículo sem a devida correção da pressão de inflação dos pneumáticos. Como se sabe, a relação imposta pela pressão de inflação versus força normal sobre o pneumático exerce grande influência sobre a rigidez de esterço dos pneus. 


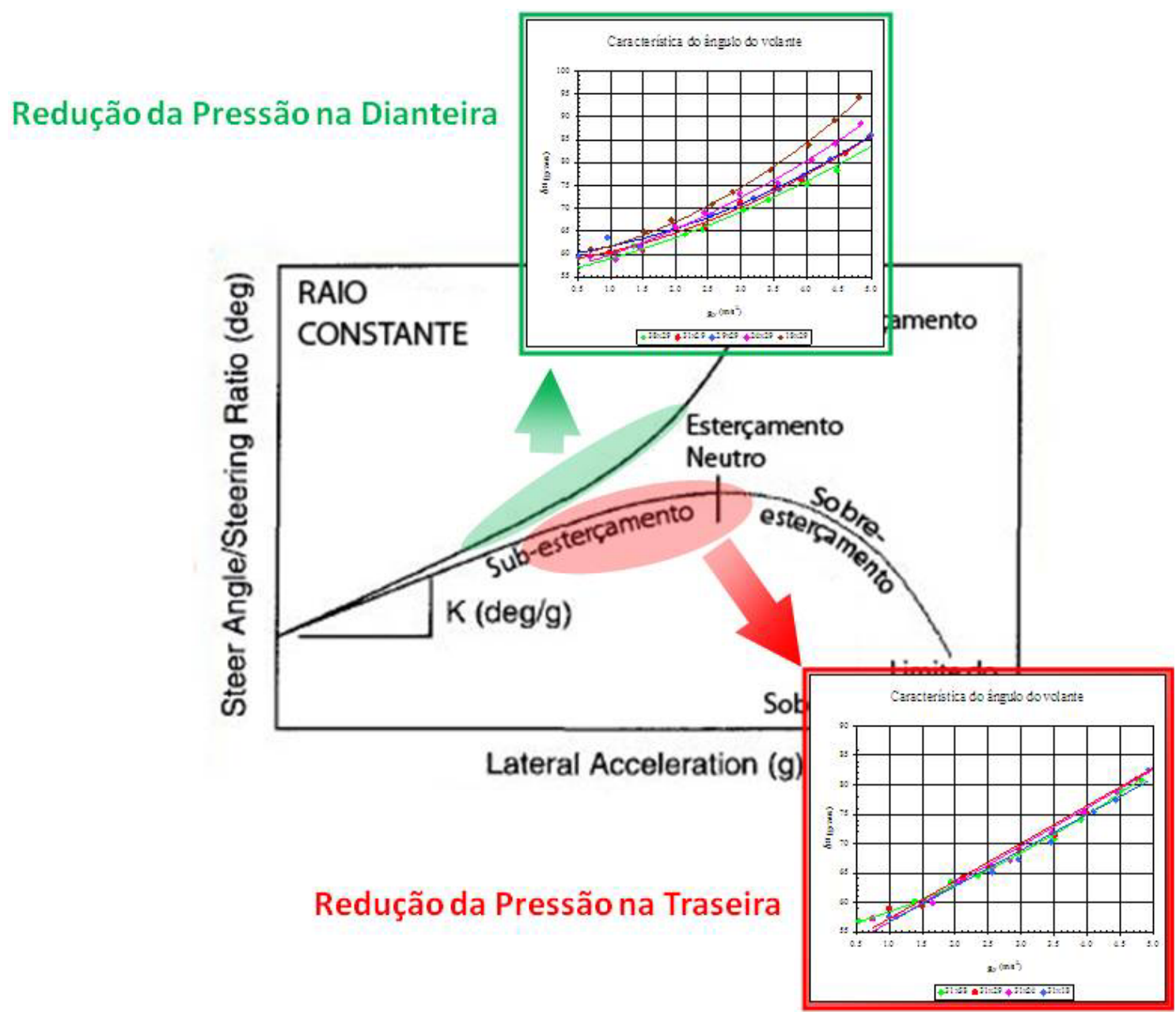

Figura 21 - Evolução do comportamento dinâmico do veículo 


\section{CONCLUSÃO}

O campo do estabelecimento antecipado do comportamento esperado dos veículos é bastante

profícuo uma vez que engenheiros e pesquisadores do campo de dinâmica de máquinas e sistemas caminham no sentido de transformar o automóvel em um sistema cada vez mais seguro e estável, reduzindo a possibilidade de ocorrências que possam levar a vitimar condutores ou passageiros e desta forma aumentar sua confiabilidade.

Acontece porém que, devido à facilidade de acesso, os veículos passaram a exercer um papel muito mais comum à vida das pessoas e seus condutores passaram a desempenhar sua função de condução de modo muito menos atenta, muito disso também devido ao alto nível de qualidade e confiabilidade conseguidas pela indústria automobilística aos seus produtos.

Neste, como em alguns outros casos onde a reação do condutor deva ser ponderada, e obviamente possa ser ponderada, através do fechamento da malha do sistema dinâmico, deve ser verificado o comportamento dos veículos, também levando em consideração a qualidade e confiabilidade da resposta que este veículo dará ao condutor comum, para aperfeiçoar o sistema em seu equilíbrio. Mais do que simplesmente fazer uma análise matemática dos números obtidos como resultado é preciso discernir e atuar por meio de instrumentos indutivos ou dedutivos a fim de alcançar um entendimento, equilibrando a decisão entre os números fornecidos por medições com suas respostas objetivas e os sentidos dos profissionais treinados para interpretar e oferecer também respostas subjetivas consistentes. Desta forma, será possível adequar a resposta do veículo ao comportamento esperado tanto a um veículo popular, quanto a um com características esportivas, suposto a ser dirigido por um condutor mais sensível às respostas fornecidas pelo veículo. 


\section{APÊNDICE A - RESULTADOS NUMÉRICOS}

A seguir serão apresentados os resultados numéricos medidos durante a realização do procedimento de medição do coeficiente de sub-esterçamento pelo método do raio constante.

Estes resultados já foram tabulados e formatados de forma a se obter, conforme solicitado pelo procedimento, os valores médios para a plotagem dos resultados das características do ângulo do volante, das características do ângulo de escorregamento lateral e das características da velocidade de guinada. Para análises ou plotagens diferentes destas aqui apresentadas, outros intervalos de dados e um tratamento diverso deve ser dado aos valores brutos obtidos.

Caracterização inicial

\begin{tabular}{|c|c|c|c|c|c|c|}
\hline \multicolumn{7}{|c|}{ Pressões de inflação de 31 psi na dianteira e 29 psi na traseira } \\
\hline $\begin{array}{c}\delta_{\mathrm{H}} \\
\text { graus }\end{array}$ & $\begin{array}{c}\mathrm{a}_{\mathrm{y}} \\
\mathrm{m} / \mathrm{s}^{2}\end{array}$ & $\begin{array}{c}\boldsymbol{\beta} \\
\text { graus }\end{array}$ & $\begin{array}{c}\Psi \\
\text { graus/s }\end{array}$ & $\begin{array}{c}\mathrm{V}_{\mathrm{x}} \\
\mathrm{km} / \mathrm{h}\end{array}$ & $\begin{array}{c}\mathrm{M}_{\mathrm{H}} \\
\mathrm{Nm}\end{array}$ & $\begin{array}{c}\boldsymbol{\varphi} \\
\text { graus }\end{array}$ \\
\hline 59,42 & 0,43 & 0,62 & 6,75 & 20,24 & $-2,26$ & 0,00 \\
\hline 60,26 & 0,99 & 0,80 & 8,05 & 26,93 & $-2,47$ & 1,09 \\
\hline 60,92 & 1,49 & 0,94 & 9,12 & 32,26 & $-2,56$ & 0,08 \\
\hline 65,79 & 2,00 & 1,24 & 10,67 & 35,62 & $-2,85$ & 0,33 \\
\hline 66,06 & 2,45 & 1,35 & 11,32 & 39,34 & $-2,93$ & $-0,54$ \\
\hline 71,13 & 3,00 & 1,67 & 12,91 & 42,38 & $-3,01$ & $-0,44$ \\
\hline 74,25 & 3,53 & 1,93 & 13,91 & 45,66 & $-3,12$ & 0,38 \\
\hline 76,18 & 3,93 & 2,05 & 14,45 & 48,46 & $-3,23$ & $-0,12$ \\
\hline 82,16 & 4,60 & 2,41 & 15,71 & 51,69 & $-3,22$ & $-0,12$ \\
\hline 85,69 & 4,98 & 2,59 & 16,17 & 54,22 & $-3,32$ & 0,18 \\
\hline
\end{tabular}

Tabela 3 - Resultados da caracterização do veículo com as pressões recomendadas pelo fabricante 
Redução da pressão na roda dianteira externa

\begin{tabular}{|c|c|c|c|c|c|c|}
\hline \multicolumn{6}{|c|}{ Pressões de inflação de 38 psi na dianteira e 29 psi na traseira } \\
\hline $\begin{array}{c}\delta_{\mathrm{H}} \\
\text { graus }\end{array}$ & $\begin{array}{c}\mathrm{a}_{\mathrm{y}} \\
\mathrm{m} / \mathrm{s}^{2}\end{array}$ & $\begin{array}{c}\boldsymbol{\Psi} \\
\text { graus }\end{array}$ & $\begin{array}{c}\Psi \\
\text { graus/s }\end{array}$ & $\begin{array}{c}\mathrm{V}_{\mathrm{x}} \\
\mathrm{km} / \mathrm{h}\end{array}$ & $\begin{array}{c}\mathrm{M}_{\mathrm{H}} \\
\mathrm{Nm}\end{array}$ & $\begin{array}{c}\boldsymbol{\varphi} \\
\text { graus }\end{array}$ \\
\hline 55,18 & 0,39 & 0,54 & 6,71 & 19,87 & $-1,76$ & $-0,38$ \\
\hline 60,02 & 0,96 & 0,81 & 8,54 & 26,45 & $-2,42$ & 0,64 \\
\hline 61,78 & 1,36 & 0,93 & 9,30 & 30,29 & $-2,58$ & 0,09 \\
\hline 64,35 & 2,15 & 1,26 & 11,21 & 37,02 & $-2,90$ & $-0,22$ \\
\hline 65,39 & 2,42 & 1,38 & 11,78 & 38,89 & $-2,94$ & $-0,31$ \\
\hline 69,75 & 3,05 & 1,64 & 13,30 & 42,50 & $-3,12$ & $-0,50$ \\
\hline 71,85 & 3,41 & 1,85 & 14,09 & 45,10 & $-3,13$ & 0,06 \\
\hline 75,21 & 4,02 & 2,09 & 15,01 & 48,72 & $-3,20$ & $-0,23$ \\
\hline 78,34 & 4,48 & 2,27 & 15,74 & 51,50 & $-3,27$ & $-0,06$ \\
\hline 85,43 & 5,07 & 2,77 & 16,88 & 54,18 & $-3,39$ & $-0,03$ \\
\hline
\end{tabular}

Tabela 4 - Resultados da caracterização do veículo com as pressões de 38 psi na dianteira e 29 psi na traseira

\begin{tabular}{|c|c|c|c|c|c|c|}
\hline \multicolumn{6}{|c|}{ Pressões de inflação de 29 psi na dianteira e 29 psi na traseira } \\
\hline $\begin{array}{c}\delta_{\mathrm{H}} \\
\text { graus }\end{array}$ & $\begin{array}{c}\mathrm{a}_{\mathrm{y}} \\
\mathrm{m} / \mathrm{s}^{2}\end{array}$ & $\begin{array}{c}\boldsymbol{\beta} \\
\text { graus }\end{array}$ & $\begin{array}{c}\Psi \\
\text { graus/s }\end{array}$ & $\begin{array}{c}\mathrm{V}_{\mathrm{x}} \\
\mathrm{km} / \mathrm{h}\end{array}$ & $\begin{array}{c}\mathrm{M}_{\mathrm{H}} \\
\mathrm{Nm}\end{array}$ & $\begin{array}{c}\boldsymbol{\varphi} \\
\text { graus }\end{array}$ \\
\hline 59,42 & 0,51 & 0,62 & 6,55 & 20,38 & $-1,93$ & $-0,42$ \\
\hline 63,63 & 0,96 & 0,83 & 8,24 & 26,42 & $-2,27$ & 2,09 \\
\hline 61,66 & 1,43 & 1,01 & 8,93 & 31,50 & $-2,36$ & 0,43 \\
\hline 66,06 & 1,99 & 1,27 & 10,29 & 35,16 & $-2,74$ & $-0,15$ \\
\hline 68,65 & 2,54 & 1,43 & 11,56 & 39,34 & $-2,91$ & 0,04 \\
\hline 72,20 & 3,20 & 1,73 & 12,92 & 43,76 & $-3,00$ & 0,03 \\
\hline 74,12 & 3,58 & 1,91 & 13,67 & 46,30 & $-3,03$ & $-0,53$ \\
\hline 77,15 & 3,95 & 2,06 & 14,48 & 48,27 & $-3,09$ & $-0,37$ \\
\hline 80,70 & 4,37 & 2,29 & 15,21 & 50,45 & $-3,15$ & $-0,04$ \\
\hline 86,18 & 4,99 & 2,63 & 16,06 & 54,09 & $-3,20$ & $-0,16$ \\
\hline
\end{tabular}

Tabela 5 - Resultados da caracterização do veículo com as pressões de 29 psi na dianteira e 29 psi na traseira 


\begin{tabular}{|c|c|c|c|c|c|c|}
\hline \multicolumn{7}{|c|}{ Pressões de inflação de 24 psi na dianteira e 29 psi na traseira } \\
\hline $\begin{array}{c}\boldsymbol{\delta}_{\mathrm{H}} \\
\text { graus }\end{array}$ & $\begin{array}{c}\mathrm{a}_{\mathrm{y}} \\
\mathrm{m} / \mathrm{s}^{2}\end{array}$ & $\begin{array}{c}\boldsymbol{\Psi} \\
\text { graus }\end{array}$ & $\begin{array}{c}\Psi \\
\text { graus/s }\end{array}$ & $\begin{array}{c}\mathrm{V}_{\mathrm{x}} \\
\mathrm{km} / \mathrm{h}\end{array}$ & $\begin{array}{c}\mathrm{M}_{\mathrm{H}} \\
\mathrm{Nm}\end{array}$ & $\begin{array}{c}\boldsymbol{\varphi} \\
\text { graus }\end{array}$ \\
\hline 59,63 & 0,69 & 0,69 & 7,76 & 22,60 & $-2,00$ & 0,10 \\
\hline 58,84 & 1,08 & 0,73 & 8,78 & 28,01 & $-2,32$ & 0,58 \\
\hline 61,27 & 1,47 & 0,94 & 9,57 & 31,39 & $-2,44$ & 0,53 \\
\hline 66,27 & 1,98 & 1,18 & 11,13 & 34,78 & $-2,62$ & $-0,25$ \\
\hline 69,06 & 2,45 & 1,42 & 12,29 & 38,25 & $-2,81$ & $-0,83$ \\
\hline 73,19 & 2,98 & 1,66 & 13,61 & 41,54 & $-2,91$ & $-1,03$ \\
\hline 75,58 & 3,56 & 1,84 & 14,39 & 45,87 & $-2,99$ & $-1,37$ \\
\hline 80,63 & 4,08 & 2,10 & 15,54 & 48,51 & $-3,08$ & $-0,82$ \\
\hline 84,27 & 4,45 & 2,30 & 16,16 & 50,59 & $-3,12$ & $-0,01$ \\
\hline 88,64 & 4,85 & 2,55 & 16,97 & 52,68 & $-3,16$ & 0,26 \\
\hline
\end{tabular}

Tabela 6 - Resultados da caracterização do veículo com as pressões de 24 psi na dianteira e 29 psi na traseira

\begin{tabular}{|c|c|c|c|c|c|c|}
\hline \multicolumn{7}{|c|}{ Pressões de inflação de 18 psi na dianteira e 29 psi na traseira } \\
\hline $\begin{array}{c}\delta_{\mathrm{H}} \\
\text { graus }\end{array}$ & $\begin{array}{c}\mathrm{a}_{\mathrm{y}} \\
\mathrm{m} / \mathrm{s}^{2}\end{array}$ & $\begin{array}{c}\boldsymbol{\beta} \\
\text { graus }\end{array}$ & $\begin{array}{c}\Psi \cdot \\
\text { graus/s }\end{array}$ & $\begin{array}{c}\mathrm{V}_{\mathrm{x}} \\
\mathrm{km} / \mathrm{h}\end{array}$ & $\begin{array}{c}\mathrm{M}_{\mathrm{H}} \\
\mathrm{Nm}\end{array}$ & $\begin{array}{c}\boldsymbol{\varphi} \\
\text { graus }\end{array}$ \\
\hline 61,04 & 0,70 & 0,71 & 7,64 & 22,71 & $-2,25$ & 0,09 \\
\hline 60,55 & 1,07 & 0,80 & 8,32 & 27,75 & $-2,49$ & 0,18 \\
\hline 64,82 & 1,52 & 0,95 & 9,59 & 31,07 & $-2,63$ & $-0,07$ \\
\hline 67,55 & 1,93 & 1,16 & 10,61 & 34,29 & $-2,73$ & $-0,13$ \\
\hline 70,96 & 2,57 & 1,36 & 12,05 & 39,39 & $-2,87$ & 0,00 \\
\hline 73,58 & 2,87 & 1,54 & 12,71 & 41,23 & $-2,93$ & $-0,79$ \\
\hline 78,39 & 3,45 & 1,76 & 13,92 & 44,76 & $-3,02$ & $-0,22$ \\
\hline 83,77 & 4,04 & 2,09 & 15,33 & 48,48 & $-3,15$ & $-0,40$ \\
\hline 89,29 & 4,43 & 2,30 & 15,98 & 50,02 & $-3,18$ & 0,59 \\
\hline 94,23 & 4,81 & 2,52 & 16,54 & 52,55 & $-3,22$ & $-0,39$ \\
\hline
\end{tabular}

Tabela 7 - Resultados da caracterização do veículo com as pressões de 18 psi na dianteira e 29 psi na traseira 
Redução da pressão na roda traseira externa

\begin{tabular}{|c|c|c|c|c|c|c|}
\hline \multicolumn{6}{|c|}{ Pressões de inflação de 31 psi na dianteira e 38 psi na traseira } \\
\hline $\begin{array}{c}\delta_{\mathrm{H}} \\
\text { graus }\end{array}$ & $\begin{array}{c}\mathrm{a}_{\mathrm{y}} \\
\mathrm{m} / \mathrm{s}^{2}\end{array}$ & $\begin{array}{c}\boldsymbol{\beta} \\
\text { graus }\end{array}$ & $\begin{array}{c}\Psi \\
\text { graus/s }\end{array}$ & $\begin{array}{c}\mathrm{V}_{\mathrm{X}} \\
\mathrm{km} / \mathrm{h}\end{array}$ & $\begin{array}{c}\mathrm{M}_{\mathrm{H}} \\
\mathrm{Nm}\end{array}$ & $\begin{array}{c}\boldsymbol{\varphi} \\
\text { graus }\end{array}$ \\
\hline 56,87 & 0,55 & 0,55 & 7,12 & 20,18 & $-1,16$ & 0,31 \\
\hline 57,71 & 1,00 & 0,72 & 7,72 & 25,81 & $-1,86$ & $-0,25$ \\
\hline 60,20 & 1,39 & 0,95 & 8,53 & 29,41 & $-2,10$ & $-0,13$ \\
\hline 63,47 & 1,93 & 1,17 & 9,95 & 34,07 & $-2,24$ & $-0,57$ \\
\hline 64,42 & 2,34 & 1,28 & 10,69 & 37,41 & $-2,39$ & $-0,92$ \\
\hline 68,54 & 2,98 & 1,54 & 12,09 & 41,40 & $-2,50$ & 0,98 \\
\hline 70,86 & 3,49 & 1,74 & 13,02 & 45,28 & $-2,60$ & 0,82 \\
\hline 74,15 & 3,91 & 2,00 & 13,85 & 47,63 & $-2,62$ & 0,60 \\
\hline 79,19 & 4,50 & 2,34 & 15,03 & 50,58 & $-2,66$ & 0,55 \\
\hline 80,84 & 4,82 & 2,43 & 15,49 & 52,31 & $-2,65$ & $-0,32$ \\
\hline
\end{tabular}

Tabela 8 - Resultados da caracterização do veículo com as pressões de 31 psi na dianteira e 38 psi na traseira

\begin{tabular}{|c|c|c|c|c|c|c|}
\hline \multicolumn{6}{|c|}{ Pressões de inflação de 31 psi na dianteira e 29 psi na traseira } \\
\hline $\begin{array}{c}\delta_{\mathrm{H}} \\
\text { graus }\end{array}$ & $\begin{array}{c}\mathrm{a}_{\mathrm{y}} \\
\mathrm{m} / \mathrm{s}^{2}\end{array}$ & $\begin{array}{c}\beta \\
\text { graus }\end{array}$ & $\begin{array}{c}\Psi \\
\text { graus/s }\end{array}$ & $\begin{array}{c}\mathrm{V}_{\mathrm{X}} \\
\mathrm{km} / \mathrm{h}\end{array}$ & $\begin{array}{c}\mathrm{M}_{\mathrm{H}} \\
\mathrm{Nm}\end{array}$ & $\begin{array}{c}\boldsymbol{\varphi} \\
\text { graus }\end{array}$ \\
\hline 57,21 & 0,75 & 0,64 & 6,91 & 22,75 & $-1,58$ & $-0,04$ \\
\hline 58,94 & 1,00 & 0,81 & 7,46 & 25,18 & $-1,55$ & 0,32 \\
\hline 59,44 & 1,50 & 0,96 & 8,44 & 31,17 & $-1,96$ & 0,54 \\
\hline 64,23 & 2,13 & 1,28 & 9,88 & 35,49 & $-2,15$ & 0,09 \\
\hline 65,99 & 2,52 & 1,38 & 10,82 & 38,43 & $-2,26$ & $-0,89$ \\
\hline 68,91 & 2,97 & 1,61 & 11,98 & 41,37 & $-2,36$ & 0,53 \\
\hline 71,41 & 3,51 & 1,74 & 12,94 & 44,92 & $-2,45$ & $-0,45$ \\
\hline 75,26 & 3,98 & 2,03 & 13,96 & 47,67 & $-2,45$ & 0,18 \\
\hline 80,95 & 4,76 & 2,49 & 15,34 & 52,08 & $-2,55$ & 0,07 \\
\hline 86,93 & 5,11 & 2,77 & 16,42 & 53,23 & $-2,57$ & 0,02 \\
\hline
\end{tabular}

Tabela 9 - Resultados da caracterização do veículo com as pressões de 31 psi na dianteira e 29 psi na traseira 


\begin{tabular}{|c|c|c|c|c|c|c|}
\hline \multicolumn{6}{|c|}{ Pressões de inflação de 31 psi na dianteira e 24 psi na traseira } \\
\hline $\begin{array}{c}\delta_{\mathrm{H}} \\
\text { graus }\end{array}$ & $\begin{array}{c}\mathrm{a}_{\mathrm{y}} \\
\mathrm{m} / \mathrm{s}^{2}\end{array}$ & $\begin{array}{c}\boldsymbol{\Psi} \\
\text { graus }\end{array}$ & $\begin{array}{c}\Psi \\
\text { graus/s }\end{array}$ & $\begin{array}{c}\mathrm{V}_{\mathrm{x}} \\
\mathrm{km} / \mathrm{h}\end{array}$ & $\begin{array}{c}\mathrm{M}_{\mathrm{H}} \\
\mathrm{Nm}\end{array}$ & $\begin{array}{c}\boldsymbol{\varphi} \\
\text { graus }\end{array}$ \\
\hline 57,41 & 0,74 & 0,68 & 6,59 & 22,55 & $-1,17$ & $-0,37$ \\
\hline 57,59 & 1,11 & 0,86 & 6,47 & 27,23 & $-1,72$ & 0,31 \\
\hline 59,95 & 1,66 & 0,98 & 8,31 & 32,62 & $-1,84$ & 0,11 \\
\hline 63,55 & 2,09 & 1,19 & 9,59 & 35,55 & $-2,08$ & 0,03 \\
\hline 65,96 & 2,56 & 1,45 & 10,90 & 38,66 & $-2,08$ & $-0,58$ \\
\hline 67,14 & 2,83 & 1,52 & 11,52 & 40,83 & $-2,19$ & $-0,61$ \\
\hline 71,89 & 3,47 & 1,83 & 13,00 & 44,22 & $-2,29$ & $-0,36$ \\
\hline 75,25 & 3,94 & 2,09 & 13,99 & 46,76 & $-2,36$ & $-0,80$ \\
\hline 78,75 & 4,45 & 2,32 & 14,77 & 50,42 & $-2,44$ & 0,27 \\
\hline 85,42 & 5,05 & 2,73 & 16,08 & 53,00 & $-2,51$ & $-0,13$ \\
\hline
\end{tabular}

Tabela 10 - Resultados da caracterização do veículo com as pressões de 31 psi na dianteira e 24 psi na traseira

\begin{tabular}{|c|c|c|c|c|c|c|}
\hline \multicolumn{6}{|c|}{ Pressões de inflação de 31 psi na dianteira e 18 psi na traseira } \\
\hline $\begin{array}{c}\delta_{\mathrm{H}} \\
\text { graus }\end{array}$ & $\begin{array}{c}\mathrm{a}_{\mathrm{y}} \\
\mathrm{m} / \mathrm{s}^{2}\end{array}$ & $\begin{array}{c}\boldsymbol{\beta} \\
\text { graus }\end{array}$ & $\begin{array}{c}\Psi \\
\text { graus/s }\end{array}$ & $\begin{array}{c}\mathrm{V}_{\mathrm{x}} \\
\mathrm{km} / \mathrm{h}\end{array}$ & $\begin{array}{c}\mathrm{M}_{\mathrm{H}} \\
\mathrm{Nm}\end{array}$ & $\begin{array}{c}\boldsymbol{\varphi} \\
\text { graus }\end{array}$ \\
\hline 57,85 & 0,75 & 0,74 & 6,53 & 22,63 & $-1,46$ & $-0,51$ \\
\hline 57,61 & 0,99 & 0,80 & 5,99 & 25,67 & $-1,74$ & 0,50 \\
\hline 60,34 & 1,54 & 1,07 & 7,84 & 30,89 & $-1,68$ & $-0,12$ \\
\hline 63,67 & 2,00 & 1,28 & 9,34 & 34,20 & $-1,90$ & $-0,10$ \\
\hline 65,19 & 2,56 & 1,47 & 10,69 & 38,73 & $-2,16$ & $-0,02$ \\
\hline 67,30 & 2,96 & 1,61 & 11,75 & 41,78 & $-2,19$ & $-0,08$ \\
\hline 70,28 & 3,45 & 1,86 & 12,85 & 44,89 & $-2,23$ & 0,32 \\
\hline 75,56 & 4,10 & 2,22 & 14,16 & 47,62 & $-2,39$ & 0,21 \\
\hline 77,41 & 4,43 & 2,40 & 14,69 & 50,06 & $-2,41$ & 0,16 \\
\hline 82,55 & 4,93 & 2,73 & 15,71 & 52,30 & $-2,51$ & 0,21 \\
\hline
\end{tabular}

Tabela 11 - Resultados da caracterização do veículo com as pressões de 31 psi na dianteira e 18 psi na traseira 


\section{BIBLIOGRAFIA}

ABE, M.; KANO, Y.; SHIBAHATA, Y. \& FURUKAWA, Y. Improvement of vehicle handling safety with vehicle side-slip control by direct yaw moment. Lisse: Swets \& Zeitlinger Publishers, 1999.

ALVARENGA, Maria A. de F. Pereira. Apontamentos de metodologia para a ciência e técnicas de redação científica. 2. ed. rev. e ampl. Porto Alegre: Sergio Antonio Fabris Ed., 2001.

AMMON, D. Vehicle dynamics analysis tasks and related tyre simulation challenges. Vehicle System Dynamics , 2005.

ASSOCIAÇÃO BRASILEIRA DE NORMAS TÉCNICAS. NBR 6023: Informação e documentação: Referências - Elaboração. Rio de Janeiro, 2002.

ASSOCIAÇÃO BRASILEIRA DE NORMAS TÉCNICAS. NBR 10520: Informação e documentação: Citações em documentos - Apresentação. Rio de Janeiro, 2002.

BAKKER, E.; NYBORG, L. \& PACEJKA, H. B. Tyre modelling for use in vehicle dynamics studies. International Congress and Exposition. Detroit: Society of Automotive Engineers, Inc., 1987.

BAKKER, E.; PACEJKA, H. B. \& LIDNER, L. A new tire model with an application in vehicle dynamics studies. (s.d.).

BARBIERI, N. Suspensions optimization. Campinas: Universidade de Campinas, (s.d.).

BARRETO, M. A. Análise dinâmica do chassis de um veículo de competição minibaja. São Carlos, (s.d.).

BEVLY, David M.; DAILY, Robert \& TRAVIS, William. Estimation of critical tire parameters using GPS based sideslip measurements. International Congress and Exposition. Novi: Society of Automotive Engineers, Inc., 2006.

BRANDÃO, F. T. \& SPERANZA NETO, M. Procedimento para especificação de componentes de suspensões passivas empregando modelos dinâmicos e simulação computacional. Rio de Janeiro: Pontifícia Universidade do Rio de Janeiro, (s.d.).

BUNDORF, R. T. The influence of vehicle design parameters on characteristic speed and understeer. International Congress and Exposition. Society of Automotive Engineers, Inc. 1967.

BUNDORF, R. T. \& LEFFERT, R. L. The cornering compliance concept for description of vehicle directional control properties. International Congress and Exposition. Society of Automotive Engineers, Inc., 1976.

BURGESS, M. J.; WOOTTON, N. P. \& WILLIAMS, S. J. A tool for rapid vehicle suspension design. Congresso Internacional da SAE , 2004. 
CALLEA, Giuseppe. Race car tire modeling: a simplified approach for vehicle dynamic analysis and real-time simulation. International Congress and Exposition. Dearborn: Society of Automotive Engineers, Inc., 2004.

CANALE, Antonio C. Automobilística: dinâmica e desempenho. São Paulo: Ed. Érica, 1989.

CHALLEN, B. J. Defining driveability - limits to modelling. Sussex: Professional Engineering Publishing, 2002.

CHUNG, Taeyoung, et al. Closed-loop evaluation of vehicle stability control (vsc) system using a combined vehicle and human driving model. International Congress and Exposition. Detroit: Society of Automotive Engineers, Inc, 2004.

COSTA, Argemiro L. A. et al. The impact of infation pressure on vehicle handling and tire performance. Congresso e exposição internacionais da tecnologia da mobilidade. São Paulo: Society of Automotive Engineers, Inc., 2005.

CROLLA, D.A. \& KING, R.P. Olley's "flat ride" revisited. Vehicle System Dynamics Supplement 33, 1999.

DIXON, John. C. Tires, Suspension and Handling. Warrendale: Society of Automotive Engineers, Inc., 1996.

DURSTINE, J. W. The truck steering system from hand wheel to road wheel. International Congress and Exposition: Society of Automotive Engineers, Inc. 1973.

ECO, Umberto. Como se faz uma tese. São Paulo: Perspectiva, 1994.

EITZINGER, Stefan; SCHMID, Markus \& SCHOLZ, Robert. Analysis of two active chassis systems to improve agility and stability. Stuttgart: Vehicle Dynamics Expo, 2005.

ELLIS, J. R. Vehicle dynamics . Londres: Business Books Limited, 1994.

FONDA, Albert G. Tyre test and interpretation of experimental data. Westminster: Research in Automobile Stability and Control and in Tyre Performance, 1956-7.

FORSÉN, A. Parameter identification in heavy vehicle simulation. Vehicle System Dynamics Supplement 33, 1999.

GILLESPIE, Thomas D. Fundamentals of vehicle dynamics. Warrendale: Society of Automotive Engineers, Inc., 1992.

GIM, G. \& NIKRAVESH, P. E. An analytical model of pneumatic tyres for vehicle dynamic simulations. Part 1: pure slips. International Journal of Vehicle Design , 1990.

GIM, G. \& NIKRAVESH, P. E. An analytical model of pneumatic tyres for vehicle dynamic simulations. Part 2: comprehensive slips. International Journal of Vehicle Design, 1991. 
GIM, G. \& NIKRAVESH, P. E. An analytical model of pneumatic tyres for vehicle dynamic simulations. Part 3: validation against experimental data. International Journal of Vehicle Design, 1991.

GOLAND, M. \& JINDRA, F. Car handling characteristics. Automotive Engineer, 1961.

GOOD, M. C. Sensitivity of drive-vehicle performance to vehicle characteristics revealed in open-loop tests. Vehicle Systems Dynamics, 1977.

HOUAISS, Antonio. Dicionário eletrônico houaiss da língua portuguesa. Rio de Janeiro: Objetiva, 2002.

INTERNATIONAL ORGANIZATION FOR STANDARDIZATION. ISO 4138: Steadystate circular driving behaviour - Open-loop test procedure. Genebra: International Organization for Standardization, 1996.

INTERNATIONAL ORGANIZATION FOR STANDARDIZATION. ISO 4138: Steadystate circular test procedure. Genebra: International Organization for Standardization, 1982.

INTERNATIONAL ORGANIZATION FOR STANDARDIZATION. ISO 8855: Road vehicles - Vehicle dynamics and road-holding ability - Vocabulary. Genebra: International Organization for Standardization, 1991.

JINDRA, Frederick. Tractor and semi-trailer handling. Automobile Engineer, 1963.

JINDRA, Frederick. Tractor and trailer handling. Automobile Engineer, 1965.

KIM, Chul \& RO, Paul I. An accurate simple model for vehicle handling using reducedorder model techiniques. International Congress and Exposition. Costa Mesa: Society of Automotive Engineers Inc., 2001.

LIU, Qing; LEE, Jonah H. \& GUO, Konghui. Analysis of non-steady state tire cornering properties based on sting-concept deformation and geometic relationship of contact patch. International Congress and Exposition. Detroit: Society of Automotive Engineers, Inc., 2007.

LUGNER, P. \& SPRINGER, H. Uber den enfluss der lenkgiometrie auf die stationare kurventfahrt eines LKW. Automobile Industrie, 1974

METZ, L. D. What constitutes good handling? Motorsports Engineering Conference and Exhibition, 2004.

MILLIKEN, William F. \& MILLIKEN, Douglas L. Race car vehicle dynamics. Warrendale: Society of Automotive Engineers, Inc., 1995.

MILLIKEN, William F. \& WHITCOMB, B. A. General introduction to a programme of dynamic research. Westminster: Research in Automobile Stability and Control and in Tyre Performance, 1956-7. 
MINAKER, B. \& ANDERSON, R. J. Modelling the dynamics of a vehicle with active geometry suspension. Vehicle System Dynamics Supplement 33, 1999.

MITCHELL, Wm. Asymmetric roll centers. Motorsports Engineering Conference and Exposition. Dearborn: Society of Automotive Engineers, Inc., 1998.

MITCHELL, Wm. C., STANIFORTH, Allan \& SCOTT, Ian. Analysis of ackermann steering geometry. Motorsports Engineering Conference \& Exhibition. Dearborn: Society of Automotive Engineers, Inc., 2006.

NORDEEN, D. L. \& CORTESE, A. D. Force and moment characteristics of rolling tires. International Congress and Exposition. Society of Automotive Engineers, Inc., 1963.

OGATA, Katsuhiko. Engenharia de controle moderno. Prentice Hall, 2003.

OLLEY, M. National influences on American passanger car design. Proceedings of the Institute of Automobile Engineers, 1938.

ORTIZ, Mark. The design \& tuning of asymmetrical racecars. Racecar, 1999.

OSTEN, J. V. \& BAKKER, E. Determination of magic tyre model parametesrs. Procedings $1^{\circ}$ International Colloquium on Tyre Models for Vehicle Dynamics Analysis, 1991.

PACEJKA, Hans B. Tire and vehicle dynamics, Warrendale: Society of Automotive Engineers, Inc., 2002.

PACEJKA, H. B. \& BAKKER, E. The magic formula tyre model. $1^{\circ}$ International Colloquium on Tyre Models for Vehicle Dynamics Analysis, 1999.

PITTS, S. \& WILDIG, A. W. Effect of steering geometry on self centering torque and feel during low-speed maneuvers. Automotive Engineer. Institution of Mechanical Engineers, 1978.

PRADO, M. \& COSTA, A. L. The three degree of freedom bus model considering the airspring suspension nonlinear tire model. (s.d.).

RADT JR., H. S. \& DIS, D. J. Vehicle handling responses using stability derivatives. International Congress \& Exposition. Detroit: Society of Automotive Engineers, Inc., 1996.

REIMPELL, Jörnsen; STOLL, Helmut \& BETZLER, Jurgen W. The automotive chassis: engineering principals. Warrendale: Society of Automotive Engineers Inc., 2001.

RENNER, Thomas E. \& BARBER, Andrew J. Accurate tire models for vehicle handling using the empirical dynamics method. Orlando: International Adams User Conference, 2000. 
SOCIETY OF AUTOMOTIVE ENGINEERS. SAE J266: Steady-State Directional Control Test Procedures for passenger Cars and Light Trucks. Proposed Recommended Practice. Warrendale: Society of Automotive Engineers, Inc., 1996.

SOCIETY OF AUTOMOTIVE ENGINEERS. SAE J2181: Steady-state circular test procedure for trucks and buses. Proposed Recommended Practice. Warrendale: Society of Automotive Engineers, Inc., 1998.

SOCIETY OF AUTOMOTIVE ENGINEERS. SAE J670: Vehicle dynamics terminology. Warrendale: Society of Automotive Engineers, Inc., 2008.

SALAANI, Mohamed Kamel. Analytical tire forces and moments model with validated data. International Congress and Exposition. Detroit: Society Automotive Engineers, Inc., 2007.

SALAANI, Mohamed Kamel; HEYDINGER, Gary J. \& GRYGIER, Paul A. Vehicle oncenter directional and steering sensitivity. International Congress and Exposition. Detroit: Society of Automotive Engineers, Inc., 2005.

SAMSUNDAR, John \& HUSTON, Jeffrey C. Lateral stability analysis of a 2 degree-offreedom vehicle using a time lagged lateral tire force model. Internacional Congress and Exposition. Detroit: Society of Automotive Engineers, Inc., 1999.

SAVI, C. Linear and transient tyre characterization. 2000.

SAYERS, Michael W. \& HAN, Dongsuk. A generic multibody vehicle model for simulating handling and braking. Ann Arbor: Symposium of the International Association of Vehicle System Dynamics, 1995.

SAYERS, Michael W. \& MINK, Carrie. A Simulation Graphical User Interface for Vehicle Dynamics Models. University of Michigan Transpotation Research Institute. (s.d.).

SCHUSTER, Christian; LANGE, Olav \& HILLER, Manfred. Structural variable models for simulating the vehicle dynamics at low velocities. Vehicle System Dynamics Supplement 33, 1999.

SHIM, Taegyun \& VELUSAMY, Pradheep C. Influence of suspension properties on vehicle roll stability. International Congress and Exposition. Novi: Society of Automotive Engineers, Inc., 2006.

SMILEY, R. F. \& HORNE, W. B. Mechanical properties of pneumatic tires with special reference to modern aircraft tires. Washington DC: National Advisory Committee for Aeronautics, 1958.

TOPPING, R. W. \& B. F. Goodrich Co. A primer on nonlinear, steady-state vehicle turning behavior. Toronto: Society of Automotive Engineers, Inc., 1974.

NETHERLANDS ORGANISATION FOR APPLIED SCIENTIFIC RESEARCH - TNO. $\boldsymbol{M} \boldsymbol{f}$ tyre user manual - A design and analysis tool for modeling and simulation of tyre behaviour. Delft: TNO, 1996. 
VICHIS, J.-C. A.; MOLINA, J.-J. M. \& WIT, C. C. A new bicycle model with 3-d dynamic tire / road friction forces. Grenoble, 2003.

THE TIRE \& RIM ASSOCIATION. 1991 Yearbook of The tire \& Rim Association Inc. Copley: 1991.

WHITCOMB, David W. \& MILLIKEN, William F. Design implications of a general theory of automobile stability and control. Westminster: Research in Automobile Stability and Control and in Tyre Performance, 1956-7.

WRANG, M. Instability phenomena of a passenger coach, caused by internal yaw damper flexibility. Vehicle System Dynamics Supplement 33, 1999. 